\title{
Deriva litorânea e evolução da linha de costa no sul do Espírito Santo (Brasil)
}

\author{
Dissertação apresentada ao Instituto \\ Oceanográfico da Universidade de São \\ Paulo como parte dos requisitos para \\ obtenção do título de Mestre em Ciências, \\ Programa de Pós-Graduação em \\ Oceanografia, Área de Concentração \\ Oceanografia Geológica. \\ Orientador: Prof. Dr. Eduardo Siegle
}

São Paulo 
Universidade de São Paulo

Instituto Oceanográfico

\section{Deriva litorânea e evolução da linha de costa no sul do Espírito Santo (Brasil)}

\section{NERY CONTTI NETO}

Dissertação apresentada ao Instituto Oceanográfico da Universidade de São Paulo como parte dos requisitos para obtenção do título de Mestre em Ciências, Programa de Pós-

Graduação em Oceanografia, Área de Concentração Oceanografia Geológica.

Julgada em 11

Prof. Dr.

Conceito

Prof. Dr.

$\overline{\text { Conceito }}$

Prof. Dr.

$\overline{\text { Conceito }}$

São Paulo 
Quando eu falei ó mãe vou ser cantor o laço materno foi lasso e se escondeu o que trago em meus braços são braços de viola do tempo que o vô tocava acordeão

Terra que foi cultivada lá na serra que desce por debaixo do aluvião e se acumula nalgum ponto entre as pedras limo de onde eu tiro minha canção

Ê pai me ensina a cuidar meu pé de moleque pra dar sustento pra depois voltar pra minha estrada

Ê poeira em pneu de trator pinguela pra se atravessar polenta que a gente jantou vida estradeira

Ê pai, ê mãe, ê violão Meu pé na estrada prum dia eu voltar nesse chão

Ê minha casa, vida estradeira

Autoria: Fernando Zorzal Músico, poeta, oceanógrafo e amigo. 


\section{SUMÁRIO}

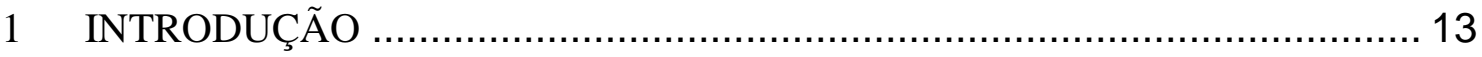

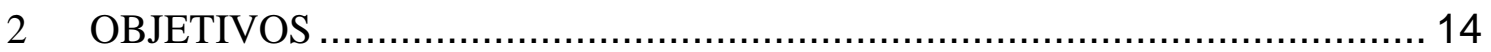

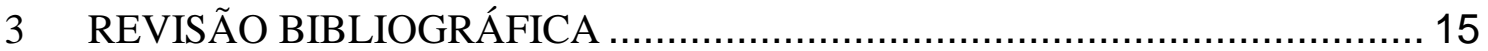

3.1 Métodos de análise de tendências de sedimento (Sediment Trend Analysis STA) 16

3.2 Críticas e problemáticas referentes ao modelo ...................................... 19

3.3 Modelos derivados do STA - Análise bidimensional ............................. 21

3.4 Aplicações do modelo de STA no Brasil e no mundo................................ 22

3.5 Uso de minerais pesados (MP) na inferência de transporte de sedimento...... 23

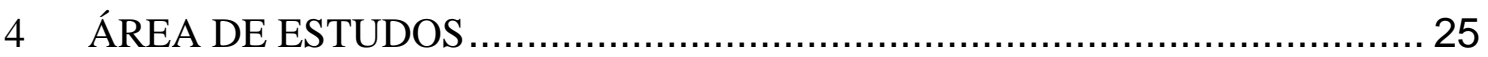

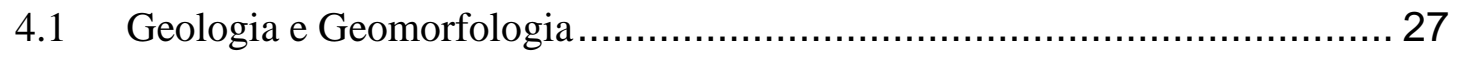

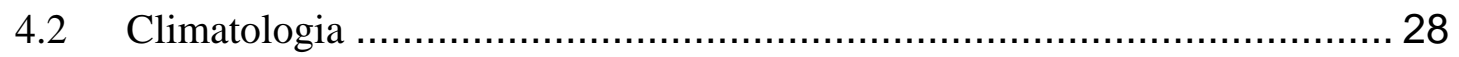

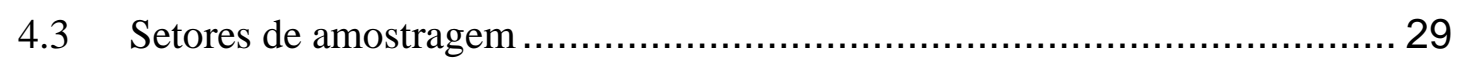

4.3.1 Setor Presidente Kennedy-Marataízes (PKMA) ................................ 29

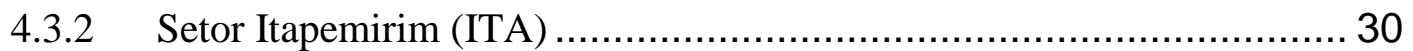

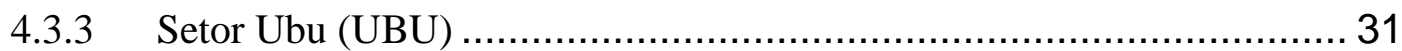

4.3.4 Setor Vila Velha e Guarapari (VVGU) ....................................... 32

4.3.5 Setor Vila Velha (VL) ........................................................ 33

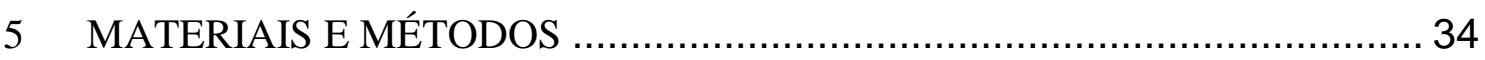

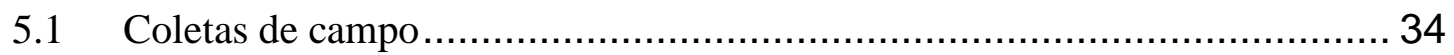

5.1.1 Tratamento das amostras em laboratório ...................................... 35

$5.1 .2 \quad$ Processamento dos dados ..................................................... 36

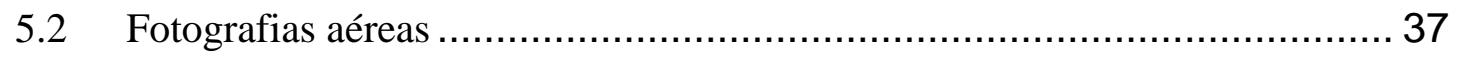

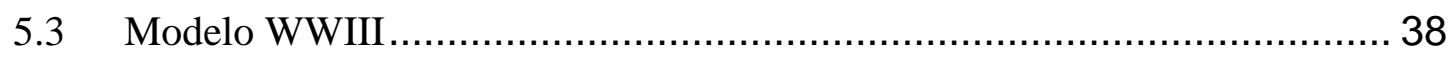

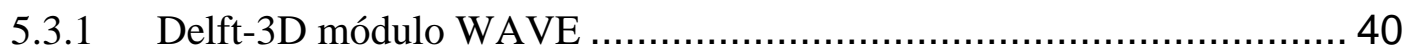

5.3.2 Estudo da Deriva Longitudinal Potencial .................................. 44 


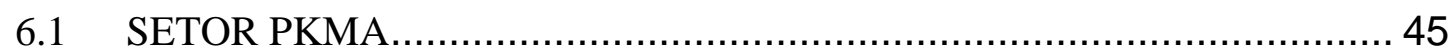

6.1.1 Descrição dos parâmetros no setor PKMA ………………………... 45

6.1.2 Análise de STA para o setor PKMA ............................................... 48

6.1.3 Análise de imagens e fotografias aéreas no setor PKMA …………...... 54

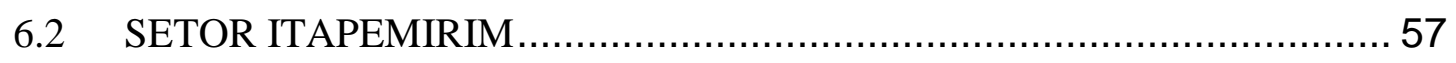

6.2.1 Descrição dos parâmetros no setor ITA.............................................. 57

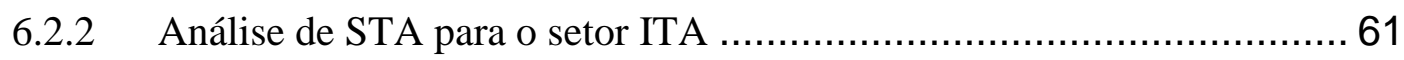

6.2.3 Análise de imagens e fotografias aéreas do setor ITA........................... 65

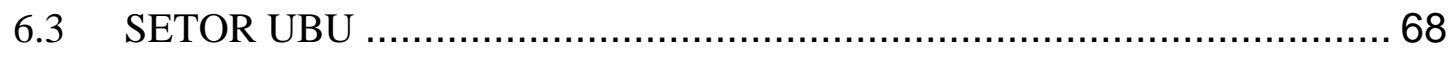

6.3.1 Descrição dos parâmetros no setor UBU ………………………....... 68

6.3.2 Análise de STA no setor UBU ......................................................... 71

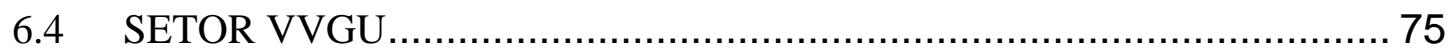

6.4.1 Descrição dos parâmetros no setor VVGU ……………………….... 75

6.4.2 Análise de STA para o Setor VVGU ……………………….......... 79

6.4.3 Resultado da análise STA para o setor VVGU .................................. 81

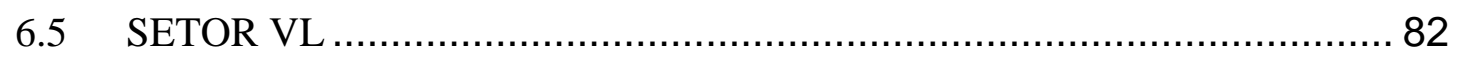

6.5.1 Análise de STA para o setor VL................................................... 82

6.5.2 Resultados da análise STA nos setores conjuntamente........................ 89

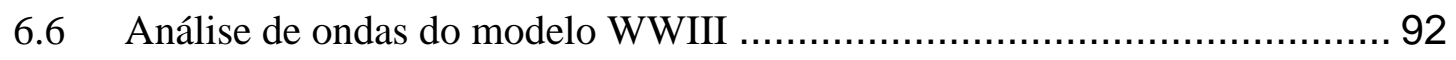

6.6.1 Resultados do modelo Delft-3D aplicados ao transporte longitudinal de

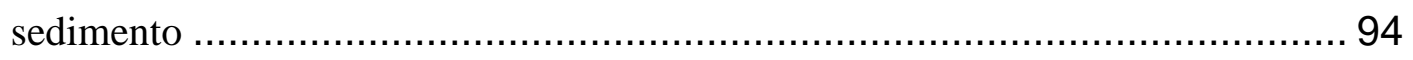

6.6.2 Análise da orientação da linha de costa ........................................... 98

6.6.3 Análise do comprimento da praia .................................................... 100

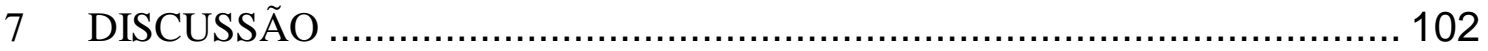

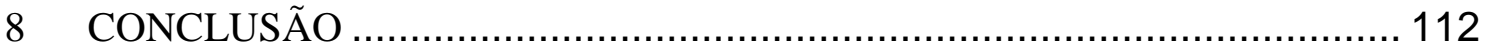

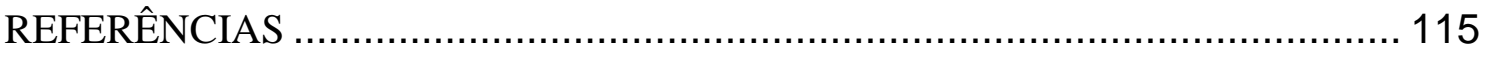




\section{LISTA DE FIGURAS}

Figura 1: Geração de correntes longitudinais devido à angulação entre as ortogonais de onda e a linha de costa (Silva, et al., 2004) .............................................. 13 Figura 2: Variação de parâmetros texturais sedimentares entre a fonte, zona de transporte e deposição (Gao e Collins, 1991) .............................................. 18 Figura 3: Composição de fotografias aéreas da área de estudos indicando os cinco arcos praiais. Fonte: IEMA, 2009 26

Figura 4: Formação Barreiras no Espírito Santo: localização (à esquerda, segundo Amador e Dias, 1978) e fotografia em campo (Praia de Meaípe). 27

Figura 5: Praia central de Marataízes em distintos momentos: à esquerda, em 2005, com diversos molhes perpendiculares à linha de costa, em tentativa frustrada de conter a erosão; à direita, a última tentativa de contenção de erosão (2010), e ao centro, fotografia tirada em 2012, indicando que a praia ainda está passando por um processo de adaptação. A escala na imagem à direita refere-se às duas das extremidades. ........ 29

Figura 6: Fotografia em campo da zona entre cordões do setor ITA ...................... 31

Figura 7: Organograma da metodologia de pesquisa .................................... 34

Figura 8: Medição da declividade praia em campo ..................................... 35

Figura 9: Exemplo de Rosa de ondas (Período e Altura) e Histograma para o ano de 1997 - resultado do modelo WaveWatch III ................................................... 40

Figura 10: Resolução da grade usada no modelo Delft-3D ............................. 42

Figura 11: Localização dos pontos de coleta no setor PKMA .............................. 46

Figura 12: Caracterização sedimentar e geométrica das estações amostrais no setor

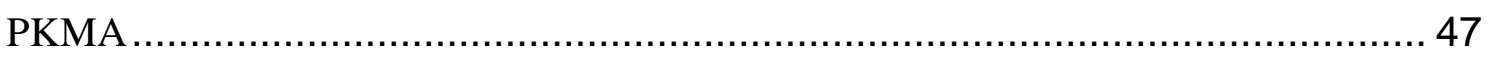

Figura 13: Fotografias em campo da zona de falésias vivas com maior concentração de MP (sedimento escuro), baixa declividade e de areia fina no setor PKMA. 48

Figura 14: Correlação entre os parâmetros texturais usados na STA para o setor PKMA. O número ao lado da linha representa o coeficiente de Correlação de Pearson calculado.

Figura 15: Fotografias do ponto de coleta PKMA-24. No sentido horário, a começar pela foto superior esquerda, um quiosque que é periodicamente inundado, construído sobre a vegetação de restinga; falésias vivas; arenitos de praia protegendo a linha de costa contra a erosão; escarpa abrupta evidenciando erosão. 50

Figura 16: Correlação espacial dos parâmetros texturais no setor PKMA 51 
Figura 17: Representação gráfica dos resultados da análise de STA para o setor PKMA, sendo $\mathrm{CB}+\mathrm{o}$ sedimento mais grosso, melhor selecionado e com assimetria mais positiva; FB- o sedimento mais fino, melhor selecionado e com assimetria mais positiva. As setas pontilhadas representam a tendência com menor nível de confiança.

Figura 18: Evolução da linha de costa (em vermelho escuro) na foz do Rio Itabapoana. A orientação de norte aplica-se a todas as imagens. Para os anos de 1969, 1990 e 2008 foram usadas fotografias aéreas; nas demais, imagens de satélite

Figura 19: Vazões médias e mínimas do Rio Itabapoana entre os anos de 1969 e 2005.

Figura 20: Posição da linha de costa entre 1969 e 2010 da Praia Central de Marataízes. Fonte: Imagens de satélites 56

Figura 21: Localização dos pontos de coleta no setor ITA. 58 Figura 22: Caracterização sedimentar e geométrica das estações amostrais no setor ITA.

Figura 23: Fotografias em campo do setor ITA

Figura 24: Correlação entre os parâmetros texturais usados na STA para o setor ITA. O número ao lado da linha representa o coeficiente de Correlação de Pearson calculado. 61 Figura 25: Correlação espacial dos parâmetros texturais no setor ITA .......................62 Figura 26: Representação gráfica dos resultados da análise de STA para o setor ITA, sendo $\mathrm{CB}+\mathrm{o}$ sedimento mais grosso, melhor selecionado e com assimetria mais positiva. 64

Figura 27:Análise da variação da linha de costa no setor ITA .............................66

Figura 28: Registro das vazões médias, máximas e mínimas do Rio Itapemirim......... 67

Figura 29: Localização dos pontos de coleta no setor UBU.............................. 69

Figura 30: Caracterização sedimentar e geométrica das estações amostrais no setor

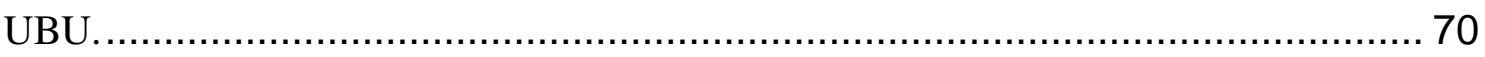

Figura 31: Correlação entre os parâmetros texturais usados na STA para o setor UBU 71 Figura 32: Escarpas na praia do setor UBU-3 …......................................... 72 Figura 33: Correlação espacial dos parâmetros no setor UBU ............................ 72 Figura 34: Representação gráfica dos resultados da análise STA para o setor UBU, sendo $\mathrm{CB}+\mathrm{o}$ sedimento mais grosso, melhor selecionado e com assimetria mais positiva; FB- o sedimento mais fino, melhor selecionado e com assimetria mais positiva. 
Figura 35: Tômbolo e Porto da SAMARCO no setor UBU. Fonte: Google Earth ....... 75

Figura 36: Localização dos pontos de coleta no setor VVGU ............................. 76

Figura 37: Caracterização sedimentar e geométrica das estações amostrais no setor VVGU

Figura 38: Arenitos de praia controlando a dinâmica oceanográfica no setor VVGU-18

Figura 39: Fotografia em campo dos arenitos de praia (Praia do Sol)

Figura 40: Correlação entre os parâmetros texturais usados na STA para o setor VVGU

Figura 41: Correlação espacial dos parâmetros texturais no setor VVGU 80

Figura 42: Representação gráfica dos resultados da análise de STA para o setor VVGU, sendo $\mathrm{CB}+\mathrm{o}$ sedimento mais grosso, melhor selecionado e com assimetria mais positiva; FB- o sedimento mais fino, melhor selecionado e com assimetria mais positiva.

Figura 43: Localização dos pontos de coleta no setor VL

Figura 44: Caracterização sedimentar e geométrica das estações amostrais no setor VL

Figura 45: Correlação entre os parâmetros texturais usados na STA para o setor VL .. 87

Figura 46: Correlação espacial dos parâmetros texturais no setor VL..................... 87

Figura 47: Representação gráfica dos resultados de STA para o setor VL, sendo FB- o sedimento mais fino, melhor selecionado e com assimetria mais positiva.

Figura 48: Análise STA em todos os setores conjuntamente

Figura 49: Clima de ondas na região sul Espíritossantense entre os anos de 1997 e 2010, modelados através do WWIII

Figura 50: Rosa de ondas (altura e período) para o verão entre os anos 1997 e 2010... 93

Figura 51: Rosa de ondas (altura e período) para o outono entre os anos 1997 e 2010. 93 Figura 52: Rosa de ondas (altura e período) para o inverno entre os anos 1997 e 201094 Figura 53: Rosa de ondas (altura e período) para a primavera entre os anos 1997 e 2010

Figura 54: Transporte longitudinal médio $\left(\mathrm{m}^{3} / \mathrm{ano}\right)$ na área de estudos. Números positivos representam transporte para norte;números negativos, para sul 95 Figura 55: Representação dos vetores mais significativos de transporte longitudinal de acordo com as estações do ano, segundo resultados do modelo DELFT-3D. 96 
Figura 56: Representação dos vetores mais significativos de transporte longitudinal de acordo com as estações do ano, segundo resultados do modelo DELFT-3D............... 97

Figura 57: Orientação da linha de costa (azimute) da área de estudos........................ 99

Figura 58: Comprimento da praia em todos os setores ................................. 101

Figura 59: Rosa de ondas (1991 a 2004) para a praia central de Marataízes (Elfrink et

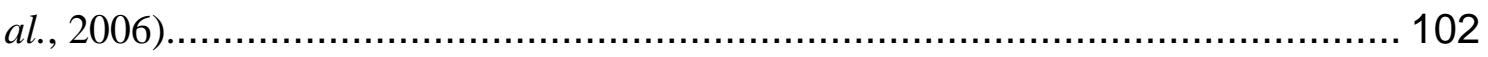

Figura 60: Praia em erosão na Ponta da Fruta .................................................. 108

Figura 61: Fotografias em campo do setor UBU............................................. 110 


\section{LISTA DE TABELAS}

Tabela 1: Casos possíveis de transporte combinando os parâmetros média, assimetria e desvio padrão

Tabela 2: Histograma de frequências das alturas e períodos de ondas para o ano de 1997

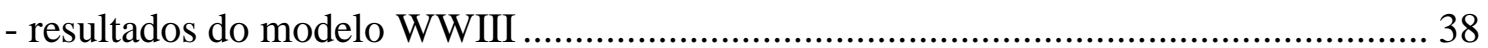

Tabela 3: Exemplo de simulações rodadas para o ano de 1997 ................................... 41

Tabela 4: Parâmetros usados na modelagem numérica com o programa Delft-3D ....... 43

Tabela 5: Correlação entre a variação espacial dos parâmetros texturais e distância das estações

Tabela 6: Resultado da análise STA para o setor PKMA............................................. 52

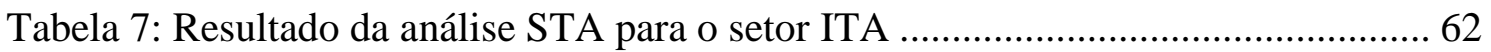

Tabela 8: Resultado da análise STA no setor UBU utilizando todas as amostras ......... 73

Tabela 9: Resultado da análise de STA para o setor VVGU ...................................... 81

Tabela 10: Resultado da análise STA para o setor VL ............................................. 88

Tabela 11: Tabela síntese dos resultados obtidos em campo e laboratório quanto à

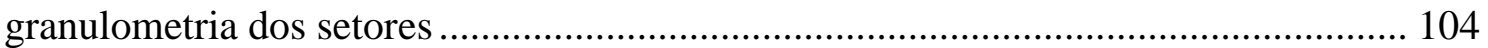

Tabela 12: Anos, volumes e locais de despejo do material dragado no Terminal de Ubu. 


\section{AGRADECIMENTOS}

Agradeço primeiramente a minha família, fonte de todo amor e suporte incondicionais. Sem vocês nada disso seria possível.

Ao orientador, Professor Eduardo Siegle por todo apoio e considerações feitas durante o mestrado. Aos demais professores, que também contribuíram imensamente para meu crescimento profissional e intelectual, em especial ao Paulo César Gianinni, Célia Regina Gouveia de Souza e Jacqueline Albino, que, mesmo à distância estava sempre pronta para responder meus questionamentos.

Aos companheiros de laboratório pelo auxílio diário, resolvendo dúvidas, debatendo questões ou apenas nos descontraindo, em especial a Ana Amélia, Mirella, Paulo e Juliana.

Aos amigos que fiz em São Paulo, que tornaram meu caminho mais leve e divertido: Leilane, Ana Paula, Augusto, Grasiane, Gilberto, Dalton, André, Luciana, Juliana e Diego. Sentirei falta da pausa para o café sem tomar café.

Aos meus grandes amigos de todas as partes. Seja em Vitória, Rio de Janeiro, Rio Grande do Sul ou México - sem vocês esse processo seria muito mais cansativo! Agradeço em especialmente a Rafaela e Júnior por todo o apoio, energia, otimismo e companheirismo durante a campanha de campo.

A todos os funcionários do Instituto pelo apoio prestado na secretaria, biblioteca, limpeza e comissões. 


\section{RESUMO}

A deriva litorânea é estudada no litoral sul do Espírito Santo através de diferentes técnicas: distribuição de Minerais Pesados (MP); modelo conceitual Análise de Transport de Sedimento (Sediment Trend Analysis - STA), através da variação de parâmetros texturais do sedimento; dados de clima de onda entre 1997 e 2010 do modelo global WaveWatch III propagados para a zona costeira através do modelo Delft3D, fornecendo parâmetros necessários para as equações de deriva; e imagens de satélite e fotografias aéreas para avaliar a variação espaço-temporal da morfologia costeira. O modelo STA mostrou-se confiável apenas nos dois setores ao norte, enquanto nos demais os resultados foram mascarados por altos teores de MP e/ou carbonato e a entrada de outras fácies no sistema; as equações representaram bem a variação da morfologia costeira na área de estudos. De maneira geral, os setores ao sul apresentaram transporte longitudinal para sul, e os setores ao norte, para norte, fato relacionado à batimetria local. A orientação da linha de costa auxiliou na compreensão dos fenômenos erosivos, pois em sua maioria estão orientados no sentido NEN, formando $45^{\circ}$ com as ondas dos setores de ESE e SE.

Palavras-chave: Deriva litorânea, Sediment Trend Analysis, Delft-3D, sedimentologia, ondas, dinâmica costeira. 


\begin{abstract}
Longshore drift is studied in the southern portion of Espírito Santo through different techniques: Heavy Minerals (HM) distribution; the conceptual model Sediment Trend Analysis (STA) by sediment textural parameters fluctuation; wave climate data between 1997 and 2010 from WaveWatch III propagated to the coastal zone through Delft-3D model, providing the required data for longshore drift equations; and satellite images and aerial photograph to survey time-space coastline variations. The STA model appears to be trustworthy only within the northern sectors, as high HM and/or carbonate content and different facies input into the system may mask the results. Broadly speaking, the southern sectors showed longshore transport southward, while northern sectors showed northward longshore transport, which is related to local bathymetry. Shoreline azimuth helped understanding the location of erosive zones, since most of them are turned NEN, $45^{\circ}$ with ESE and SE wave sectors.
\end{abstract}

Keywords: Longshore drift, Sediment Trend Analysis, Delft-3D, sedimentology, waves, coastal dynamics 


\section{INTRODUÇÃO}

A incidência de ondas na zona litorânea pode resultar em duas distintas correntes: uma, transversal, é responsável pela troca sedimentar zona imersa/emersa e outra, longitudinal, transporta o sedimento para diferentes setores na praia emersa e imersa. Segundo Komar (1991) e Carter (1988), a corrente longitudinal é o processo mais importante de transporte de sedimento na zona costeira, agindo especialmente na zona de surfe (Galvin e Eagleson, 1964).

Devido aos efeitos de refração, as ondas raramente atingem a linha de costa ortogonalmente, formando angulações diferentes de zero entre as ortogonais de onda e a linha de costa. Esse processo é o principal responsável por criar correntes longitudinais, que correm paralelamente ao litoral (Longuet-Higgins, 1970), como mostra a Figura 1.

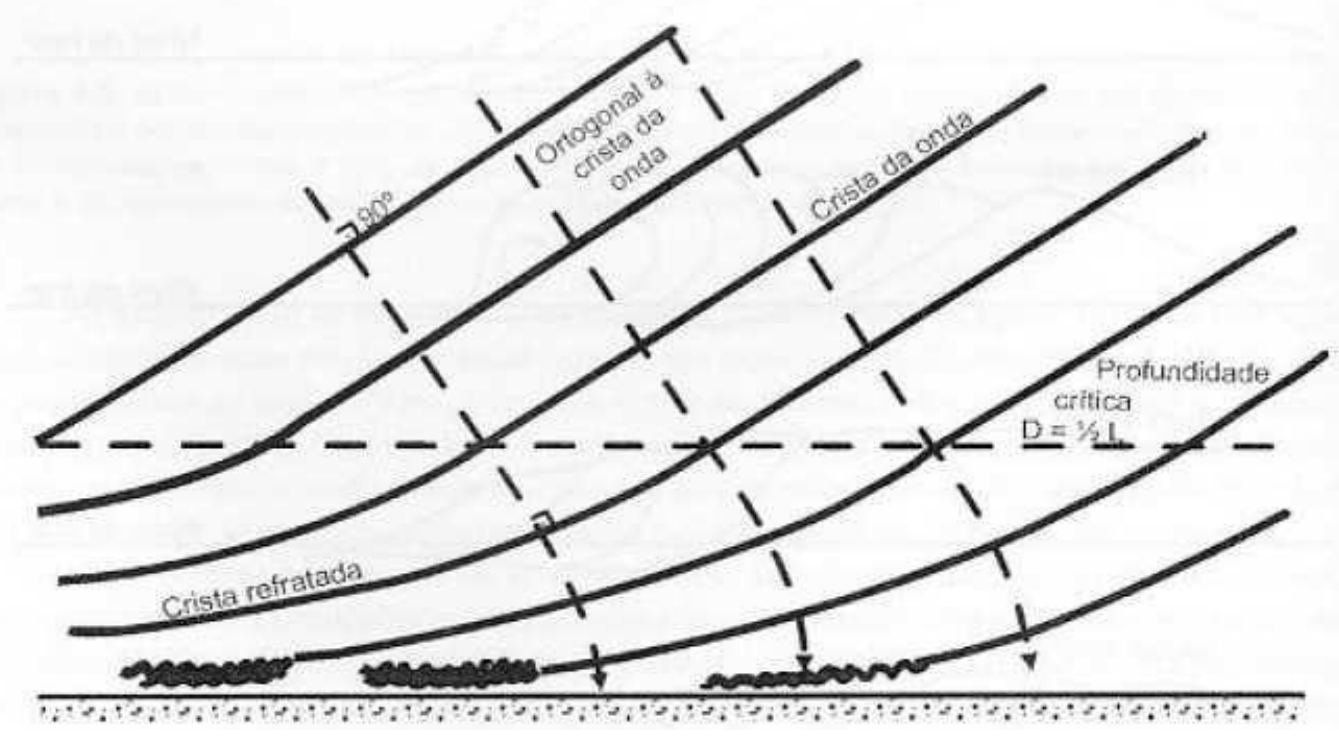

Figura 1: Geração de correntes longitudinais devido à angulação entre as ortogonais de onda e a linha de costa (Silva, et al., 2004)

Também podem originar correntes longitudinais a diferença de altura do nível d'água entre pontos distintos na costa, correntes de maré e o cisalhamento local do vento (Bowen, 1969; Komar e Inman, 1970; Noda, 1971).

Como consequências, a corrente longitudinal pode levar à construção de feições como barras fluviais, cristas submersas ou feições rítmicas ou transportar o sedimento por longas distâncias, causando acresção e erosão em distintas partes de uma mesma praia. 
O fluxo de sedimento, entretanto, pode ser interrompido através da captura por cânions submarinos ou por obras de engenharia costeira, como molhes e quebra-mares. Por esses motivos, o estudo de origem, comportamento e consequências da corrente longitudinal na zona costeira faz-se tão importante para oceanógrafos, engenheiros e geólogos (CERC, 2002).

Traçadores radioativos (White, 1998), minerais pesados (Rittenhouse, 1943; Frihy e Dewidar, 1993, 2003), armadilhas de sedimento (Schoones e Theron, 1993), geomorfologia (Reddering, 1983, Kunte e Wagle, 1993, Appendini et al., 2012), modelo numérico (Pilkey e Cooper, 2002, Peter et al., 2011) ou mesmo a integração desses (Benkhaldoun e Seaïd, 2011) constituem ferramentas importantes na análise de transporte longitudinal de sedimento. No presente trabalho são empregadas duas distintas técnicas no estudo da corrente longitudinal: (1) modelo conceitual de McLaren e Bowles (1985) e (2) modelo numérico de propagação de ondas.

A partir da compartimentação do litoral sul do Espírito Santo em cinco arcos praiais de comprimentos distintos, fez-se a coleta de sedimento para o estudo da corrente longitudinal a partir da variação dos parâmetros texturais do sedimento (STA Sediment Trend Analysis). Paralelamente, dados de ondas extraídos do modelo global Wave Watch III foram usados como entrada do modelo Delft-3D para o estudo de sua propagação para a linha de costa. O teor de Minerais Pesados e a observação das variações da linha de costa somados ao estudo da orientação e batimetria dos setores auxiliaram no estudo da deriva longitudinal de sedimento e na compreensão dos processos litorâneos. Dessa maneira, foi possível uma atualização do Atlas de Erosão e Progadação do Litoral Brasileiro dentro do setor estudado.

\section{OBJETIVOS}

O objetivo principal do trabalho é compreender os processos de deriva litorânea em função do clima de ondas e relacioná-los com a evolução da linha de costa do litoral sul do Espírito Santo.

Os objetivos específicos compreendem: 
- Definir as tendências do transporte longitudinal através do modelo conceitual de McLaren e Bowles (1985) - Sediment Trend Analysis e Grain-Size Trend Analysis (Gao, 1996);

- Avaliar a variação interanual das feições geomorfológicas costeiras;

- Modelar a propagação das ondas na zona costeira através do modelo numérico Delft-3D;

- Relacionar os resultados do modelo Delft-3D com os da análise STA;

- Estudar o histórico das obras de engenharia costeira na área de estudos e entender possíveis alterações causadas por sua presença na linha de costa;

- Compreender a variação espacial do teor de Minerais Pesados e carbonato de cálcio;

\section{REVISÃO BIBLIOGRÁFICA}

Segundo Hartmann (2007), a análise do tamanho das partículas sedimentares pode ser realizada de duas maneiras distintas: na primeira, descritiva, faz-se a análise das amostras e então seus resultados são aplicados de maneira comparativa. Na segunda, parte-se do pressuposto que o tamanho das partículas está relacionado com o processo sedimentar em questão, e não com o ambiente (Boggs, 2001), como iniciado por Pettijohn (1975).

Entre os anos de 1930 e 1980 o uso de parâmetros texturais na análise de transporte de sedimentos, visando sua relação com processos de transporte era realizado escolhendo um parâmetro estatístico único, relacionando-o com a região de transporte e depósito (Pettijohn e Ridge, 1932; Pettijohn et al., 1972; McCave, 1978). Nesse sentido, MacCarthy (1931), Self (1977) e Nordstrom (1989) encontraram diminuição das partículas sedimentar na direção de transporte, enquanto Schalk (1938), McCave (1978), McLaren (1981) e Bryant (1982) encontraram aumento das partículas na direção de transporte.

No começo da década de 1980, entretanto, McLaren (1981) e McLaren e Bowles (1985) empregaram três diferentes parâmetros texturais (a saber: média, assimetria e desvio padrão) para tal estudo. De acordo com Martins (2003), esses três parâmetros são os 
mais importantes na análise sedimentar, sendo influenciados pela dinâmica de transporte e deposição.

Assimetria negativa, e.g., é relacionada à retirada do sedimento fino por efeito de joeiramento (winnowing), tendo relação com eventos de maior intensidade e duração de um agente deposicional altamente energético. Pode ser também atribuída à entrada de outra população, como conchas carbonáticas (Martins, 1965; Guedes et al., 2011). Adiciona-se aqui, como um paralelo e atestado pelas amostras, que a entrada de minerais pesados (MP) também pode causar assimetria negativa. Assimetria positiva, por outro lado, pode ser atribuída à menor competência de um fluxo unidirecional, incapaz de transportar material mais grosso, como atestado por Guedes et al. (2011).

\subsection{Métodos de análise de tendências de sedimento (Sediment Trend Analysis - STA)}

Sendo precursores na análise de transporte de sedimento a partir dos três parâmetros texturais, McLaren (1981) e McLaren e Bowles (1985) partem do pressuposto básico (a ser usado por todos os outros posteriormente) de que grãos menores possuem maior probabilidade de serem transportados do que grãos maiores (a probabilidade de transporte aumenta monotonicamente com o aumento em $\phi$ dos grãos). Além disso, a média, assimetria e desvio padrão seguem tendências que tornam possíveis a identificação da direção de transporte, processos de joeiramento e deposição seletiva e total.

Combinando os três parâmetros (média, assimetria e desvio padrão) são possíveis $2^{3}=8$ hipóteses (onde F refere-se a mais fino, $\mathrm{C}$ a mais grosso, $\mathrm{B}$ a melhor selecionado, $\mathrm{P}$ a pior selecionado $\mathrm{e}+\mathrm{e}-$ assimetria mais positiva ou negativa, respectivamente), indicadas na Tabela 1: 
Tabela 1: Casos possíveis de transporte combinando os parâmetros média, assimetria e desvio padrão

\begin{tabular}{cccl}
\hline Tendência & $\begin{array}{c}\text { Média (em } \\
\boldsymbol{\phi})\end{array}$ & $\begin{array}{c}\text { Desvio } \\
\text { Padrão }\end{array}$ & Assimetria \\
\hline FP- & $\mu_{1}<\mu_{2}$ & $\sigma_{1}<\sigma_{2}$ & $\mathrm{Sk}_{1}>\mathrm{Sk}_{2}$ \\
FP+ & $\mu_{1}<\mu_{2}$ & $\sigma_{1}<\sigma_{2}$ & $\mathrm{Sk}_{1}<\mathrm{Sk}_{2}$ \\
FB- & $\mu_{1}<\mu_{2}$ & $\sigma_{1}>\sigma_{2}$ & $\mathrm{Sk}_{1}>\mathrm{Sk}_{2}$ \\
FB+ & $\mu_{1}<\mu_{2}$ & $\sigma_{1}>\sigma_{2}$ & $\mathrm{Sk}_{1}<\mathrm{Sk}_{2}$ \\
CP- & $\mu_{1}>\mu_{2}$ & $\sigma_{1}<\sigma_{2}$ & $\mathrm{Sk}_{1}>\mathrm{Sk}_{2}$ \\
CP+ & $\mu_{1}>\mu_{2}$ & $\sigma_{1}<\sigma_{2}$ & $\mathrm{Sk}_{1}<\mathrm{Sk}_{2}$ \\
CB- & $\mu_{1}>\mu_{2}$ & $\sigma_{1}>\sigma_{2}$ & $\mathrm{Sk}_{1}>\mathrm{Sk}_{2}$ \\
CB+ & $\mu_{1}>\mu_{2}$ & $\sigma_{1}>\sigma_{2}$ & $\mathrm{Sk}_{1}<\mathrm{Sk}_{2}$ \\
\hline
\end{tabular}

Entretanto, como atestado por McLaren (1981), apenas duas das situações inferem a direção de transporte, o que foi testado em experimentos laboratoriais, posteriormente por McLaren e Bowles (1985).

Assim, chegam a três distintas possibilidades de transporte, em que se consideram os depósitos $\mathrm{d}_{1}$ e $\mathrm{d}_{2}$ (como mostrado na Figura 2):

- Depósito residual (Lag Deposit - Caso A): Caso $\mathrm{d}_{2}$ possua distribuição mais grossa, melhor selecionada (menor desvio padrão) e assimetria mais positiva (ou seja, para o lado dos grossos), $\mathrm{d}_{2}$ funciona como um depósito de $\mathrm{d}_{1}$ e ambas as distribuições possuem a mesma origem. Assim, não se pode determinar uma direção de transporte.

- Sedimento afinando (Caso B): No caso de $\mathrm{d}_{2}$ ser mais fino, melhor selecionado e possuir assimetria mais negativa do que o sedimento de origem (notação "FB-" usada no presente trabalho, como sugerida por Poizot et al., 2008), a direção de transporte é de $\mathrm{d}_{1}$ para $\mathrm{d}_{2}$, e a transferência energética diminui na mesma direção. Assim, sedimentos mais grossos são depositados preferencialmente.

- Sedimento engrossando (Caso $\mathrm{C}$ ): No caso de $\mathrm{d}_{2}$ ser mais grosso, melhor selecionado e possuir assimetria mais positiva do que o sedimento de origem (notação " $\mathrm{CB}+$ " usada no presente trabalho, como sugerida por Poizot et al., 2008), a direção de transporte é de $\mathrm{d}_{1}$ para $\mathrm{d}_{2}$, e a transferência energética é tão 
grande que possibilita a deposição dos grãos mais grossos apenas a partir de maiores distâncias.

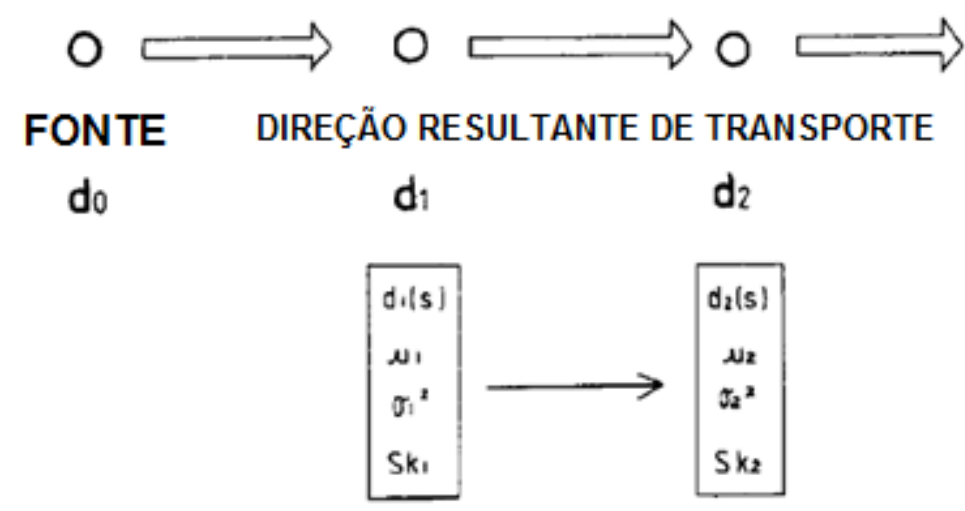

Figura 2: Variação de parâmetros texturais sedimentares entre a fonte, zona de transporte e deposição (Gao e Collins, 1991)

Entende-se, dessa maneira, que apenas os casos FB- e CB+ representam processos de deposição seletiva, indicando assim, direção preferencial de transporte.

Assim sendo, todas as amostras são comparadas par a par, em sentidos opostos, sendo posteriormente aplicado um teste-Z (Spiegel, 1961) para que seja validada a hipótese da direção, com diferentes graus de confiança. Caso seja atestado que ambas as direções são estatisticamente significantes, é dito que a praia passa por um estado de equilíbrio, como afirmado pelo autor ${ }^{1}$.

O teste-Z é aceito de acordo com a seguinte fórmula:

$$
Z=\frac{x-N p}{\sqrt{N p q}}>1,645
$$

(para significância de 95\% ou >2,33 para significância maior que 99\%).

Na fórmula, $\mathrm{x}$ representa o número de pares que seguem uma das duas tendências (FBou $\mathrm{CB}+), p=\frac{1}{8}$ e $q=\frac{7}{8}$, sendo $p$ a probabilidade de ocorrência randômica de uma das hipóteses de transporte e $p=1-q$. O número de pares totais é representado por $\mathrm{N}$, em

1 Comunicação pessoal com o autor Patrick McLaren via e-mail, em 15/07/2012 
que $N=\frac{n^{2}-n}{2}$, sendo n o número de amostras em sequencia. O teste é válido para um $\mathrm{N}$ maior que 30, o que requer um mínimo de 8 ou 9 amostras (McLaren e Bowles, 1985).

\subsection{Críticas e problemáticas referentes ao modelo}

No ano de 1991, Gao e Collins publicaram a primeira crítica ao método STA, em que atestaram matematicamente que há possibilidade de transporte também para as situações FB+ e CB-. Gao e Collins (1992) aplicaram essas possibilidades no porto de Yangpu (China), considerando, dessa maneira, um transporte bidimensional, e aplicaram teste de significância.

Masselink (1992) coletou 29 amostras nos centímetros superficiais do sedimento da face praial nas praias próximas à foz do Rio Reno (Mar Mediterrâneo) para testar a validade do modelo de McLaren e Bowles (1985). O autor encontrou correlação muito baixa na assimetria e grau de seleção, e com resultados de direção oposta do esperado e atestado por estudos prévios locais. $\mathrm{O}$ erro foi atribuído ao modelo por suas próprias afirmativas - por assumir que o transporte é unidirecional, proveniente de uma única fonte e que o transporte longitudinal é o principal fator causador da presente característica textural. Como na praia em questão o transporte é bidirecional, outras fontes podem existir, como dunas costeiras. Além disso, o autor entende que outros fatores são mais relevantes, como o transporte transversal, e afirma que sua aplicabilidade é restrita ao ambiente praial.

McLaren (1993) responde às críticas e faz as seguintes recomendações:

- Usar um intervalo de peneiramento de $1 / 2 \quad \phi$ ao invés de $1 / 4$ (obtido empiricamente, já que menores intervalos aumentam o ruído);

- Quando o valor de correlação $\mathrm{R}^{2}$ for muito pequeno, provavelmente há mais de uma direção de transporte envolvida no arco praial, e isso deve ser considerado, separando as amostras em grupos;

- Caso se queira entender a dinâmica de longo período, a amostragem dos centímetros superficiais do sedimento praial deve ser feita com a coleta mais profunda do sedimento.

- O artigo anterior (McLaren e Bowles, 1985), ao contrário do que Masselink (1992) afirma, não considera que há apenas uma direção de transporte, mas sim 
uma direção resultante de transporte; além disso, o método não considera que há apenas uma única fonte de sedimento, mas sim que esse pode servir como indicador de novas fontes, a partir do momento em que tendências são quebradas. Por fim, McLaren et al. (1993a) reafirma que de fato o transporte total é responsável pelas variações texturais do sedimento, como observado por diversos trabalhos aplicados em diferentes ambientes.

No mesmo ano, McLaren et al. (1993b) publicaram outro estudo, em um fiorde inglês, onde ratificam algumas recomendações: o valor de $\mathrm{R}^{2}$ é eliminatório no processo de análise. Valores baixos de $\mathrm{R}^{2}$ associados com valores altos no teste- $\mathrm{Z}$ podem significar a entrada de diferentes fácies no sistema, ou mesmo de material estranho ao sistema, como o de dragagem ou de acresção artificial de praia, como pode ser observado nas amostragens de campo. Os autores ressaltam no mesmo artigo que a interpretação dos resultados é a parte mais importante, devendo ser coerentes entre si e com a dinâmica esperada para o local.

Em um artigo de revisão, Le Roux e Rojas (2007) criticam o fato do modelo STA ser unidimensional, concordando com Asselman (1999) ao afirmar que a escolha de diferentes linhas é feita pelo pesquisador, e pode fornecer resultados tendenciosos e falaciosos. Uma adaptação é proposta por Lucio et al. (2004), em que são estudadas as funções de autocorrelação de um processo tendo por base a cadeia de Markov, e propõe uma análise de componentes principais. Tais problemáticas e soluções são feitas para estudos bidimensionais (que com o método de McLaren torna-se unidimensional).

Em revisão publicada pelo próprio autor (McLaren et al., 2007), novas afirmações são feitas e confirmadas. O modelo inicial previa que os processos de transporte afetam diretamente o tamanho do grão do depósito. Foi observado, entretanto, que alguns fatores podem mascarar essa afirmativa, como quando os grãos mais grossos impedem o transporte de grãos mais finos, que por sua vez são mais coesos. Alguns outros problemas e remediações do modelo são apontados:

- O sedimento amostrado representa a resultante do transporte, a depender da profundidade de amostragem. Assim, o depósito $d_{1}$ pode representar uma deposição resultante de um ciclo de marés, e o depósito $d_{2}$ a resultante de anos de deposição. 
- O espaçamento entre as amostras deve levar em conta fatores como a escala do evento de deposição, o formato da área e o número de ambientes a serem amostrados. De acordo com o autor (op. cit.), amostras coletadas com uma distância $x$ representam processos que ocorrem sobre uma distância superior a $2 x$. Para ambientes praiais o autor recomenda um espaçamento de $1 \mathrm{~km}$.

- Ruídos atrapalham a análise, e estão sempre presentes, podendo ser administrados através de uma regressão linear e do aumento do número amostral;

- Ainda segundo o artigo (McLaren et al., 2007), alguns fatores podem auxiliar na análise, interpretação e filtragem dos resultados:

- Familiaridade com os dados: plotagem em ambiente SIG (Sistema de Informações Geográficas), análise cluster para a identificação de fácies distintas;

- A mistura de técnicas de análise diferentes não produz bons resultados (como peneiramento e laser);

○ Não considerar amostras com perda maior do que $1 \%$ durante o processo de peneiramento, e esse percentual também não deve ser atingido pela classe que encerra a distribuição ( $>4 \phi)$;

- Análise das caudas da distribuição: como a assimetria é um momento de terceira ordem, pequenas variações numéricas causam grandes mudanças no resultado. Assim, a robustez do resultado pode ser atestada aumentando os valores das caudas empiricamente. Caso não haja grandes variações no resultado da assimetria, pode-se considerar tal análise estatística como confiável.

- Outra maneira de se atestar a confiabilidade dos resultados é plotando-se e analisando-se as relações média/assimetria/desvio padrão. Valores altos de $\mathrm{R}^{2}$ fornecem maior confiabilidade aos resultados.

\subsection{Modelos derivados do STA - Análise bidimensional}

Gao e Collins (1994) publicaram o programa em linguagem FORTRAN denominado GSTA, incluindo as outras duas tendências afirmadas originalmente pelos autores (FBe $\mathrm{CB}+$ ). Outras modificações do programa foram propostas, como o GSTAST (que inclui um teste de significância maior, proposto por Chang et al., 2001) e EcsedTrend 
(Poizot et al.,2008). Além desses, Le Roux (1994a) publicou outro programa, em linguagem VBA, considerando as quatro estações vizinhas de uma estação central para a análise, incluindo as quatro formas de relação. O modelo é denominado TRANSVEC.

Apesar das críticas, o método STA ainda é amplamente utilizado, não tendo sido superado por outro no que tange a ambientes unidimensionais, como as praias. Poizot et al. (2008) fornecem uma boa revisão bibliográfica apresentando os programas existentes no mercado que fazem a análise.

Todos os modelos citados fazem referências a coletas bidimensionais, com aplicações em estuários (Mc Laren e Little,1987; Wu e Shen, 1999; Mallet et al., 2000; Duck et al., 2001; Pascoe et al., 2002; Friend et al., 2006), plataforma continental (Lanckneus et al., 1992; Gao e Collins, 1994a; Gao e Collins, 1994b; Ehrhold, 1999; Van Wesenbeck e Lanckneus, 2000; Le Bot et al., 2001; Lucio et al., 2002; Garnaud, 2003; Duman et al., 2004, 2006), e cânions submarinos (Liu et al., 2002, 2004).

O modelo de STA toma, em geral, uma malha bidimensional de amostragem, mas sua análise é feita de maneira unidirecional, escolhendo caminhos de transporte e aplicando os testes estatísticos. Por esse motivo, sua análise é perfeitamente plausível em ambientes praiais, em que o transporte é analisado de maneira unidimensional.

\subsection{Aplicações do modelo de STA no Brasil e no mundo}

Diversos foram os trabalhos envolvendo a análise de STA, como citados anteriormente. A técnica tem sido aplicada tanto em estudos ambientais (McLaren,1983, 1984; McLaren e Little, 1987; McLaren et al.,1993a, b; Uriarte et al., 1998; Pascoe et al., 2002; Hughes, 2005) quanto em investigações sedimentologógicas (McCave,1978; Nordstrom, 1981, 1989; Zhang e Zhu, 1989; Gao e Collins, 1992,1994a, 1994b; Guillén e Jiménez, 1995; Van Wesenbeeck e Lanckneus, 2000; Mallet et al., 2000; Carriquiry et al., 2001; Ríos et al., 2002; Veiga, 2005; Poizot et al., 2006).

Como a metodologia de Gao e Collins (1991) e LeRoux (1994a, 1994b) são adaptações daquela originalmente apresentada por McLaren (1981) e McLaren e Bowles (1985), serão apontados trabalhos que empregam essas metodologias como um todo. 
Asselman (1999) apresentou uma nova adaptação do modelo de Gao e Collins (1991), em que usa conceitos de interpolação a partir do variograma das amostras. Assim, dados não obtidos in situ, mas calculados, são usados, fornecendo resultados confiáveis em seu estudo (aplicado em uma planície de inundação). Sua justificativa baseia-se no fato de a obtenção de uma malha regular de dados interpolados ser menos sensível às irregularidades amostrais.

No Brasil, Tanaka et al. (2009) aplicou o modelo na planície de cordões litorâneos em Laguna (SC), aliado com análise de MP, que ajudaram na conclusão de um modelo de evolução quaternária para a região. Veiga et al. (2005) testaram a validade dos modelos GSTA, GSTAST e TRANSVEC no Complexo Estuarino de Paranaguá, encontrando no segundo a maior coerência com a hidrodinâmica local.

Souza (2007) aplicou uma metodologia que segue os princípios de McLaren e Bowles (1985), porém simplificada, sem envolver dados de confiabilidade estatística, como proposto por Taggart e Schuwartz (1988) nas praias do litoral de São Paulo. Foi também constatado pelos autores a proporcionalidade inversa entre energia de onda e curtose, tendo Souza (1997) encontrado correlação no estado de São Paulo de até 0,90.

Por fim, a aplicação do método STA no Espírito Santo foi feita por Dadalto e Albino (2009) na Praia erosiva da Curva da Jurema como idealizado por Gao e Collins (1992), fornecendo resultados condizentes com a hidrodinâmica local. Pavani (2006) testou o modelo de STA nas praias arenosas entre Setiba e Ponta da Fruta (setor VVGU do presente trabalho) e encontrou uma deriva para Sul.

\subsection{Uso de minerais pesados (MP) na inferência de transporte de sedimento}

Consideram-se MP aqueles cuja densidade supera a do Bromofórmio $\left(\mathrm{CHBr}_{3}, \rho=2,85\right.$ $\mathrm{kg} \mathrm{l}^{-1}$ ), como monazita, turmalina, zircão, rutilo, epídoto, dentre outros. Quando encontrados em altas concentrações e com possibilidade de exploração econômica são denominados pláceres (Silva, 2000).

Desde o começo do século XX, com Rittenhouse (1943) e Trask (1952), posteriormente com Van Andel (1964), os MP vem sendo utilizados na inferência da fonte de sedimento e processos de transporte e selecionamento de grãos, seja em ambientes 
atuais ou pretéritos. Além deles, Komar (1989), Komar et al. (1989) e Li e Komar (1992) consolidaram o conhecimento, demonstrando que correntes induzidas por ondas tanto em trocas longitudinais como transversais concentram MP de granulometria mais fina, removendo minerais leves de granulometria mais grossa.

No delta do Rio Nilo, por exemplo, é realizado desde 1972 um monitoramento da variação da linha de costa com coleta de sedimento para análise de MP, parâmetros texturais e teor de carbonato em uma grande malha amostral, espacial e temporal. Frihy e Komar (1991, 1993), Frihy et al. (1995), Frihy e Dewidar (1993, 2003), obtiveram o sentido de deriva litorânea através do estudo dos MP na região e a localização de células litorâneas. Frihy e Dewidar (2003) encontraram correlação entre o teor de MP e a taxa de erosão costeira. Não encontraram, entretanto, relação entre concentração e tamanho médio dos grãos com MP ou erosão costeira.

Gonzáles-Yajimovich et al. (2010) estudaram os MP da baía de Concepcíon (Califórnia) e correlacionaram sua concentração com o transporte de sedimento a partir de parâmetros texturais usando o método STA e o de Le Roux (TRANSVEC) e encontrou no primeiro melhor relação com a hidrodinâmica local atestada por estudos anteriores. A concentração total de MP indica que sua dispersão é controlada pela declividade na batimetria local, além de dar suporte à assimetria negativa da baía.

Giannini et al. (2004) estudaram a erosão da linha de costa na Ilha do Mel (PR) e usaram os parâmetros texturais na identificação de células de transporte litorâneo. Os resultados da análise de MP auxiliaram na identificação e ratificaram um modelo proposto pelo autor previamente, em que há eliminação gradual de alguns minerais no sentido da deriva por abrasão mecânica ou química. Os autores observaram relação entre as feições geomorfológicas e a mudança dos parâmetros texturais do sedimento, como as cúspides arenosas, tômbolos e o istmo entre as ilhas.

Na mesma linha, Guedes et al. (2011) afirmam que a combinação de parâmetros texturais do sedimento com análise de minerais pesados formam um método confiável de estudo de proveniência e padrões de transporte. Os autores encontraram uma tendência FB- na direção de transporte no estuário da Ilha Comprida, concordando com estudos prévios na região (Nascimento et al., 2005, 2008; Giannini et al., 2009), empregando a análise STA. 
Dessa maneira, será aplicado no trabalho o estudo de MP de maneira quantitativa para que auxilie nos resultados da dinâmica costeira do ES.

\section{4 ÁREA DE ESTUDOS}

O litoral sul do Espírito Santo é composto pelos municípios ao sul da ilha de Vitória, sendo estes: Presidente Kennedy (na divisa com o estado do Rio de Janeiro), Marataízes, Itapemirim, Piúma, Anchieta, Guarapari e Vila Velha. Desses, o município de Píuma não foi amostrado. A Figura 3 representa composição de fotografias aéreas tomadas no local. 


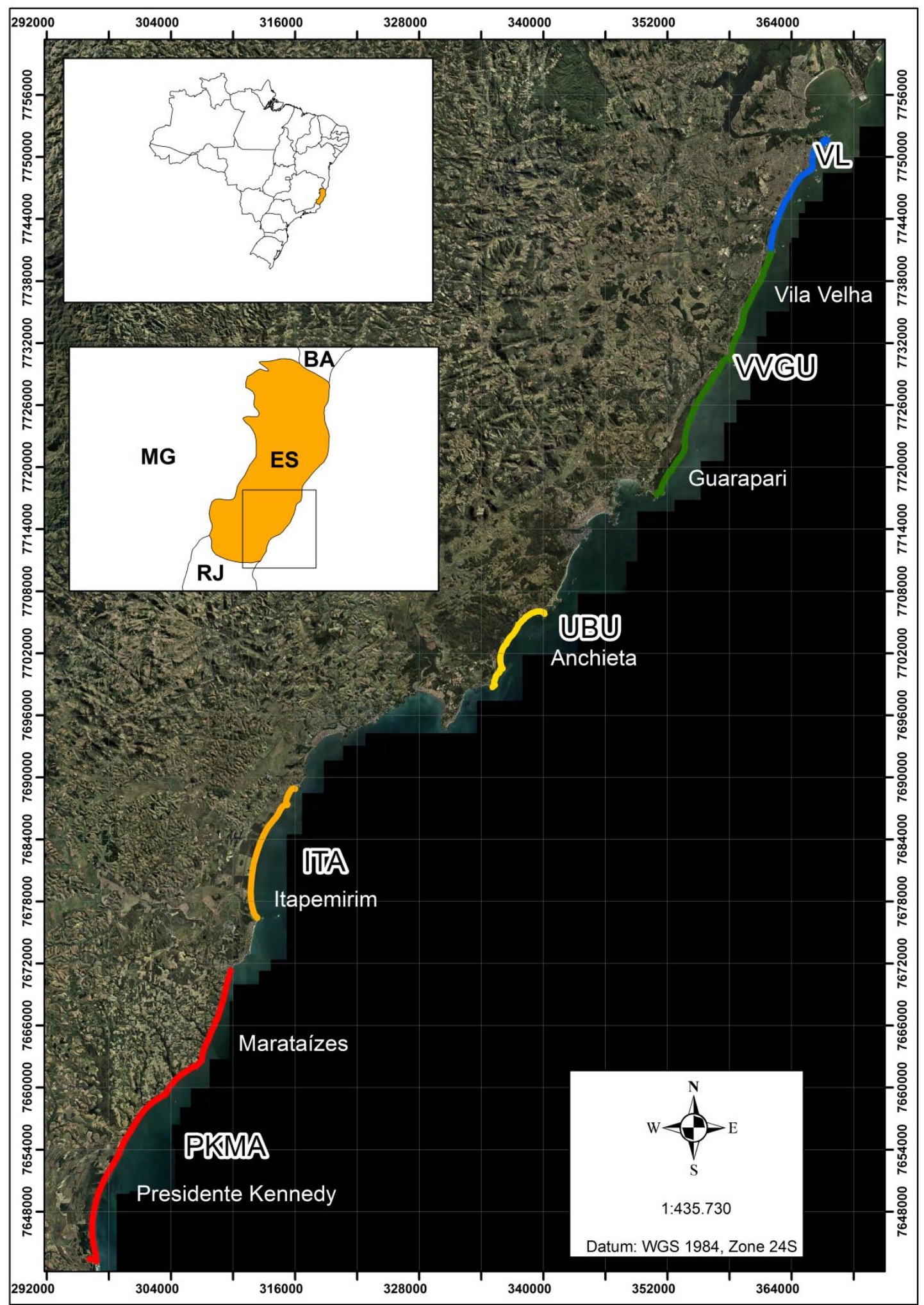

Figura 3: Composição de fotografias aéreas da área de estudos indicando os cinco arcos praiais. Fonte: IEMA, 2009 


\subsection{Geologia e Geomorfologia}

Martin et al. (1996) dividem em três as unidades geomorfológicas presentes no litoral capixaba: afloramentos cristalinos Pré-Cambrianos, tabuleiros Terciários da Formação Barreiras e planícies flúvio-marinhas Quaternárias.

A Formação Barreiras está presente no litoral brasileiro desde o Amapá ao Rio de Janeiro, e foram primeiramente descritos pelos portugueses no século XVI, em sua chegada à Bahia. No sul do Espírito Santo está presente na costa dos municípios de Presidente Kennedy, Anchieta e Guarapari, facilmente reconhecido pelas falésias de alturas expressivas na linha de costa, como indica a Figura 4.

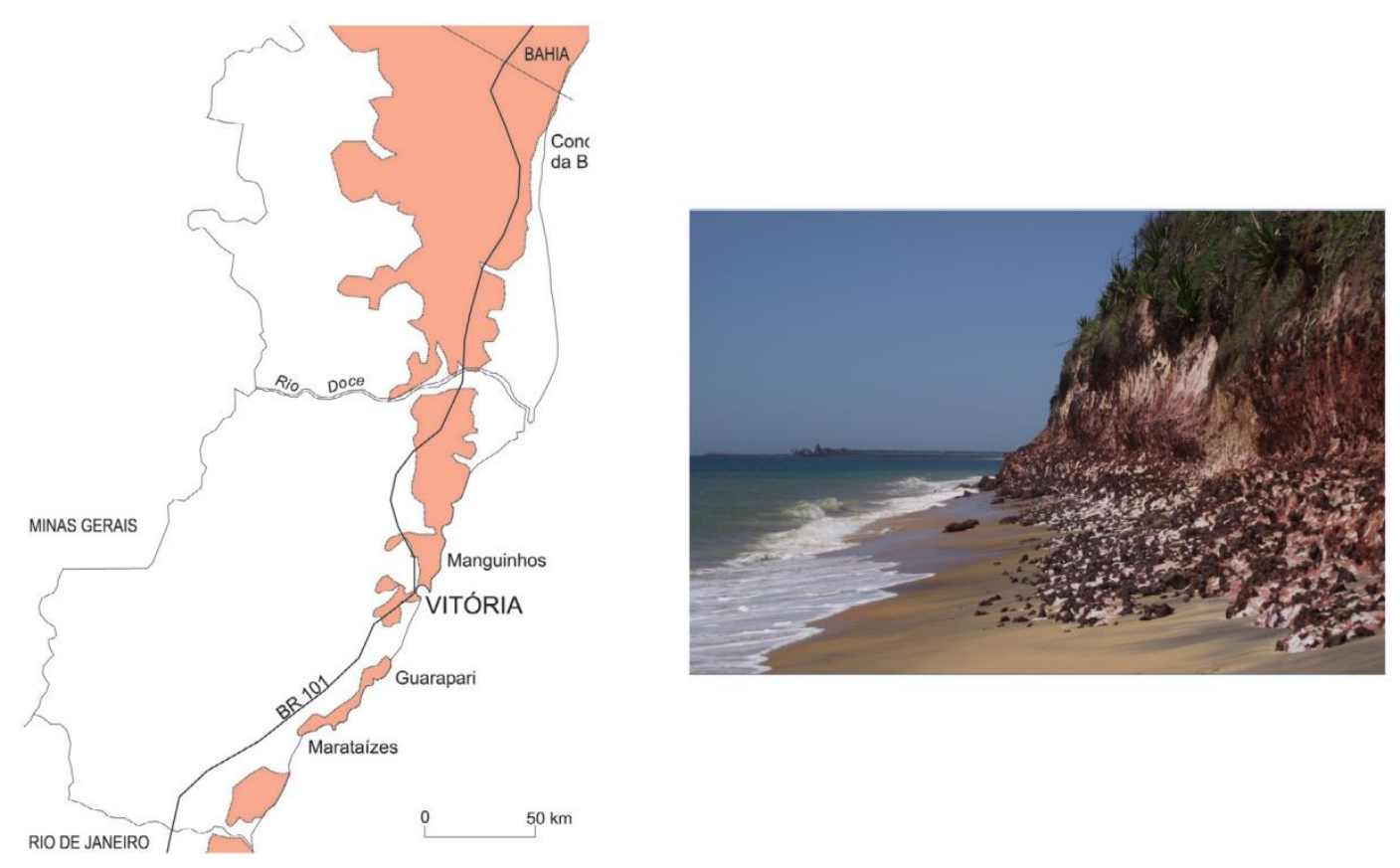

Figura 4: Formação Barreiras no Espírito Santo: localização (à esquerda, segundo Amador e Dias, 1978) e fotografia em campo (Praia de Meaípe).

A datação de palinomorfos e a estratigrafia permitiram a Arai (2005) relacionar a variação eustática do Mioceno ao início da deposição da Formação, terminando no Plioceno (entre 4 e 5 M.a). Silva (2000) atribui à Formação barreiras o maior aporte de MP, que, somado à erosão, transporte e deposição decorrentes de variações eustáticas Quaternárias, forma pláceres nas planícies costeiras, reconhecidos desde o século retrasado. Foram encontrados durante o projeto REMAC teores inferiores a $5 \%$ na plataforma continental defronte a região (Amaral, 1979). 
A curta extensão das planícies costeiras no Estado é causada pelo fraco aporte sedimentar durante o Período Quaternário, e se fazem representativas apenas em Presidente Kennedy (foz do Rio Itabapoana), Itapemirim (foz do rio homônimo) e Vila Velha (Rio Jucu). Nos demais setores a planície costeira é inexistente ou muito estreita, sendo limitada pelos depósitos Terciários ou pelo embasamento cristalino (Albino et al., 2006). Souza et al. (2005) afirmam que o depósito seguido de uma estreita planície costeira é indício de costa faminta de sedimento por aporte natural ou resultado de erosão durante o período Quaternário.

A plataforma continental defronte ao litoral sul do Estado corresponde ao embaiamento de Tubarão, que se estende desde Regência a Itapemirim. Possui largura média de 50 km e mínima de 40 km, e é composta 75\% por sedimentos biogênicos (França, 1979).

\subsection{Climatologia}

Segundo dados do IBGE (2002) o litoral sul do Espírito Santo apresenta clima quente (média $>18^{\circ} \mathrm{C}$ em todos os meses do ano) superúmido sem seca ou, ao sul, úmido com 1 a 3 meses secos. A precipitação média anual varia de $1100 \mathrm{~mm}$ em Presidente Kennedy, aumentando em direção ao norte até Vila Velha com $1250 \mathrm{~mm}$. No inverno o mesmo padrão geográfico é seguido com aumento de sul $(100 \mathrm{~mm})$ para norte $(175$ $\mathrm{mm}$ ), bem como no verão, estação de chuva, variando de $400 \mathrm{~mm}$ a $450 \mathrm{~mm}$. Segundo Amarante et al. (2009) a característica principal que influencia nesse gradiente sul/norte é o relevo.

O regime de ventos é controlado por três distintos sistemas. O sistema Tropical Atlântico é determinado pelo anticiclone semifixo do Atlântico Sul (ASA) devido ao centro de alta pressão existente no oceano. Dá origem aos ventos de NE e E, os mais frequentes na região, já que atua de forma constante.

O sistema Tropical Continental tem origem na depressão do Chaco, variando levemente sua posição no eixo E-W, sendo então denominado semifixo e origina os pouco frequentes ventos de $\mathrm{W}$ e NW.

O sistema Polar Atlântico origina o anticiclone polar, que migra para a América do Sul e, ao encontrar o sistema ASA ocasiona as frentes frias, com ventos de S e SE (Amarante et al., 2009). 


\subsection{Setores de amostragem}

Como indica a Figura 3, foram cinco os arcos praias amostrados, a serem detalhados:

\subsubsection{Setor Presidente Kennedy-Marataízes (PKMA)}

O setor PKMA compreende seis praias, sendo (de sul para norte): Praia das Neves, de Marobá, da Boa Vista, dos Cações, Lagoa do Siri (lagoa costeira) e Praia Central de Marataízes. Juntas, perfazem $31 \mathrm{~km}$ de linha de costa, sendo o maior setor amostrado. $\mathrm{Na}$ praia dos Cações situa-se o Monumento Natural Municipal das Falésias de Marataízes (Decreto Estadual nº 193/2008).

O setor é limitado ao sul pelo Rio Itabapoana (vazão média $45,77 \mathrm{~m}^{3} / \mathrm{s}$, máxima histórica de $636,94 \mathrm{~m}^{3} / \mathrm{s}$ em 1985) e ao norte pela praia Central de Marataízes. Encontra-se no sul uma larga planície costeira, entrecortada por falésias vivas da Formação Barreiras ao norte.

De acordo com Albino et al. (2006) a planície costeira na região, dita estável, foi formada pelo aporte dos rios, que, entretanto, não conseguem preencher as zonas entre as falésias vivas, em estado erosivo. Os autores apontaram estabilidade nas praias das Neves e de Marobá e retrogradação em todas as outras partes. A praia de Marataízes, p.e., de grande apelo turístico, sofreu grandes perdas por conta de ressacas ocorridas no final da década de 90 (Figura 5).

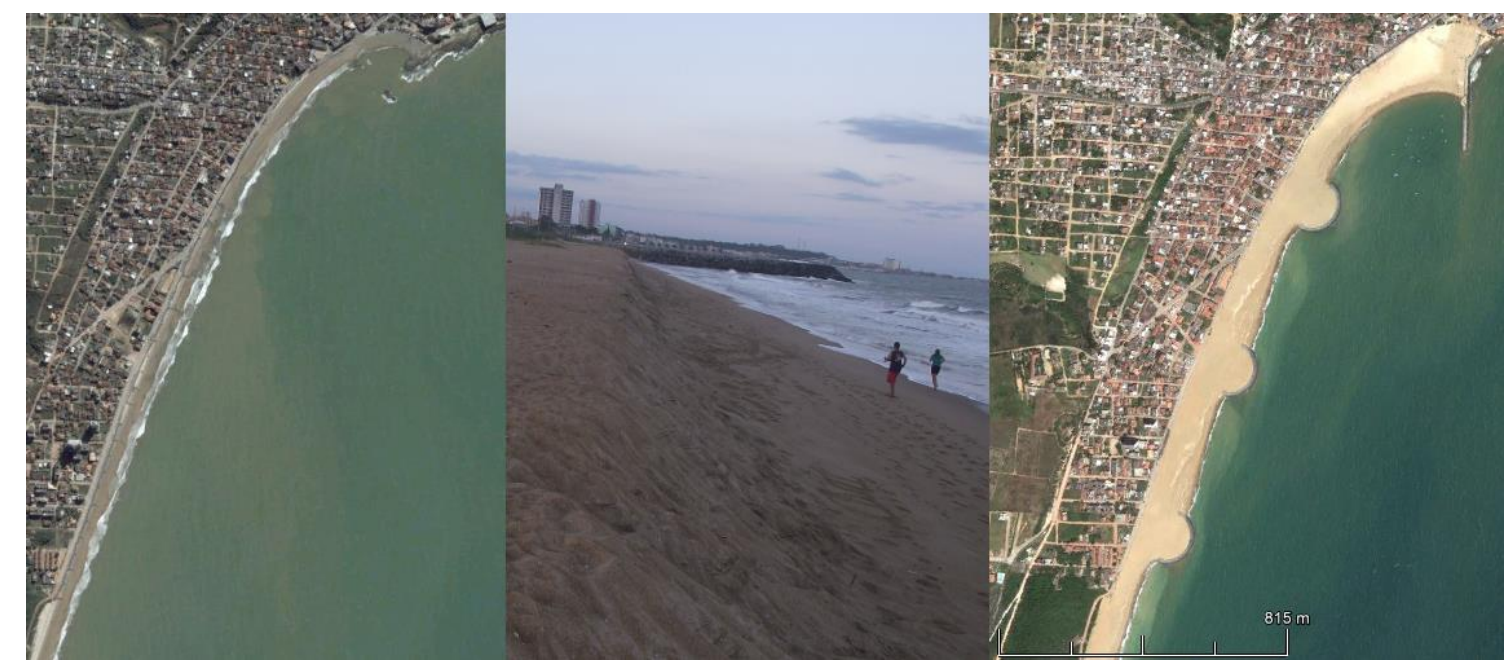

Figura 5: Praia central de Marataízes em distintos momentos: à esquerda, em 2005, com diversos molhes perpendiculares à linha de costa, em tentativa frustrada de conter a erosão; à direita, a última tentativa de contenção de erosão (2010), e ao centro, fotografia tirada em 2012, indicando que a praia ainda está passando por um processo de adaptação. A escala na imagem à direita refere-se às duas das extremidades. 
Elfrink et al. (2006) afirmam através de modelagem numérica com o programa Mike21, que no período de 1999 a 2001 houve aumento significativo da altura média das ondas na praia Central de Marataízes. De acordo com os autores, os molhes implantados em 2002 não eram suficientemente longos para englobarem todo o perfil praial, e assim, tornaram-se inúteis. Faltava sedimento na praia, que agiria como um "amortecedor" (buffer) natural da linha de costa para as variações do nível do mar.

Devido à dinâmica sedimentar influenciada pela corrente longitudinal e trocas transversais, foram propostos quatro quebra-mares (dos quais apenas 3 foram construídos), um molhe e aterro hidráulico para a contenção da erosão na região a fim de aumentar o efeito de by-pass entre os quebra-mares, minimizando a perda de sedimento na região do sotamar; eliminar correntes de retorno e melhorar a estética ganhando área útil de praia.

A parte mais ao sul do setor (município de Presidente Kennedy) não é muito ocupada, porém cálculos feitos por Contti Neto e Albino (2011) indicam que a Praia de Marobá (mais ao sul) possui vulnerabilidade alta quanto à subida do nível do mar devido às construções em cima de dunas frontais.

Moreira (2009) analisou fotografias aéreas de 1964 a 1974 na região, e encontrou na foz do Rio Itabapoana retrogradação na margem sul do rio, estimada em $105.000 \mathrm{~m}^{2}$. Ao sul, por sua vez, foi encontrada progradação de aproximadamente $300.000 \mathrm{~m}^{2}$. Segundo a autora, em 1990 foi formado um pontal, posteriormente incorporado à costa e formando uma lagoa, indicando a forte dinâmica local.

\subsubsection{Setor Itapemirim (ITA)}

O setor é composto pelas praias do Espigão, do Pontal, Itaoca e Itaipava, compreendendo um único e extenso arco praial de $13 \mathrm{~km}$. Diversas cristas de praia Quaternárias foram preservadas, como pode ser observado na Figura 6 e Figura 21. 


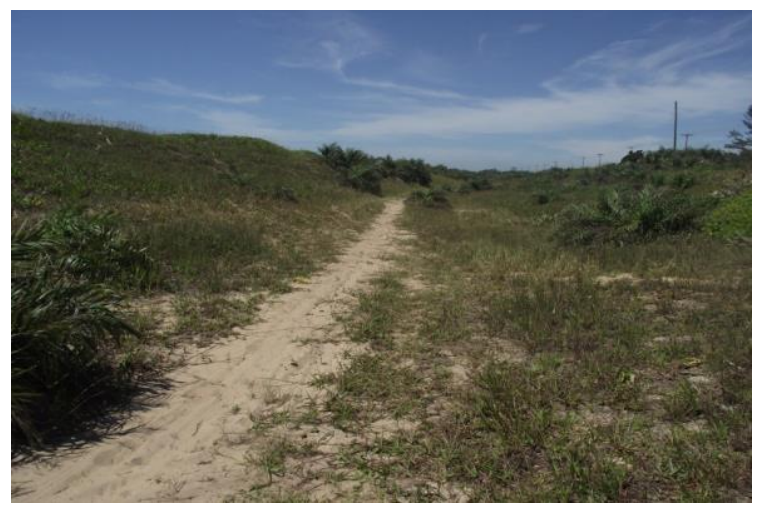

Figura 6: Fotografia em campo da zona entre cordões do setor ITA

O setor é limitado ao sul pelo Rio Itapemirim (vazão média de $80,91 \mathrm{~m}^{3} / \mathrm{s}$, máxima histórica de $725,31 \mathrm{~m}^{3} / \mathrm{s}$ em 2005), e ao norte pela praia de Itaipava, com ocupação urbana consolidada.

Segundo Albino et al. (2006) a foz do rio Itapemirim apresenta ora retrogradação, ora progradação, com as praias de Itaoca e Itaipava estáveis. Segundo os autores, a estabilidade da praia de Itaipava é causada pela rugosidade de fundo da face praial, que possibilita a dissipação das ondas e bloqueio de sedimento. Dessa maneira, a praia adapta-se facilmente às variações das condições meteo-oceanográficas.

Através da geomorfologia, observa-se que o setor seria composto de um único arco praial, limitado ao sul pela foz do rio e ancorado ao norte no promontório rochoso. A presença do promontório formou um tômbolo durante o Quaternário, dividindo o arco praial.

\subsubsection{Setor Ubu (UBU)}

O setor UBU, município de Anchieta, compreende $8,8 \mathrm{~km}$ de praia, entre a Ponta de Ubu e a Praia de Meaípe, passando pelo porto da mineradora SAMARCO. O porto iniciou suas atividades em 1977 para exportar o produto da primeira Usina de Pelotização da SAMARCO, causando uma visível quebra no balanço sedimentar, como será discutido.

O arco é marcado por grande variação morfológica e dinâmica. Os afloramentos cristalinos e falésias vivas da Formação Barreiras intercalam-se com lagoas costeiras em retroterra causada por alagamento de seus vales durante o período Quaternário. Dessas, destaca-se a lagoa Maimbá (Mãe-bá ou Maembá), com 4.691.432,01 m² (SAMARCO, 2012). 
As rochas cristalinas e as falésias vivas da FB atuam como fonte de sedimento para a praia. Assim, CEPEMAR (2011) encontrou teor médio de MP de 10\%, representados por monazita, zircão, turmalina, rutilo, silimanita, limonita e opacos, predominantemente a ilmenita. A entrada de frentes frias pode aumentar essa porcentagem, tendo sido registrada concentração de 81\% (CEPEMAR, 2011). Veiga et al. (2006) mediram a radioatividade nas praias de Meaípe e Anchieta e encontraram valores de emissão de radiação natural 35 vezes o recomendável pela Organizações Mundial de Saúde (OMS). De acordo com os autores, dentre os constituintes das rochas que geram o sedimento praial estão radionuclídeos de ${ }^{238} \mathrm{U},{ }^{232} \mathrm{Th}$ e ${ }^{40} \mathrm{~K}$ (elemento-filho), que estão intimamente ligados aos depósitos de minerais pesados encontrados nessas praias.

Albino et al. (2006) constataram a erosão costeira na praia de Maimbá como sendo decorrente da falta de aporte sedimentar fluvial, levando à erosão nas falésias da FB. Da mesma maneira, a erosão foi constatada em todas as outras praias do setor.

Machado, Santos e Albino (2003) verificaram perfil de praia de 24 m de extensão (em média) em Meaípe e Maimbá, chegando a apenas $8 \mathrm{~m}$ com a entrada de frentes frias. Com a volta às condições de tempo bom, o sedimento é novamente incorporado à praia, sendo levado pela corrente de deriva litorânea, de norte para sul.

Segundo Santos (2003), Gomes (2004), Coelho (2005) e CEPEMAR (2007a) as praias no arco UBU são do tipo refletivo a intermediário, com ondas de arrebentação frontal e ascendente, areias de granulometria média e grau de seleção moderado a bom. Os autores afirmam que há migração sazonal de barras de antepraia, com trocas transversais, tendo possibilidade de transporte em profundidades de até $8 \mathrm{~m}$. Constatouse ação combinada de transporte longitudinal com trocas transversais de sedimento no arco UBU.

Moreira (2009) encontrou entre os anos de 1964 e 1974 erosão e progradação no mesmo trecho de praia (Meaípe, extremo norte do setor), com predominância de erosão entre 1990 e 2000.

\subsubsection{Setor Vila Velha e Guarapari (VVGU)}

O setor VVGU compreende os municípios de Guarapari e Vila Velha, estando ao sul o Parque Estadual Paulo César Vinha (PCV) e ao norte a desembocadura do Rio Jucu. A 
vazão média do curso d'água (que abastece a região metropolitana de VitóriaI) calculada entre os anos de 1968 e 2005 é de $26,12 \mathrm{~m} / \mathrm{s}$, sendo a máxima registrada de $204,77 \mathrm{~m}^{3} / \mathrm{s}$, em 1979.

O setor é delimitado por dois promontórios rochosos, tendo ao sul, na praia de Setiba, a formação de um tômbolo, e ao norte, o promontório que marca a foz do Rio Jucu. Na metade do setor outro promontório causa grande diferenciação morfotextural na praia, delimitando uma praia dissipativa com tendências erosivas na praia da Ponta da Fruta, e uma praia refletiva, Praia da Baleia, com a presença de duas bermas. No total, o setor atinge comprimento de $26,8 \mathrm{~km}$.

Albino et al. (2006) caracterizam o setor VVGU pela alternância de afloramentos de rochas cristalinas e da FB com estreitas planícies Quaternárias. O comportamento de estabilidade é observado em todas as praias do setor, podendo variar de acordo com o grau de exposição, da presença de armadilhas de sedimento e da ocupação inadequada.

Albino (1996) estudou as praias do Sol, da Fruta e da Baleia. A Praia da Baleia é caracterizada como refletiva, com declividade de $10^{\circ}$ e presença de cúspides e arenitos de praia da FB. É composta de areia grossa, moderadamente bem selecionada e assimetria positiva, com largura de praia variando de 50 a $95 \mathrm{~m}$ e média de $75 \mathrm{~m}$.

Tanto a praia do Sol como a da Fruta são caracterizadas como dissipativas de baixa declividade $\left(\sim 1^{\circ}\right)$. O sedimento na praia do Sol é composto por areia fina, bem selecionada e assimetria negativa, variando para areia média, moderadamente bem selecionada e assimetria positiva. A Ponta da Fruta, por sua vez, é composta por areia fina, bem selecionada e assimetria negativa.

Moreira (2009) afirma que o maior responsável pelo suprimento sedimentar para o setor não é o Rio Jucu, mas sim as dunas frontais vegetadas e fixas presentes em diversos trechos. Entre 1971 e 2000 houve progradação da linha de costa.

\subsubsection{Setor Vila Velha (VL)}

O setor VL compreende as praias da Barrinha (ao norte da foz do rio Jucu, que delimita o fim do setor VVGU), Itaparica, Itapoã e da Costa. Todos os $12 \mathrm{~km}$ de praia são urbanizados, variando entre pouco e densamente ocupado. 
Albino et al. (2006) classificam o litoral do setor VL como altamente recortado e estável, com exceção da praia da Barrinha (extremo sul), que se encontra em retrogradação.

\section{MATERIAIS E MÉTODOS}

O organograma contendo a metodologia de pesquisa utilizada no trabalho é apresentado na Figura 7.

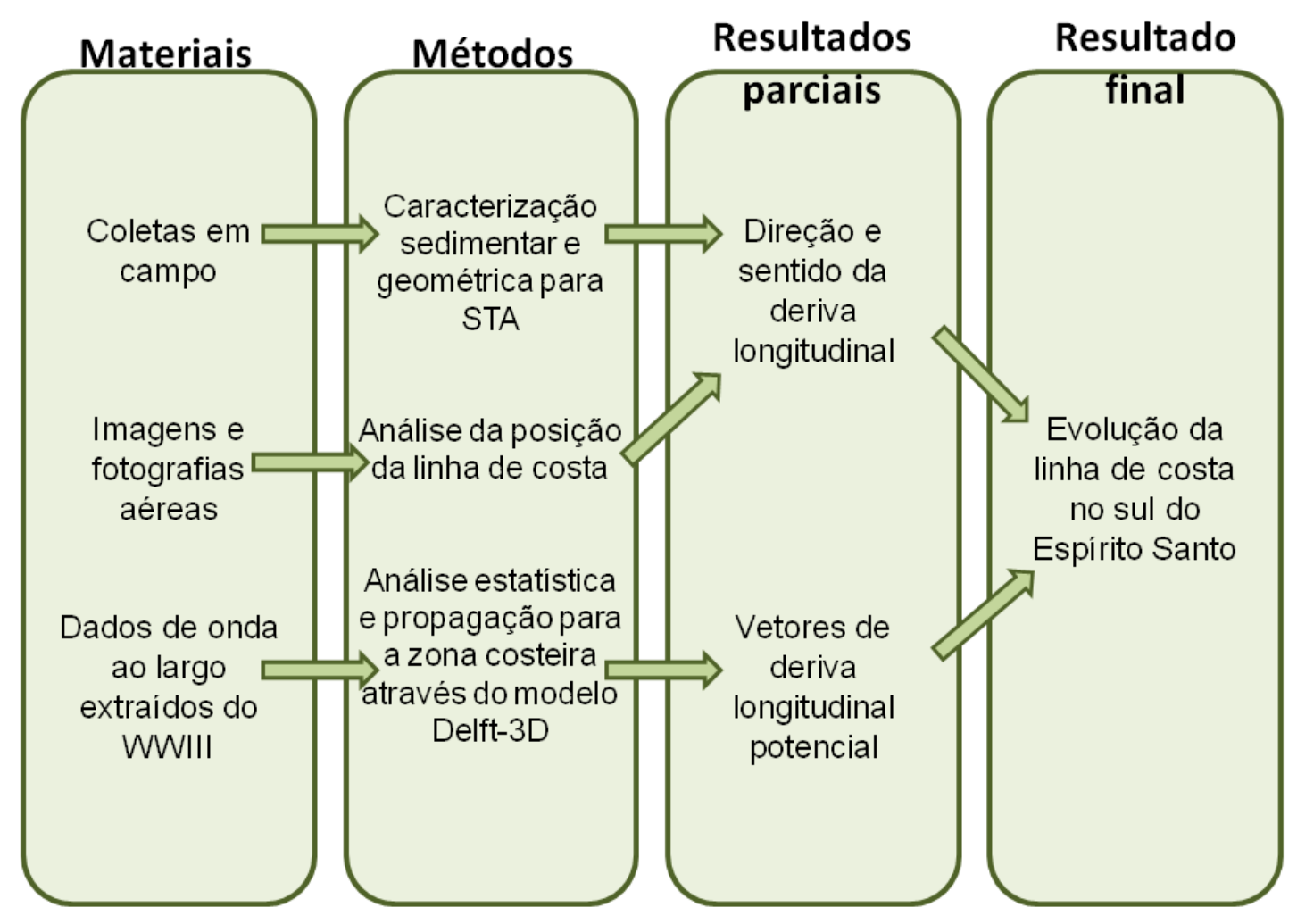

Figura 7: Organograma da metodologia de pesquisa

\subsection{Coletas de campo}

As coletas de campo foram idealizadas a partir da compartimentação da porção sul do litoral espiritossantense, em arcos de maior expressividade extensão, como mostrado na Figura 3. A partir do dia 18 de janeiro de 2012, buscou-se amostrar em um único dia todo o arco praial, seguindo a recomendação de McLaren et al. (2007) quanto à temporalidade dos estudos. 
Em cada arco praial as coletas foram amostradas num espaçamento médio de $1 \mathrm{~km}$ entre si, medidas antes do campo e conferidas com GPS de mão. Em cada estação era medido o parâmetro "largura da praia" com trena, em que se considera o ponto inicial a mudança de fisiografia (geralmente início da restinga ou parte urbanizada) e o ponto final o máximo recuo da onda.

Após tal medição, dividia-se a zona do estirâncio em três partes, considerando a linha de deixa como limite superior e a linha inferior o máximo recuo da onda. No terço inferior o sedimento era coletado com auxílio de uma pá, buscando os $10 \mathrm{~cm}$ superficiais, como recomendado pelo autor (McLaren et al., 2007).

Com auxílio da régua, era estimada a diferença de altura no estirâncio, para que pudesse ser calculada a declividade da praia, como mostra a Figura 8:

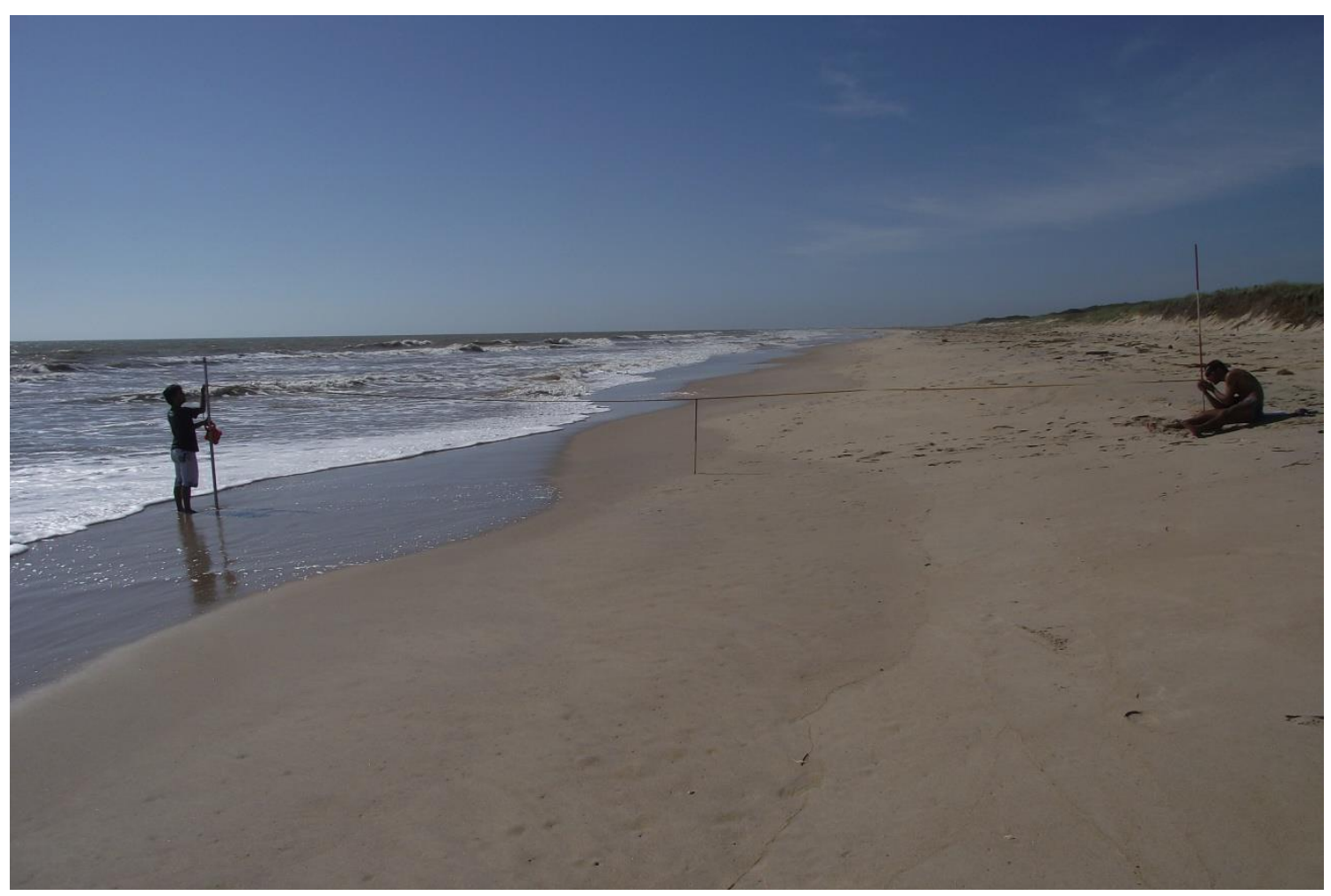

Figura 8: Medição da declividade praia em campo

\subsubsection{Tratamento das amostras em laboratório}

Em laboratório foram separados aproximadamente $200 \mathrm{~g}$ de cada amostra, devidamente identificadas e separadas por setor. As amostras foram lavadas e submetidas ao ataque 
com ácido clorídrico $(\mathrm{HCl})$ a $10 \%$ até que todo o carbonato fosse queimado. A análise deu-se no laboratório de Sedimentologia do Instituto Oceanográfico da USP.

Após secas em estufas, as amostras foram peneiradas com intervalo de 0,5 $\phi$ e pesadas. Da mesma amostra, retirou-se 50g com auxílio de quarteador de Jones para que fosse feita a análise de MP.

A análise de pesados, realizada no laboratório de Sedimentologia do Instituto de Geociências da USP foi feita com auxílio de Bromofórmio $\left(\mathrm{CHBr}_{3}, \rho=2,85 \mathrm{~g} / \mathrm{cm} 3\right)$. A subamostra era lançada no líquido, em que a fração leve boia, e a fração pesada afunda. Após pesar a fração pesada, o resultado era o teor de MP nas amostras.

\subsubsection{Processamento dos dados}

Com auxílio de softwares de geoprocessamento (ArcGis e Surfer), os dados seguintes dados foram plotados em gráficos: teor de Carbonato de Cálcio, teor de MP, largura da praia, declividade do estirâncio, média, assimetria, desvio padrão e curtose. Buscou-se a existência de correlação linear dos dados com a distância, separadamente para cada arco praial.

A análise da orientação da linha de costa foi calculada através da ferramenta EasyCalculate (Tchoukanski, 2010), considerando-se o norte como $0^{\circ}$ aumentando em sentido horário. Para tanto, foi traçada uma linha reta dentro de cada setor amostral, interligando seu ponto inicial ao final, a fim de remover ruídos no cálculo. A ferramenta fornece o cálculo no meio do setor, que por vezes, pode seguir uma pequena orientação, diferente da predominante.

Mediu-se a distância de cada setor amostral para a cota batimétrica de $10 \mathrm{~m}$, que, segundo Ministério do Meio Ambiente (2004), representa a média do perfil de fechamento das praias para o Brasil. A menor distância entre os setores amostrais e a cota batimétrica foi calculada através da ferramenta Nearest point, também do software ArcGis.

Para conferir a possibilidade de aplicação do método STA, foi estudada a correlação de Pearson entre a média e assimetria, média e desvio padrão e assimetria e desvio padrão como recomendado por McLaren et al. (2007). Foram consideradas válidas as correlações superiores a 0,6 , calculadas através da fórmula: 


$$
\rho=\frac{\sum_{i=1}^{n}\left(x_{i}-\bar{x}\right)\left(y_{i}-\bar{y}\right)}{\sqrt{\sum_{i=1}^{n}\left(x_{i}-\bar{x}\right)^{2}} \sqrt{\sum_{i=1}^{n}\left(y_{i}-\bar{y}\right)^{2}}}
$$

A principal variável analisada no método STA é o desvio padrão, de maneira que todas as amostras eram plotadas, e apenas as retas com correlação espacial superior a 0,6 eram incluídas na análise. As amostras foram, dessa maneira, comparadas uma a uma, como explicado na introdução do presente trabalho, e aceitas num nível de 99\% de confiança, o que foi feito nos dois possíveis sentidos.

Por fim, testou-se a aplicabilidade do modelo de Gao e Collins (1996 - GSTA), modificado por Chang (2001). Como explicado, o modelo requer uma malha bidimensional além do Dcr (distância característica) e o nível de confiança escolhido pelo autor. Escolheu-se o mesmo nível de confiança do modelo de McLaren, e seu resultado é apresentado no final, por não oferecer indicativo para todos os setores praiais.

Foram também processados dados de vazão dos rios Itapemirim e Itabapoana através do programa SisCAH - Sistema Computacional para Análises Hidrológicas (Sousa, 2009).

\subsection{Fotografias aéreas}

Foram usadas fotografias aéreas disponíveis para a região, datando da década de 1970 (Projeto RADAM Brasil) e 2008 (IEMA, 2009), fornecidas pelo Instituto Jones Santos Neves (IJSN) já georreferenciadas (IJSN, 2012). As fotografias foram comparadas também com imagens históricas do Google Earth, geralmente desde o começo da década de 2000, época em que grande parte das obras impactantes da linha de costa no Espírito Santo começou a ser implantada. O método de digitalização empregado foi a divisão areia seca/areia úmida, sendo que em cada arco praial é especificado o conjunto de fotografias e imagens de satélite utilizadas.

Para cada conjunto de fotografias foi calculado o Erro Quadrático Médio (EQM), gerado pelo software ArcGis ${ }^{\circledR}$, usado no processo de georreferenciamento. O EQM é calculado segundo a fórmula:

$$
E Q M=\sqrt{\left(X_{\text {foto }}-X_{\text {base }}\right)^{2}+\left(Y_{\text {foto }}-Y_{\text {base }}{ }^{2}\right)}
$$


Foram aceitas para a análise fotografias que apresentassem $E Q M<1$. O processo de georreferenciamento de imagens da década de 1970 mostrou-se bastante complicado pelo fato de não haver estruturas fixas suficientes para tal, apenas feições de vegetação, o que pode trazer erros muito grandes.

Com a análise das fotografias aéreas e imagens de satélite, objetiva-se estudar padrões de deriva litorânea e sua setorização, de acordo com o proposto por Kunte e Wagle (1993). Os autores analisaram feições geomorfológicas como barras e foz de rios, estuários, tômbolos e estruturas artificiais na identificação da direção e inversões da corrente longitudinal.

\subsection{Modelo WWIII}

O clima de ondas oceânicas no Espírito Santo foi extraído através do modelo WWIII, em formato Grib, sendo geradas rosas de ondas através do programa Matlab.

As estatísticas do clima foram extraídas entre os anos de 1997 e 2010 , no ponto $-21^{\circ} 00^{\circ}$ $00^{\circ} \mathrm{N},-40^{\circ} 00^{\circ} 00^{\circ}$ E. A manipulação estatística dos dados de onda permitiu observar o período, altura e direção predominante para cada ano, para as estações do ano separadamente e para todos os anos em conjunto.

A Tabela 2 indica como exemplo o histograma de frequência construído para o ano de 1997, seguido pela Figura 9, que mostra a rosa de ondas para o ponto de extração no mesmo ano.

Tabela 2: Histograma de frequências das alturas e períodos de ondas para o ano de 1997 - resultados do modelo WWIII

\begin{tabular}{|c|c|c|c|c|c|c|}
\hline \multicolumn{7}{|c|}{ Altura de ondas (m) } \\
\hline \multirow{2}{*}{$0,{ }^{N}$} & \multirow[t]{2}{*}{$\mathrm{NE}$} & \multirow{2}{*}{0,0745} & $\bar{E}$ & $\mathrm{SE}$ & $S$ & SW \\
\hline & & & 0,7821 & & & \\
\hline 0,75 & 0,149 & 1,6015 & 2,3091 & 1,1173 & 1,1546 & \\
\hline 1 & 0,5214 & 4,1713 & 6,2197 & 3,4264 & 3,352 & 0,1862 \\
\hline 1,25 & 0,298 & 2,905 & 7,8585 & 3,3892 & 6,0335 & 0,298 \\
\hline 1,5 & & 1,825 & 5,1397 & 3,3892 & 7,4488 & 0,2607 \\
\hline 1,75 & & 0,4469 & 2,1229 & 4,3575 & 7,2998 & 0,3352 \\
\hline 2 & & 0,4097 & 1,1918 & 2,3836 & 5,4004 & 0,2235 \\
\hline 2,25 & & 0,0745 & 0,1117 & 0,9311 & 2,7933 & 0,2607 \\
\hline 2,5 & & & 0,1862 & 0,5587 & 1,9367 & 0,0745 \\
\hline 2,75 & & & 0,0372 & 0,4469 & 1,1173 & 0,1862 \\
\hline 3 & & & & 0,3724 & 0,2235 & 0,0745 \\
\hline
\end{tabular}




\begin{tabular}{|c|c|c|c|c|c|c|}
\hline \multicolumn{7}{|c|}{ Altura de ondas (m) } \\
\hline \multicolumn{3}{|c|}{3,25} & & 0,2235 & 0,4097 & 0,0372 \\
\hline \multicolumn{3}{|l|}{3,5} & & 0,1117 & 0,4469 & \\
\hline \multicolumn{3}{|l|}{3,75} & & & 0,3352 & \\
\hline \multicolumn{3}{|l|}{4} & & & 0,2235 & \\
\hline \multicolumn{3}{|l|}{4,25} & & & 0,2607 & \\
\hline \multicolumn{3}{|l|}{4,5} & & & 0,3352 & \\
\hline \multicolumn{3}{|l|}{4,75} & & & 0,149 & \\
\hline \multicolumn{7}{|c|}{ Total } \\
\hline & 0,9683 & 11,5084 & 25,959 & 20,7076 & 38,9199 & 1,9367 \\
\hline \multicolumn{7}{|c|}{ Período de ondas (s) } \\
\hline \multicolumn{2}{|c|}{$\mathrm{N}$} & $\mathrm{NE}$ & $\mathrm{E}$ & SE & $\mathrm{S}$ & SW \\
\hline 3 & 0,2231 & 0,3347 & 0,0372 & 0,0372 & & \\
\hline 4 & 0,7438 & 2,8635 & 0,2975 & 0,4091 & 0,2231 & 0,0372 \\
\hline \multicolumn{2}{|l|}{5} & 4,7973 & 0,8553 & 0,2975 & 0,4835 & 0,0372 \\
\hline \multicolumn{2}{|l|}{6} & 2,6032 & 6,5452 & 0,7066 & 0,781 & 0,0744 \\
\hline \multicolumn{2}{|l|}{7} & 0,8925 & 11,3425 & 2,752 & 0,7438 & 0,0372 \\
\hline \multicolumn{2}{|l|}{8} & & 4,9089 & 4,1279 & 1,0785 & 0,0372 \\
\hline \multicolumn{2}{|l|}{9} & & 1,4875 & 4,0536 & 4,4998 & 0,2231 \\
\hline \multicolumn{2}{|l|}{10} & & 0,4463 & 3,9792 & 5,6155 & 0,2603 \\
\hline \multicolumn{2}{|l|}{11} & & & 2,5288 & 10,0409 & 0,2603 \\
\hline \multicolumn{2}{|l|}{12} & & & 1,2644 & 7,289 & 0,1859 \\
\hline \multicolumn{2}{|l|}{13} & & & 0,2975 & 4,6858 & 0,4835 \\
\hline \multicolumn{2}{|l|}{14} & & & 0,1859 & 2,6404 & 0,2603 \\
\hline \multicolumn{2}{|l|}{15} & & & 0,0372 & 0,595 & 0,0372 \\
\hline \multicolumn{2}{|l|}{16} & & & & 0,3347 & \\
\hline \multicolumn{7}{|c|}{ Total } \\
\hline & 0,9669 & 11,4913 & 25,9204 & 20,6768 & 39,0108 & 1,9338 \\
\hline
\end{tabular}



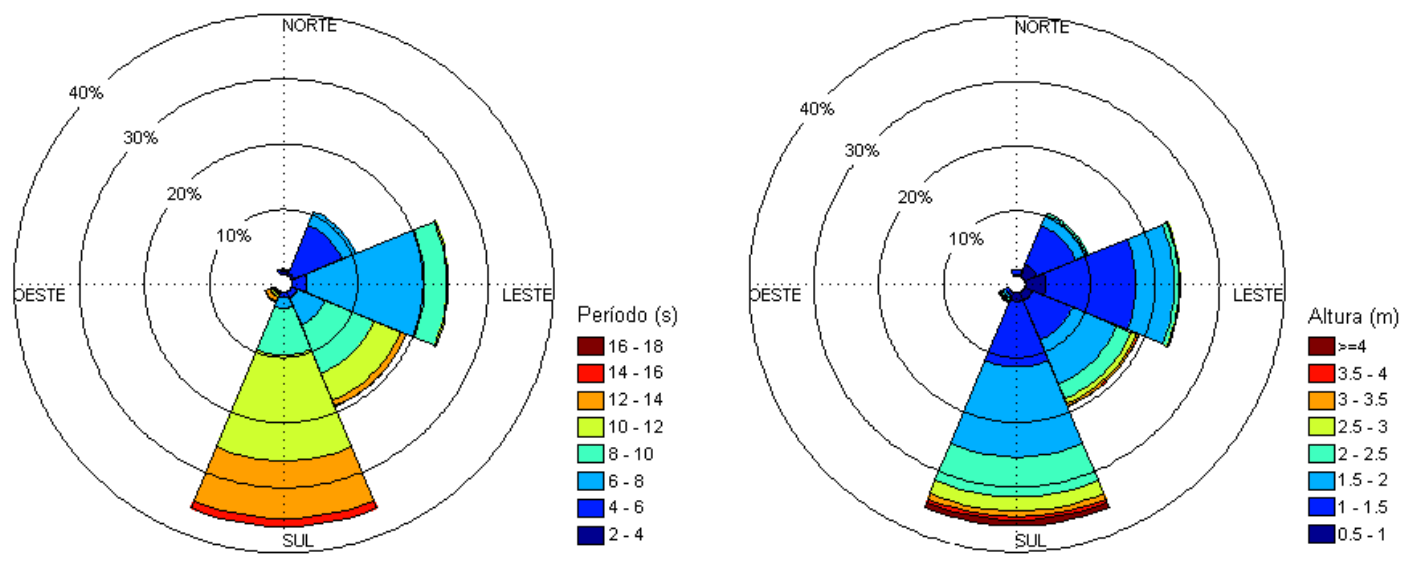

Figura 9: Exemplo de Rosa de ondas (Período e Altura) e Histograma para o ano de 1997 - resultado do modelo WaveWatch III

Os dados de saída do modelo WWIII foram agrupados em três conjuntos da seguinte maneira:

- Conjunto 1: Clima de ondas geral, no período compreendido entre Janeiro de 1997 e Dezembro de 2010;

- Conjunto 2: Clima de ondas para as estações do ano, entre os anos de 1997 e 2010;

- Conjunto 3: Clima de ondas para cada ano separadamente

Tomando os dados de output do modelo WWIII (a saber, o clima de ondas ao largo) o modelo Delft-3D pode ser aplicado para transportá-los para a zona costeira próxima.

\subsubsection{Delft-3D módulo WAVE}

O modelo Delft3D foi desenvolvido pela companhia Deltares com o objetivo de proporcionar uma modelagem multidisciplinar para computações tridimensionais em zonas costeiras, rios e lagos. Segundo os autores, fluxos induzidos por correntes, gradientes de densidade, marés e ventos podem ser modelados, além do transporte de sedimento e mudanças morfológicas.

São diversos os módulos que podem ser acoplados pelo modelo, dos quais será dada atenção apenas ao WAVE. O módulo de ondas Delft3D-WAVE é usado para modelar a 
dissipação de ondas na zona costeira, além de sua geração e interações não-lineares onda-onda para uma dada topografia e velocidade do vento e nível d'água.

O módulo é acoplado ao modelo de terceira geração SWAN - Simulating WAves Nearshore (Ris, 1997; Booij et al., 1999), que fornece resultados bi-dimensionais, baseando-se na equação espectral Euleriana discretizada. O modelo cobre todos os graus do espectro, ou seja, consegue computar interações entre ondas oriundas de diversas direções e sentidos.

Pode-se dizer que o grande avanço do modelo SWAN consiste nas suas computações referentes à geração de ondas devido ao vento, propagação, refração devido às correntes e profundidade, dissipação por whitecapping, atrito com o fundo e quebra por profundidade, além de interações não lineares onda-onda. Como desvantagem, o modelo SWAN não é recomendado para estudos que envolvam difração de ondas, portanto, não foi aplicado com o nível de detalhes para estudar a influência das obras de engenharia costeira.

O módulo utiliza a coordenada- $\sigma$, popular no meio científico, no intuito de suavizar o relevo ao assumir que a topografia da superfície livre é função apenas do plano horizontal, não variando no tempo. Representa, assim, uma boa aproximação, reduzindo o tempo computacional (Su et al., 2012).

Os principais dados de contorno necessários para a simulação do transporte de sedimento no modelo Delft-3D são altura, período e direção das ondas na zona oceânica. Combinando os três parâmetros, para cada ano, mais de 2500 simulações seriam rodadas, o que torna inviável a análise. Optou-se por uma metodologia mais simples: partindo do histograma de frequências (exemplificado na Tabela 2), os casos com frequências superiores a 3,5\% do total foram simulados. Foi utilizado o período mais frequente de cada direção para cada altura, como exemplificado na Tabela 3.

Tabela 3: Exemplo de simulações rodadas para o ano de 1997

\begin{tabular}{ccc}
\hline Direção & Período(s) & Altura(m) \\
\hline $\mathbf{N E}$ & 5,0 & 1,0 \\
$\mathbf{E}$ & 7,0 & 1,$0 ; 1,25 ; 1,5$ \\
SE & 8,0 & 1,$0 ; 1,25 ; 1,5 ; 1,75$ \\
$\mathbf{S}$ & 11,0 & 1,$0 ; 1,25 ; 1,5 ; 1,75 ; 2,0$ \\
\hline
\end{tabular}


Para as simulações foi usado um grid único, se estendendo do município de Aracruz, ao norte de Vitória, à Foz do Rio Paraíba do Sul (RJ). Sua resolução variou de $600 \mathrm{~m}$ na zona oceânica adjacente para $200 \mathrm{~m}$ aproximadamente nos arcos praiais, como mostra a Figura 10. A linha de costa foi digitalizada através do mosaico de fotografias aéreas fornecido por IEMA (2008).

Foram usados 127385 pontos de batimetria, provenientes de dados de cartas náuticas e levantamentos de campo anteriores. Para os demais pontos foi utilizada a interpolação do tipo "Grid Cell Averaging" quando o número de pontos batimétricos por célula da grade era superior a um e, do oposto, usou-se a "Triangular Interpolation" (Deltares, 2012).

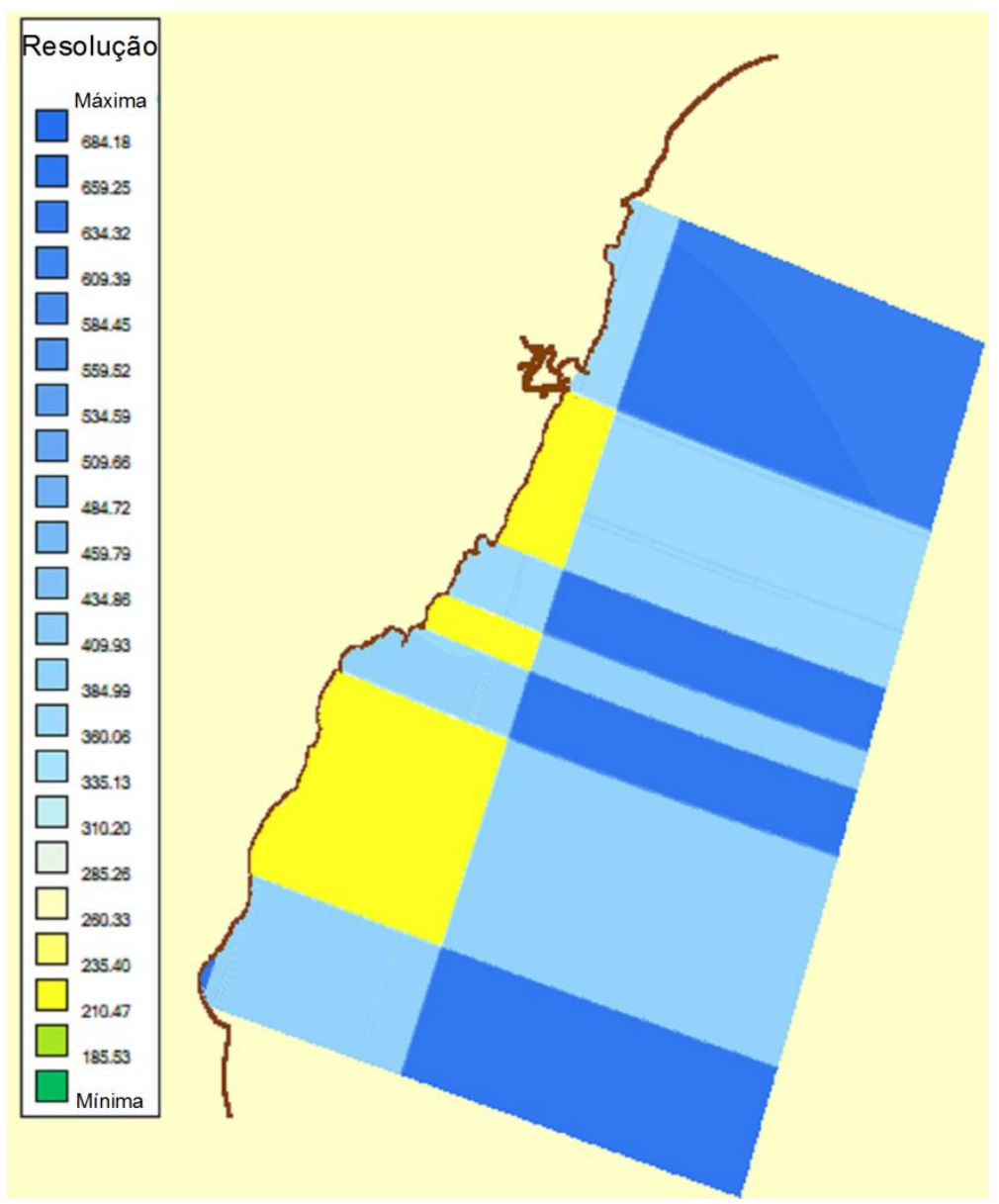

Figura 10: Resolução da grade usada no modelo Delft-3D 
Foram utilizados os parâmetros padrão do modelo no módulo de simulação de ondas (Wave), a saber:

Tabela 4: Parâmetros usados na modelagem numérica com o programa Delft-3D

\begin{tabular}{|l|l|}
\hline Gravidade & $9,81 \mathrm{~m} / \mathrm{s}^{2}$ \\
\hline Densidade da água & $1025 \mathrm{~kg} / \mathrm{m}^{3}$ \\
\hline Profundidade mínima & $0,05 \mathrm{~m}$ \\
\hline Resolução espectral & Completa, em 36 direções \\
\hline Fricção de fundo & $0,067 \mathrm{~m}^{2} / \mathrm{s}^{3}$ (JONSWAP) \\
\hline Vento & Ausente \\
\hline Geração & Terceira \\
\hline Whitecapping & Komen et al. (1984) \\
\hline Quebra de onda & $\begin{array}{l}\text { Modelo Battjes e Janssen (1978), sendo } \\
\alpha=1,0 ;\end{array}=0,73$ \\
\hline
\end{tabular}

A fricção de fundo do tipo JONSWAP (Joint North Sea Wave Project), considera que o espectro de ondas nunca é completamente desenvolvido e segue a equação:

$$
S(\omega)=\frac{\alpha g^{2}}{\omega^{5}} \exp \left[-\beta \frac{\omega_{p}^{4}}{\omega^{4}}\right] \gamma^{a}
$$

$\alpha=0,081$, constante que relaciona a velocidade do vento ao comprimento da pista

$\omega=$ frequência da onda

$\omega_{p}=$ frequência de pico da onda

$\beta=1,25$

$a=\exp \left[-\frac{\left(\omega-\omega_{p}\right)^{2}}{2 \omega_{p}^{2} \sigma^{2}}\right]$

$\sigma=\left\{\begin{array}{l}0,07 \text { se } \omega \leq \omega_{p} \\ 0,09 \text { se } \omega>\omega_{p}\end{array}\right.$

O SWAN foi rodado no módulo de em terceira geração, o que implica em considerar a rebentação parcial (whitecapping) segundo Komen et al. (1984), interações quádruplas segundo Hasselman et al. (1985) e modelo de quebra induzida segundo Battjes e Janssen (1978).

A evolução do campo de ondas é representada pela equação de conservação da densidade espectral de energia (Hasselman et al., 1973): 


$$
\frac{\partial F}{\partial t}+C_{g} \cdot \nabla F=S_{i n}+S_{n l}+S_{d s}
$$

Sendo $F=f(f, \theta, x, y, t)$ o espectro direcional da onda e $C_{g}$ o vetor de velocidade do grupo de onda. $S_{i n}$ representa a entrada de energia pelo vento, $S_{n l}$ o termo de interações não lineares onda-onda e $S_{d s}$ o termo de dissipação por rebentação parcial (Komen et al., 1984).

\subsubsection{Estudo da Deriva Longitudinal Potencial}

Para estudar o transporte longitudinal a partir do clima de ondas foram testadas as fórmulas mais aceitas mundialmente, a fim de compará-las. A taxa de transporte de sedimento é estimada através do volume $\mathrm{Q}_{1}$, que considera também os espaços intersticiais e se relaciona com taxa de transporte do peso imerso $\mathrm{I}_{1}$ :

$$
I_{l}=\left(\rho_{s}-\rho\right)(1-n) g Q_{l}
$$

Em que $\rho_{s}$ representa a densidade do sedimento, $\rho$ a densidade da água, $g$ a aceleração da gravidade e $n$ a porosidade do sedimento (adotada no presente trabalho como 0,4 ). Dado a influência de obras de engenharia costeira e até mesmo feições submarinas que podem barrar o transporte de sedimento usa-se o conceito de deriva potencial, que se relaciona com $\mathrm{I}_{1}$ da seguinte maneira:

$$
I_{l}=K P_{l}
$$

Sendo $P_{l}$ a deriva potencial, usada no trabalho, em função da energia de onda (E), velocidade de grupo $(\mathrm{Cg})$ e ângulo de incidência de onda:

$$
\begin{gathered}
P_{l}=\left(E C_{g}\right)_{b} \operatorname{sen} \alpha_{b} \cos \alpha_{b} \\
E_{b}=\frac{\rho g H_{b}^{2}}{8} \\
C_{g b}=\left(g \frac{H_{b}}{k}\right)^{1 / 2}
\end{gathered}
$$

Dessa maneira, optou-se por usar a deriva potencial para os cálculos de transporte longitudinal. 


\section{RESULTADOS}

Nesta seção serão descritos e discutidos os resultados para cada um dos setores estudados.

\subsection{SETOR PKMA}

\subsubsection{Descrição dos parâmetros no setor PKMA}

A localização das amostras coletadas é mostrada na Figura 11: 


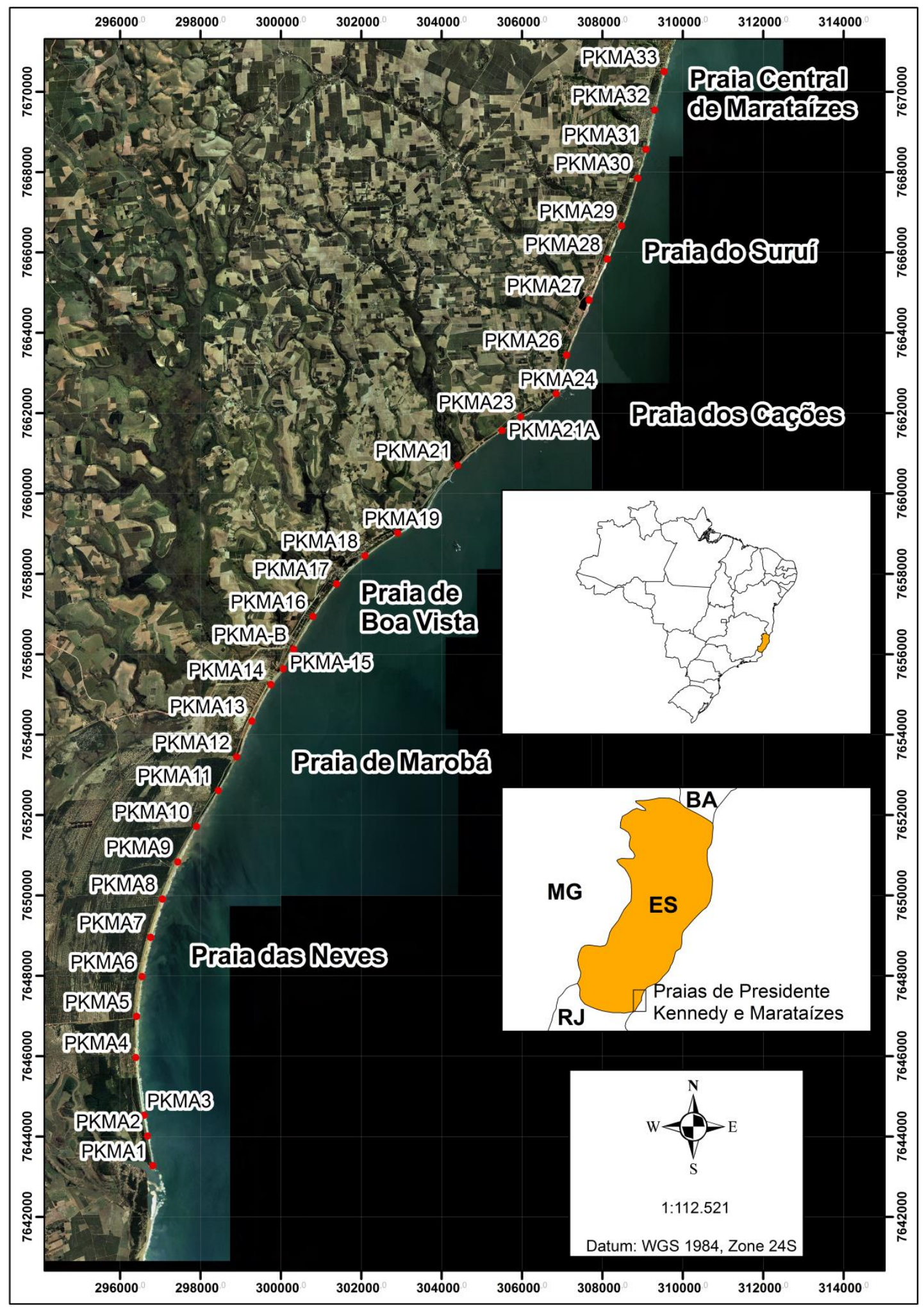

Figura 11: Localização dos pontos de coleta no setor PKMA

Os resultados obtidos são mostrados na Figura 12: 


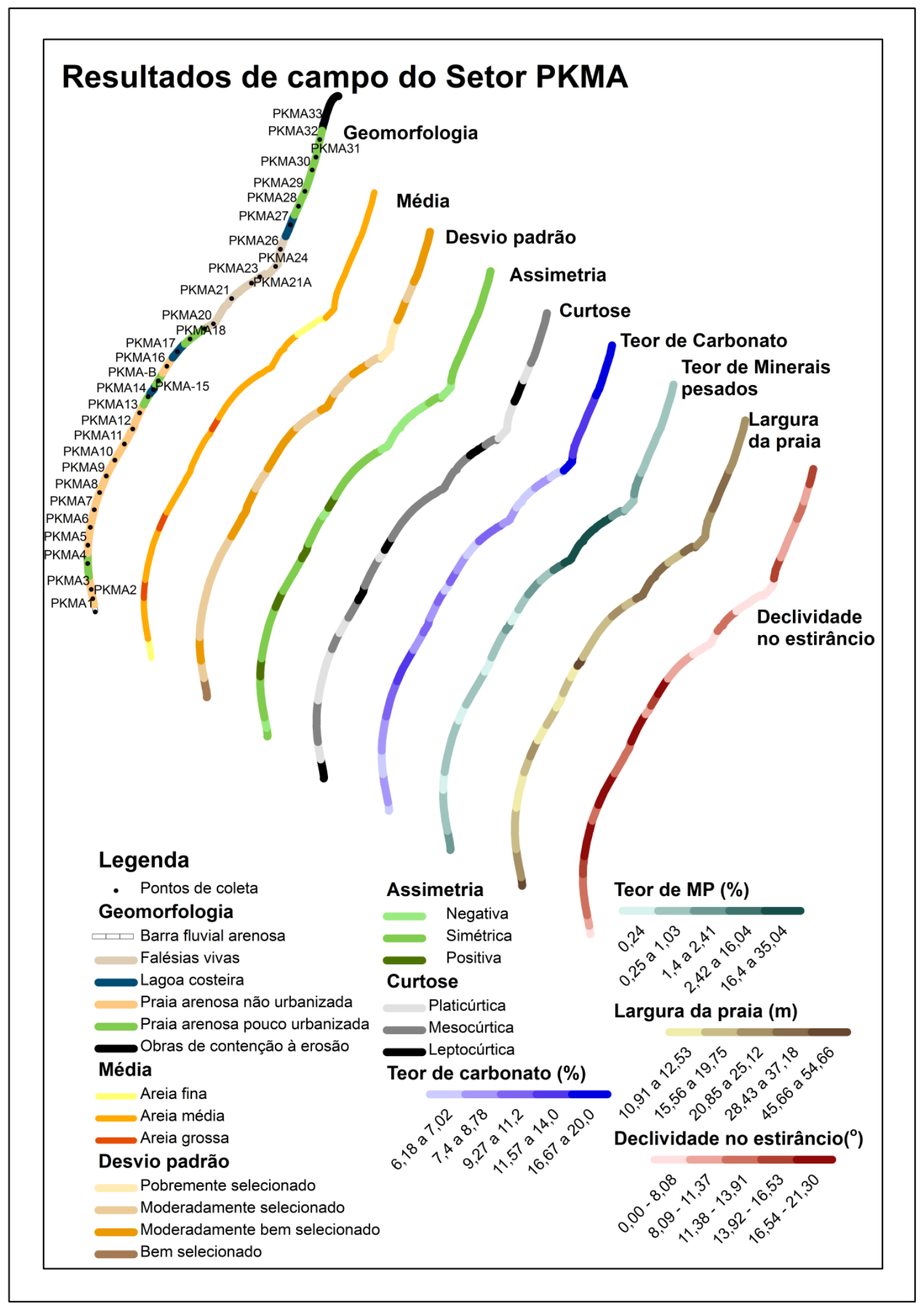

Figura 12: Caracterização sedimentar e geométrica das estações amostrais no setor PKMA

Através da Figura 12 é possível observar semelhança entre amostras que podem dividir o arco em 3 setores: um setor ao sul, entre as estações PKMA-1 e PKMA-18; central, entre PKMA-19 a PKMA-26; e outro ao norte entre PKMA-27 e PKMA-33 (Figura 12). 
O setor ao sul caracteriza-se por praias arenosas pouco extensas e de elevado grau de declividade (tendência refletiva), além do maior selecionamento. O setor central, com praias curtas e pouco inclinadas é marcado pela presença de falésias vivas que fornecem sedimento para a praia, aumentando o teor de minerais pesados e atingindo mais de $35 \%$. O setor ao norte, já mais urbanizado é onde se localiza a praia central de Marataízes, que sofreu as obras de intervenção contra erosão, como dito anteriormente.

É possível observar também um ponto de inflexão da linha de costa (passando de falésias vivas para praia arenosa). Nessa zona há maior concentração de Minerais pesados, assimetria mais negativa, menores extensões de praia e areia mais fina, como mostrado na Figura 13.

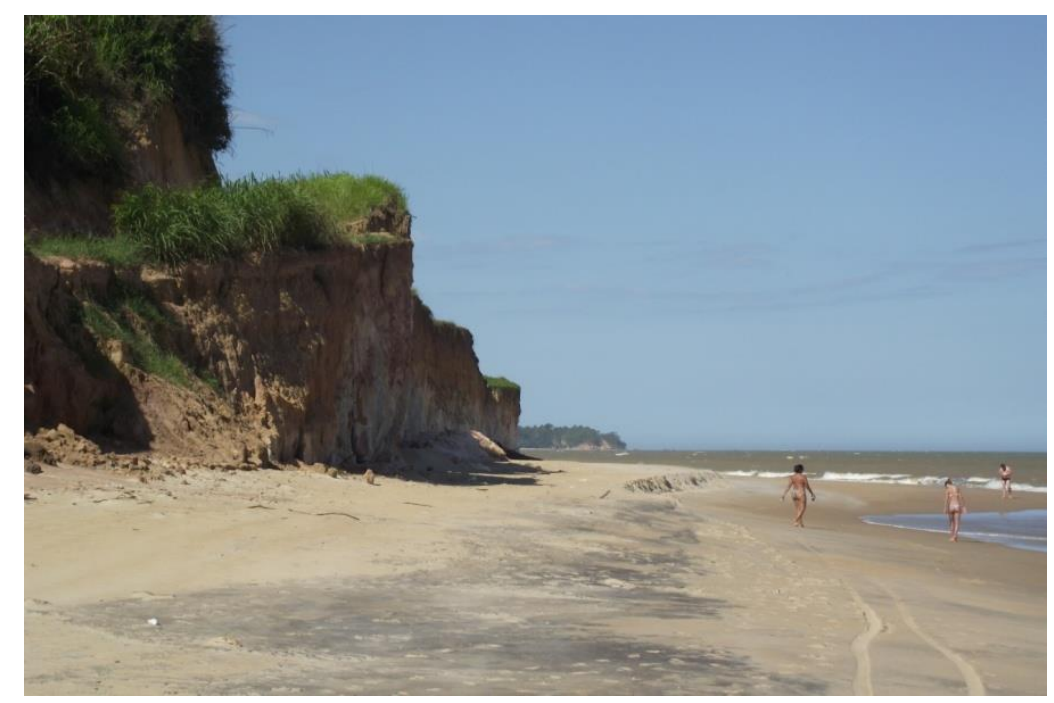

Figura 13: Fotografias em campo da zona de falésias vivas com maior concentração de MP (sedimento escuro), baixa declividade e de areia fina no setor PKMA.

\subsubsection{Análise de STA para o setor PKMA}

Como recomendado pelo autor, antes de ser feita a análise STA é feito um teste com todas as amostras, observando a correlação entre os três parâmetros texturais Figura 14: 

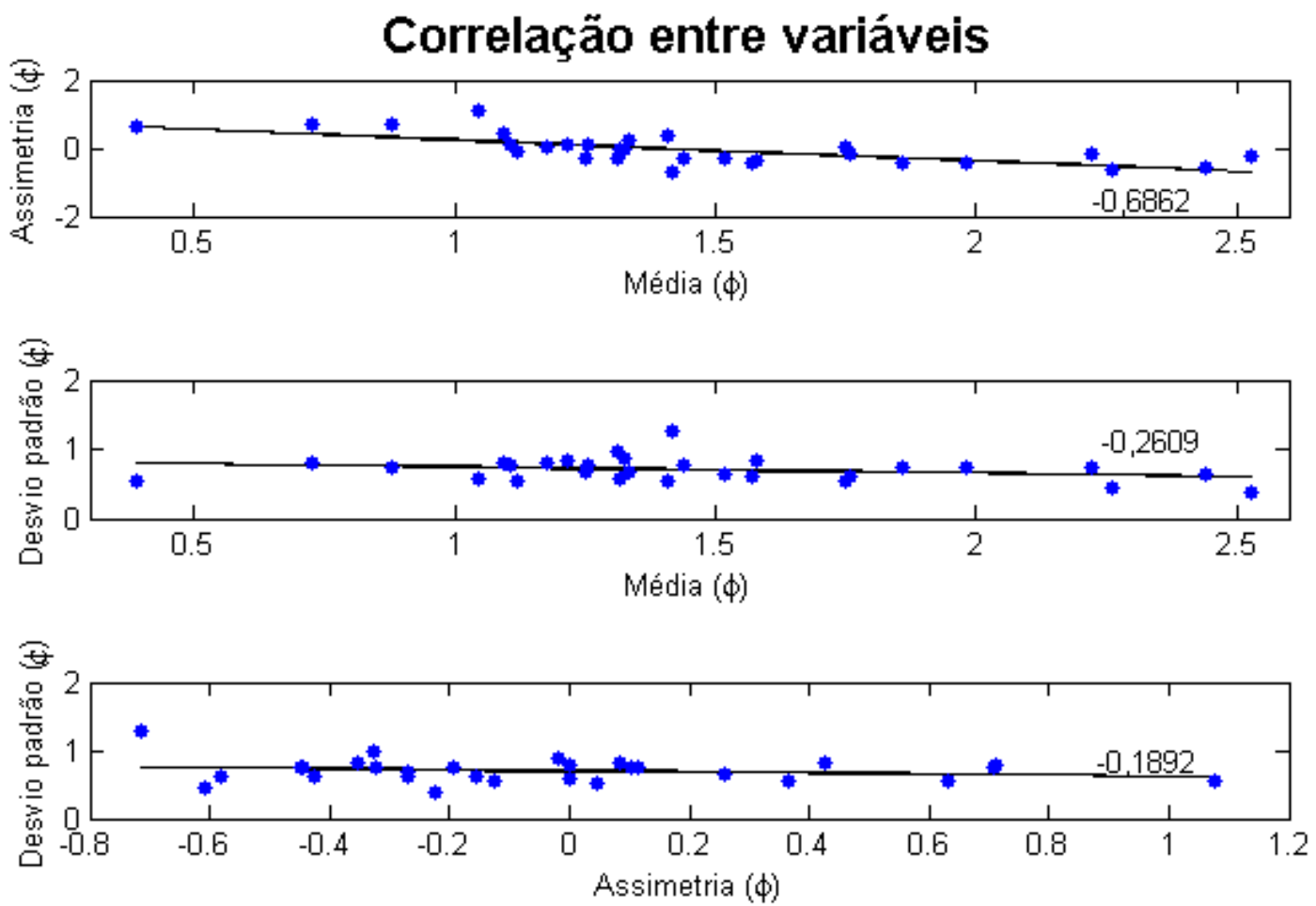

Figura 14: Correlação entre os parâmetros texturais usados na STA para o setor PKMA. O número ao lado da linha representa o coeficiente de Correlação de Pearson calculado.

Observa-se que há uma boa correlação entre os parâmetros Média e Assimetria, o que não ocorre entre os demais. No gráfico de correlação Desvio padrão por Assimetria, que atinge o menor coeficiente, percebe-se que há um ponto destoante, correspondente ao ponto PKMA-24, zona em que foi observada erosão, como indica a Figura 15. 

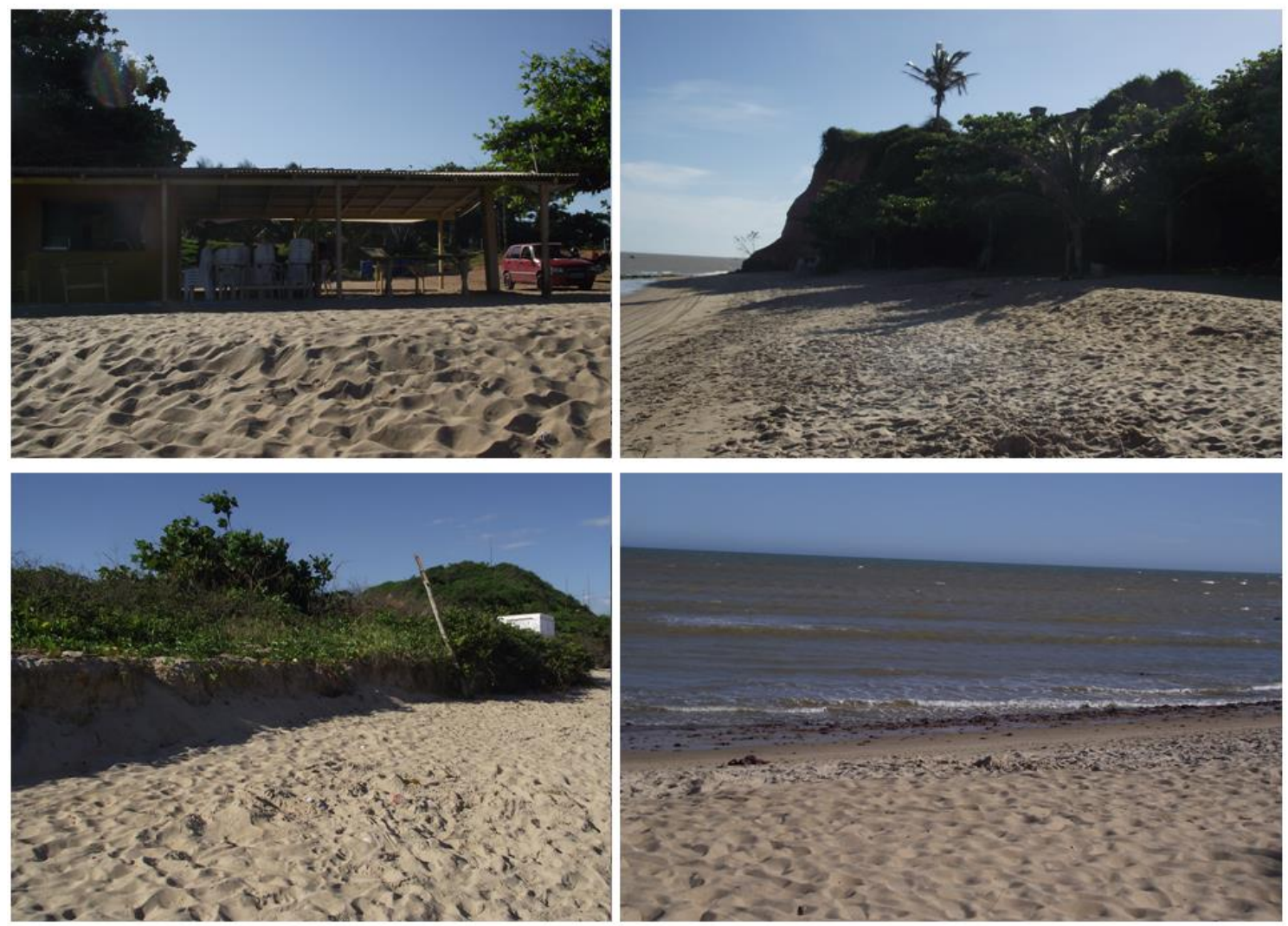

Figura 15: Fotografias do ponto de coleta PKMA-24. No sentido horário, a começar pela foto superior esquerda, um quiosque que é periodicamente inundado, construído sobre a vegetação de restinga; falésias vivas; arenitos de praia protegendo a linha de costa contra a erosão; escarpa abrupta evidenciando erosão.

O ponto de coleta PKMA-24 possui algumas particularidades: há falésias vivas na sua porção sul, entretanto, o teor de MP é considerado baixo $(2,4 \%)$ diferente do que ocorre nos outros pontos do setor norte do arco; o desvio padrão é o mais alto do setor (Mal selecionado) e a assimetria, a mais baixa (negativa). A amostragem no local foi realizada sob maré baixa (como se observa na Figura 15), o que parece ser determinante. Durante a maré baixa, os arenitos ficam emersos e protegem a região do efeito das ondas, que chegam mais fracas ao local, perdendo sua competência. Sob maré alta, as ondas atingem a praia emersa com maior energia (já que os arenitos ficam submersos) e consequentemente, mais competentes quando se refere ao sedimento carreado. Tal efeito pôde ser observado em vários trechos durante o trabalho de campo, conferindo um estado morfodinâmico típico de Terraço de Baixar Mar (TBM), forçado por fatores geológicos. No mesmo ponto há uma leve inflexão da linha de costa, causando uma quebra na tendência de todos os fatores (Figura 12).

Os gráficos da Figura 16 expressam o resultado das coletas com análise de correlação para que possa ser aplicado o estudo de STA. 


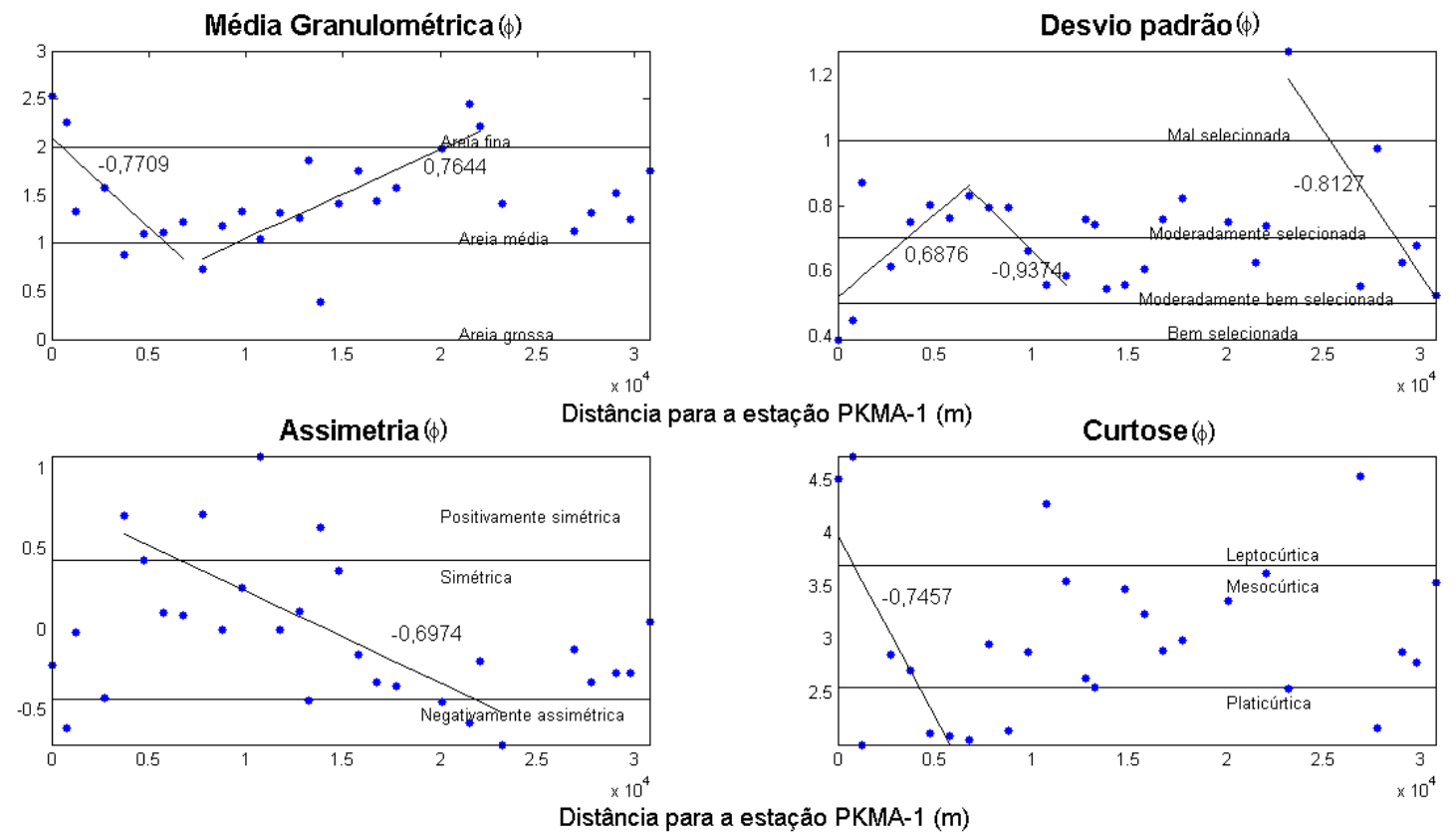

Figura 16: Correlação espacial dos parâmetros texturais no setor PKMA

Visualmente, o conjunto de gráficos na Figura 16 indica uma tendência FB- no sentido norte, que deve ser confirmado pela análise estatística.

A correlação foi obtida separadamente para cada parâmetro, desde que superiores a 0,65. A Tabela 5 indica as estações com maiores correlações para cada parâmetro, podendo ser inferido que os fatores de correlação foram altos, entretanto variando as estações usadas.

Tabela 5: Correlação entre a variação espacial dos parâmetros texturais e distância das estações

\begin{tabular}{llll}
\hline Parâmetro & $\begin{array}{l}\text { Correlação } \\
\text { 1/Estações }\end{array}$ & $\begin{array}{l}\text { Correlação } \\
\text { 2/Estações }\end{array}$ & $\begin{array}{l}\text { Correlação } \\
\text { 3/Estações }\end{array}$ \\
\hline Média & $-0,7709 / 1$ a 8 & $0,7644 / 9$ a 23 & - \\
\hline Desvio padrão & $0,6876 / 1$ a 8 & $-0,9374 / 8$ a 13 & $-0,8127 / 24$ a 29 \\
Assimetria & $-0,6974 / 5$ a 24 & - & - \\
Curtose & $-0,7457 / 1$ a 8 & - & - \\
\hline
\end{tabular}

O modelo de STA foi testado inicialmente para 8 amostras, sendo incluídas uma a uma as demais e observando-se os resultados. Foram testadas também as amostras de cada um dos três setores do arco explicados (sul, central e norte).

O resultado da análise de STA para todas as amostras do setor é mostrado na Tabela 6 e na Figura 17. 
Tabela 6: Resultado da análise STA para o setor PKMA

\begin{tabular}{ll}
\hline Estações utilizadas & Tendência \\
\hline Todas & FB- para norte (maior significância) e CB+ para sul \\
$\mathbf{1}$ a 20 & FB- para norte e para sul (maior significância) \\
$\mathbf{1 a} 15$ & FB- para sul \\
$\mathbf{1}$ a 8 & FB- para sul \\
$\mathbf{9}$ a 23 & FB- para norte e CB+ para sul (maior significância dentre \\
& todas) \\
\hline
\end{tabular}

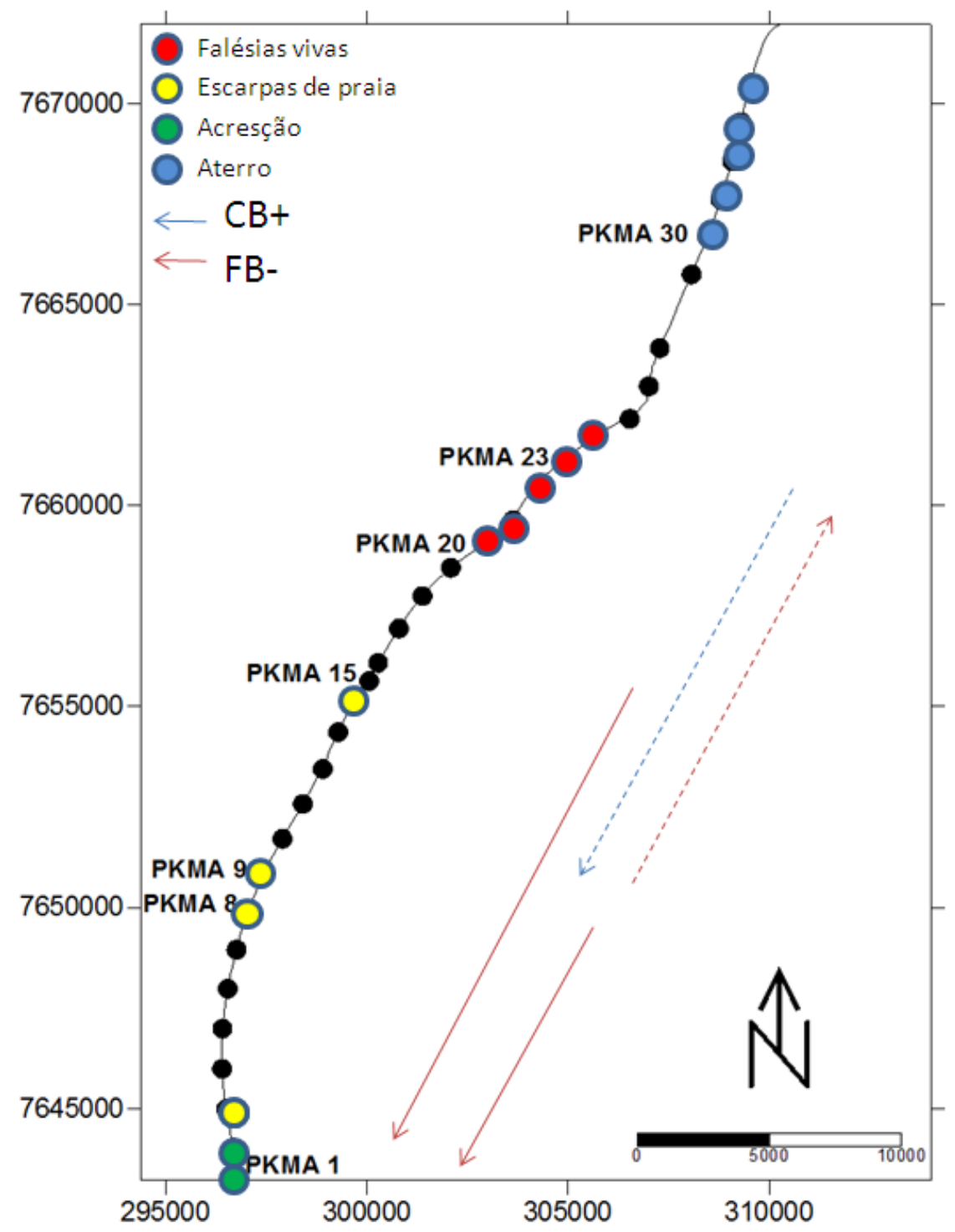

Figura 17: Representação gráfica dos resultados da análise de STA para o setor PKMA, sendo CB+ o sedimento mais grosso, melhor selecionado e com assimetria mais positiva; FB- o sedimento mais fino, melhor selecionado e com assimetria mais positiva. As setas pontilhadas representam a tendência com menor nível de confiança. 
A interpretação dos resultados da análise, segundo o autor (McLaren, 2012, comunicação pessoal) deve ser aliada ao conhecimento da área. Caso haja resultado significativo para ambos os sentidos, diz-se que a praia sofre ação de corrente por ambos os sentidos, e, portanto, encontra-se em equilíbrio.

Como o valor de significância assemelhou-se quando calculadas todas as estações, não é válido dizer que há tendência FB- para norte e $\mathrm{CB}+$ para sul. Da mesma maneira, considerando as estações 1 a 20 o resultado mostrou-se incoerente, pois as tendências FB- e CB+ para sul indicaram valores de significância semelhantes.

Valores altos de correlação, entretanto, foram encontrados entre as estações 1 e 8 e entre as estações 1 a 15 (os dois conjuntos calculados separadamente), e ambos indicando FB- para sul. Nesse caso, essas foram as tendências consideradas.

Entre as estações 9 e 23 foi encontrada a maior significância para a tendência $\mathrm{CB}+$ sentido sul. Entretanto, foi encontrada também uma tendência FB- para norte com significância alta. Duas teorias são propostas: (1) a praia encontra-se em equilíbrio dinâmico, com pouca atuação de corrente longitudinal, sendo mais atuantes as trocas transversais; (2) os arenitos de praia presentes na zona de arrebentação e os altos teores de MP mascaram os resultados, e a tendência não pode ser estabelecida. A primeira teoria é corroborada pelos altos valores de nível de confiança dos resultados, enquanto a segunda é validada pela já explicitada influência do teor de MP e da presença de arenito no local. Entre os setores PKMA-17 e PKMA-23 todas as praias são compartimentadas e delimitadas por falésias vivas da FB, de forma que a corrente longitudinal na zona de swash não consegue levar o sedimento de um setor para o outro.

Comparando esse resultado àquele mostrado na Figura 16, percebe-se que há uma mudança na tendência entre as estações 8 e 9 responsável por essa diferença na análise. De maneira geral, pode-se dizer que o setor PKMA tem um transporte líquido de sedimento para sul, não tão claro, pois há inversões locais no sentido das correntes.

Os pontos coloridos da Figura 17 indicam locais em que feições diagnósticas de estado da praia foram encontradas. Nesse setor, os pontos em vermelho indicam forte erosão, observados através do alto teor de MP e da presença de falésias vivas. Nos setores em amarelo foram encontradas escarpas de praia, feições erosivas, porém parecem corresponder a eventos episódicos de tempestade, não estando necessariamente em 
erosão. Os pontos em azul representam locais em que o aterro foi feito ou que seus efeitos foram observados, enquanto que nos pontos em verde foram observadas feições de linha de costa progradante, como uma planície de deflação e pós-praia extensos.

\subsubsection{Análise de imagens e fotografias aéreas no setor PKMA}

$\mathrm{Na}$ análise por imagens de satélite e fotografias aéreas foram escolhidos os seus pontos extremos, a saber: a foz do Rio Itabapoana e a Praia Central de Marataízes.

A foz do Rio Itabapoana foi estudada através de fotografias aéreas de 1970, 1990, 2005, 2008 e imagens de satélite de 2002 e 2011. As linhas de costa digitalizadas são apresentadas a seguir:

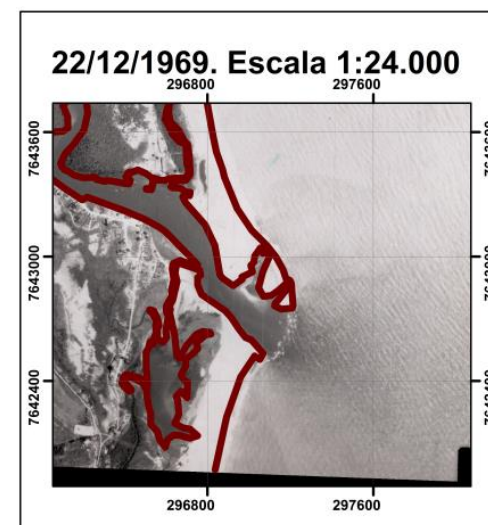

05/06/2006.Escala 1:34.000

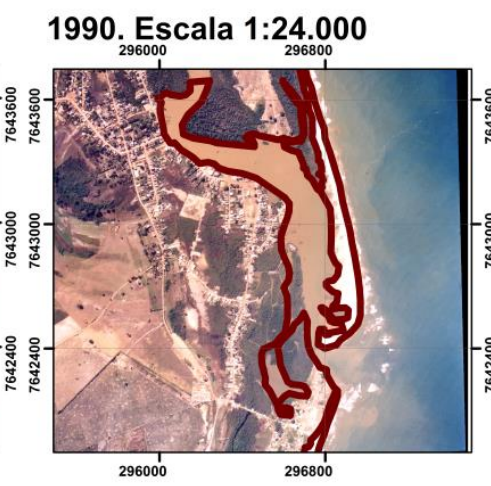

2008. Escala 1:34.000

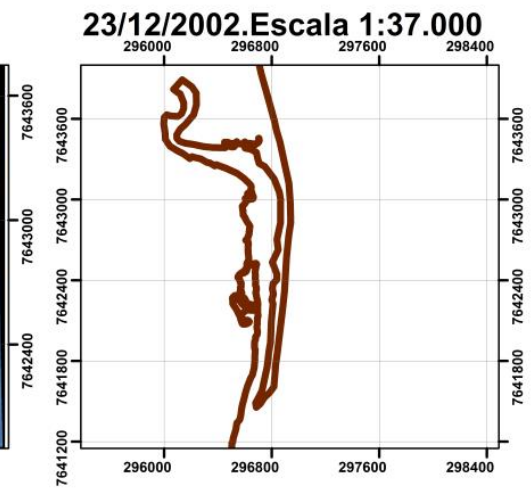

07/08/2011. Escala 1:29.000
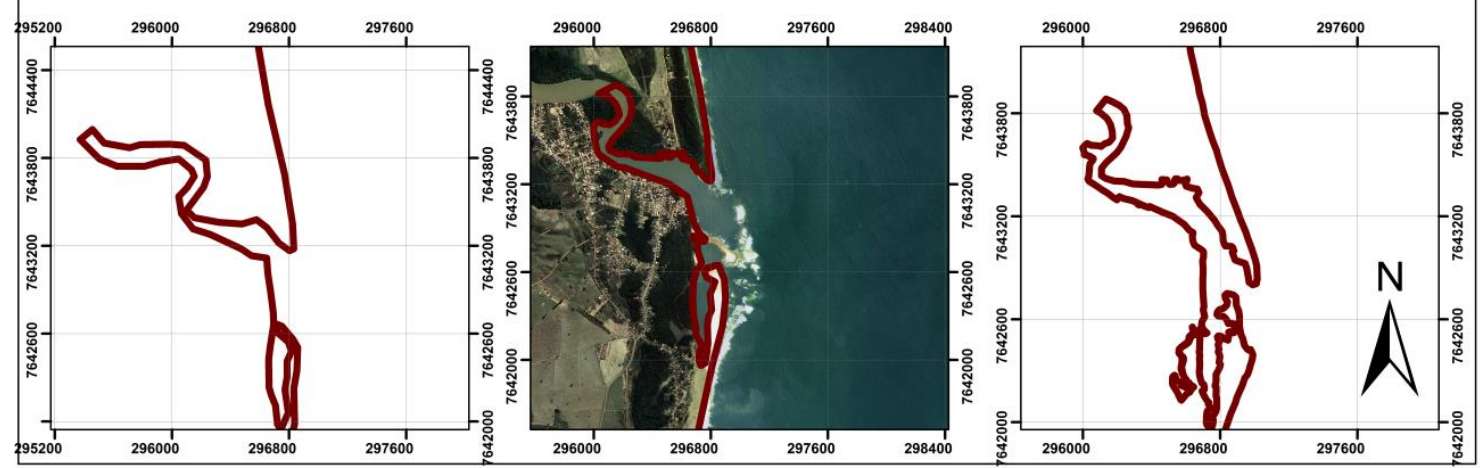

Figura 18: Evolução da linha de costa (em vermelho escuro) na foz do Rio Itabapoana. A orientação de norte aplica-se a todas as imagens. Para os anos de 1969, 1990 e 2008 foram usadas fotografias aéreas; nas demais, imagens de satélite.

Como pode ser observado na Figura 18, houve inversões no sentido da corrente longitudinal. Entre os anos de 1969 e 2005 (não consta na figura, porém foi analisada) o sentido predominante de transporte longitudinal de sedimento era para sul, fato comprovado pela criação de uma barra no rio que chegou a atingir aproximadamente dois quilômetros de comprimento e $90 \mathrm{~m}$ de largura no seu trecho central. Entre 2003 e 
2005 a barra foi diminuindo de tamanho, tendo sido extinta no ano de 2006, quando outra barra influenciada por correntes vindas de sul começou a ser formada e atualmente aumenta em processo de alargamento. A partir do ano de 2010, entretanto, uma nova barra na margem norte, influenciada pela deriva vinda de norte voltou a ser formada.

A Figura 19 indica o comportamento hídrico do Rio Itabapoana entre os anos de 1986 e 1990, mostrando uma diminuição da vazão. A comparação dos dados com a figura anterior indica que a diminuição da vazão fluvial influencia na formação da barra, posto que a corrente longitudinal torna-se relativamente mais importante no processo de transporte de sedimento.

É conhecido o efeito da descarga hídrica no transporte longitudinal, agindo como um molhe hidráulico (Komar, 1973). Uma maior vazão do rio implica em maior trapeamento do sedimento à barlamar do sentido da corrente de deriva. Como houve diminuição da vazão entre 1985 e 2002, foi possível a construção de uma barra na sua foz. Entre os anos de 1990 e 2000 há oscilações nas médias, porém diminuição gradativa das mínimas, contribuindo para o aumento da barra fluvial.

O oposto ocorre entre os anos de 2001 e 2005, mesmo período em que a barra fluvial formada no sentido sul começa a ser abandonada, e começa a ser formada a barra no sentido norte, porém não tão extensa quanto a outra.

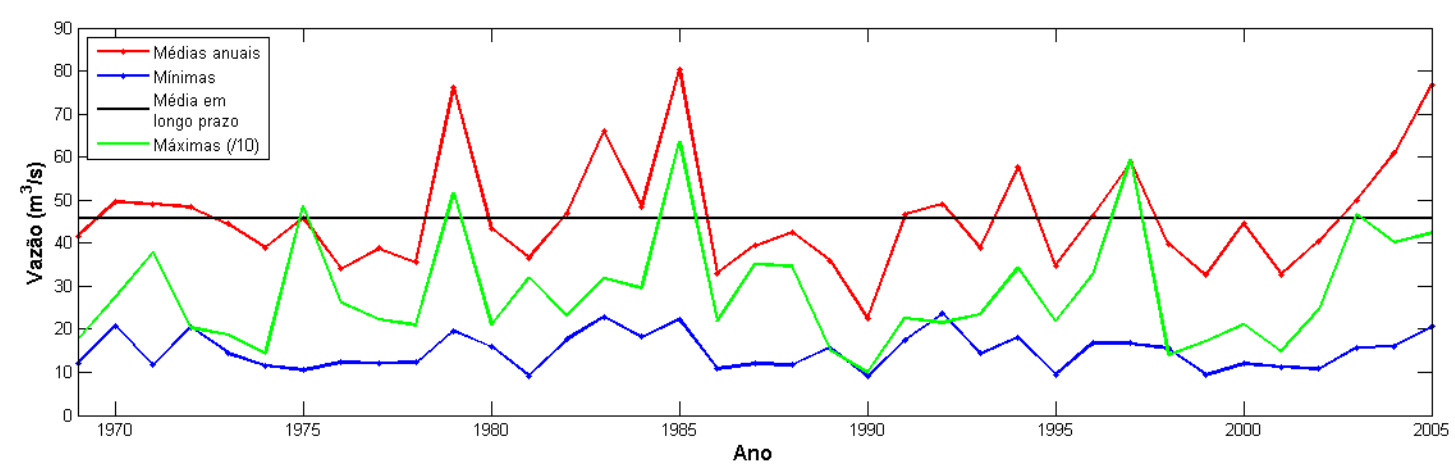

Figura 19: Vazões médias e mínimas do Rio Itabapoana entre os anos de 1969 e 2005.

Dessa maneira, pode-se dizer que até o ano de 2002 o sentido predominante líquido é para sul, havendo inversões marcantes a partir de 2005. Como dito previamente, provavelmente houve um número maior de entrada de frentes frias no período considerado. 
Reunindo as informações sedimentológicas com os dados hídricos e morfológicos, pode-se dizer que houve inversões de corrente, com predomínio atual de correntes de nordeste. As inversões dificultam o pleno entendimento e aprofundamento maior dos resultados obtidos na análise STA.

Na porção mais ao norte do setor, na Praia Central de Marataízes, verificou-se entre 1970 e 2005 um acelerado processo de erosão. A praia que 1970 possuíra $65 \mathrm{~m}$ de extensão em média atingiu seu ápice de erosão em 2005 (Figura 20), aumentou para 10 m em 2008, com a construção de vários quebra-mares perpendiculares à linha de costa, e atualmente possui uma extensão máxima de $170 \mathrm{~m}$ devido às obras de engenharia costeira.

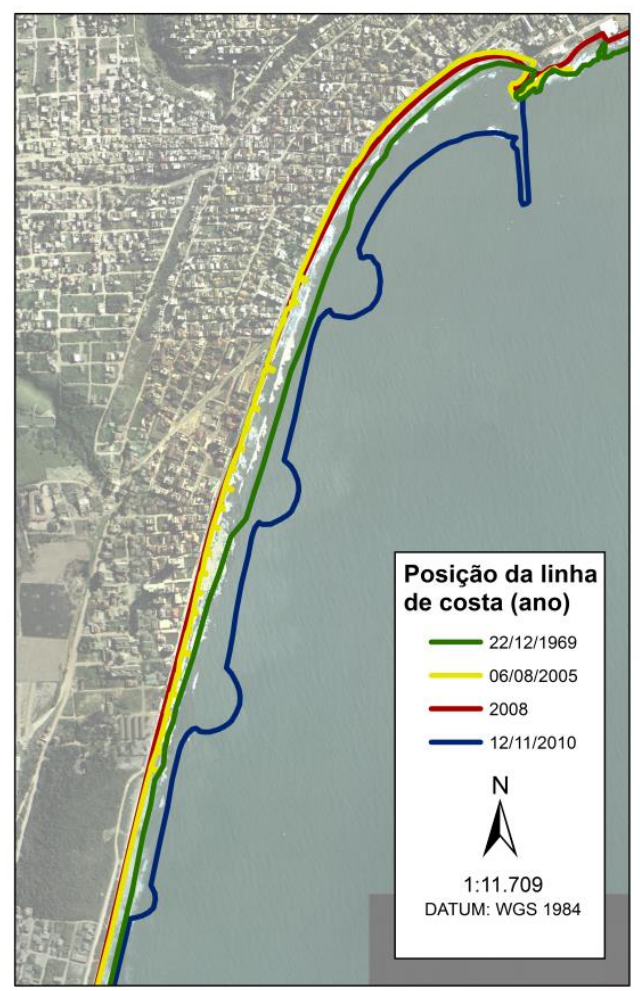

Figura 20: Posição da linha de costa entre 1969 e 2010 da Praia Central de Marataízes. Fonte: Imagens de satélites

O guia-corrente presente no Rio Itapemirim pode ser a causa da falta de sedimento para a praia Central, já que desde a década de 1960 sua presença atua como um trapeador de sedimento. Seu efeito será discutido na próxima seção.

Comparando os resultados demonstrados no presente trabalho com os apresentados por Albino et al. (2006), concorda-se que a foz do Rio Itabapoana esteja estável com tendências progradantes. Os setores correspondentes à amostra PKMA-24 e à Praia 
Central de Marataízes estão em erosão e em estabilidade, respectivamente, discordando das conclusões de Albino et al. (2006).

\subsection{SETOR ITAPEMIRIM}

\subsubsection{Descrição dos parâmetros no setor ITA}

A localização das amostras do setor Itapemirim (ITA) é mostrada na Figura 21: 


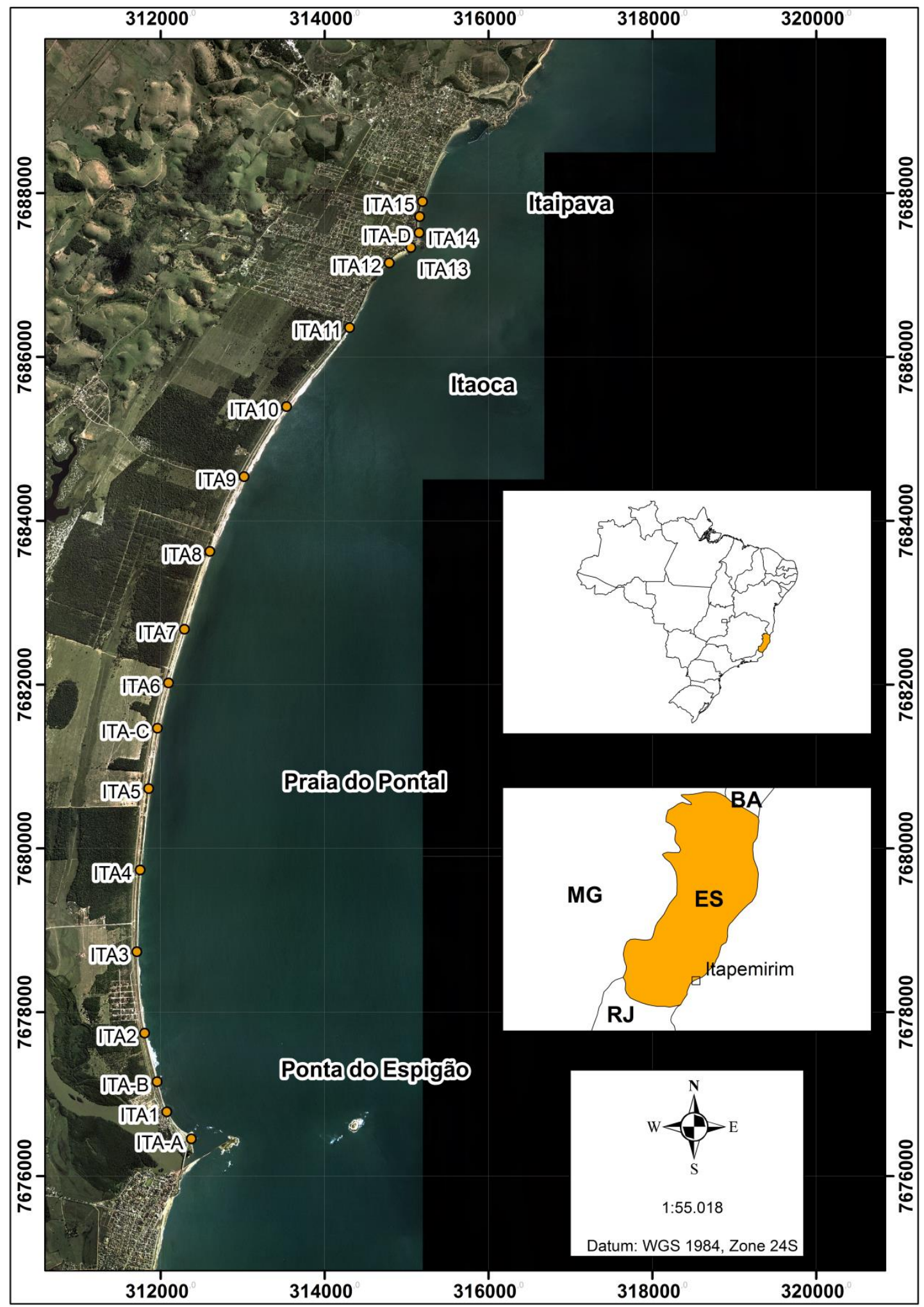

Figura 21: Localização dos pontos de coleta no setor ITA.

O resultado das análises é mostrado na Figura 22: 


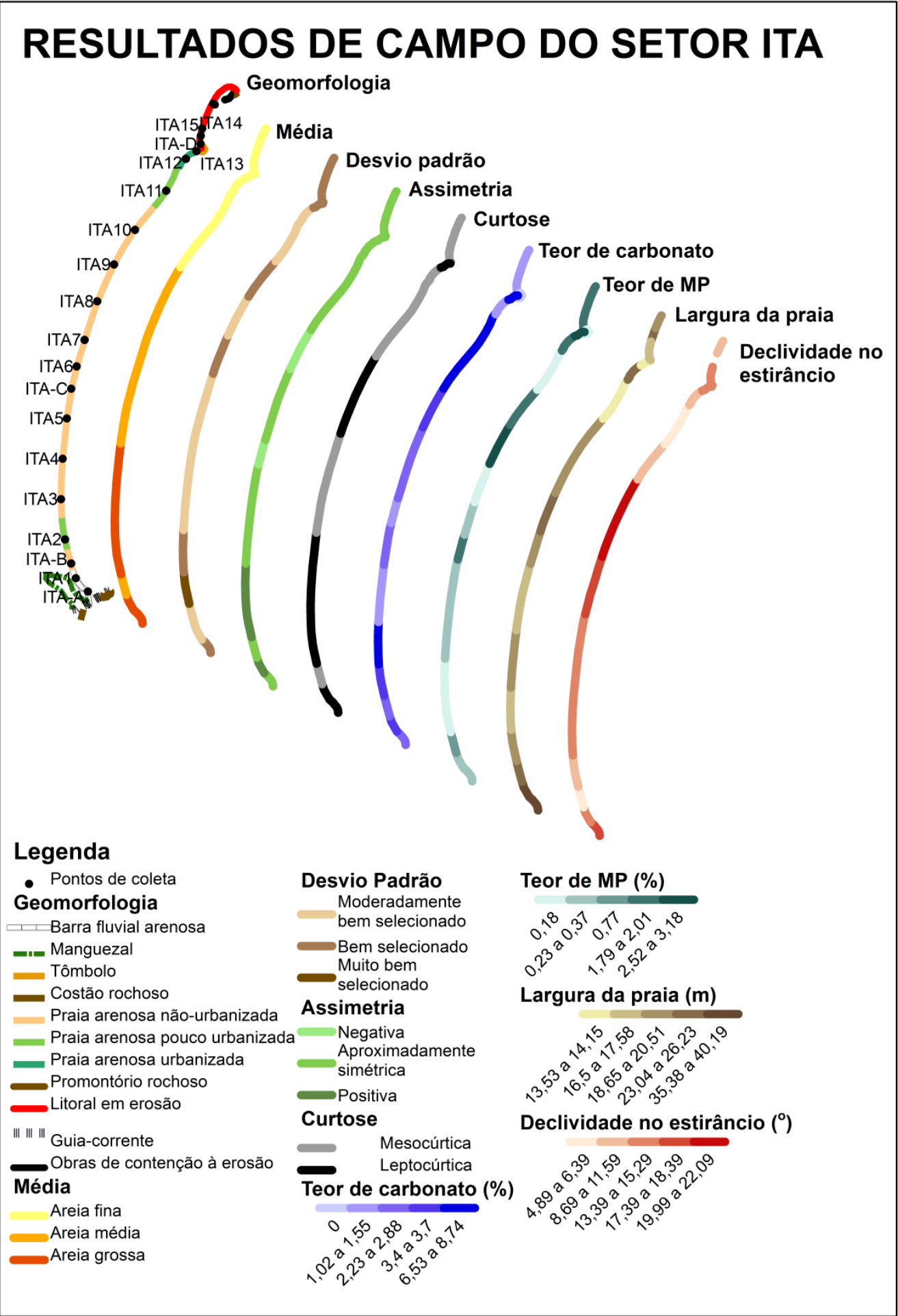

Figura 22: Caracterização sedimentar e geométrica das estações amostrais no setor ITA.

O setor ITA apresentou uma variação bastante clara quanto à média granulométrica, com tendência de engrossamento dos grãos e melhora no grau de seleção em direção ao sul, diminuição da declividade e no teor de MP. A curtose e a assimetria dos grãos 
também aumentam em direção ao sul, sendo que para norte a tendência não é tão clara, com exceção do teor de MP e diminuição da largura da praia (\%)

Foi também o arco com maiores variedades de classificações geomorfológicas da costa: um guia-corrente e píer, praia não urbanizada, pouco urbanizada e em erosão, promontório rochoso, tômbolo, e manguezal.

Na estação de coleta ITA-6 da Figura 22 há grande diferenciação dos parâmetros texturais e mesmo da morfologia da praia no local. A assimetria é negativa, o teor de pesados é maior do que em seu entorno, a largura da praia menor, apesar de possuir uma longa vegetação de restinga preservada até a praia. Além disso, a declividade do estirâncio é menor do que nas estações ao redor, quebrando a tendência. A Figura 23-C mostra fotografias tomadas nesse setor.

A porção central do setor, de maneira geral, parece comportar-se de maneira distinta dos extremos: maior declividade, teor de MP e curtose altos, o que pode representar um ponto de concentração da ação de ondas.

A Figura 23-A representa a feição dominante do local: um longo arco praial contínuo com cristas praiais abandonadas, tendo um promontório rochoso no setor mais ao norte, como indicado na Figura 22; a Figura 23-B indica o padrão observado entre as estações ITA-2 e ITA-C, e entre as estações ITA-8 e ITA-12, com duas bermas, sendo um provavelmente de tempesatade. A Figura 23-C mostra a morfologia das estações ITAC,6 e 7, com uma praia mais plana e maior teor de MP. Por fim, a figura Figura 23-D mostra o norte do setor, com tendência erosiva e um píer ao fundo, construído para estabilizar a linha de costa. 

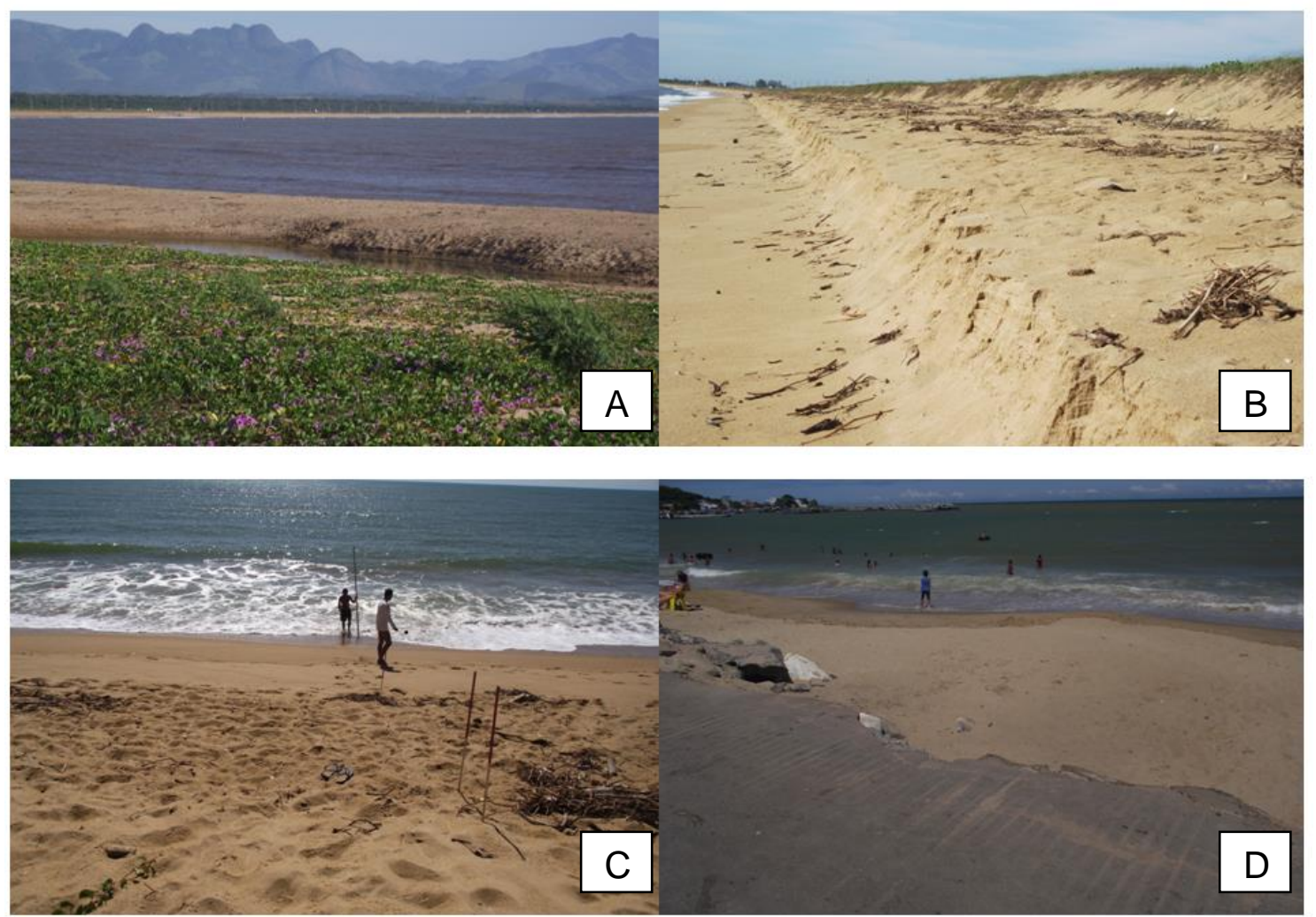

Figura 23: Fotografias em campo do setor ITA

\subsubsection{Análise de STA para o setor ITA}

A correlação entre as variáveis de STA é mostrada na Figura 24:
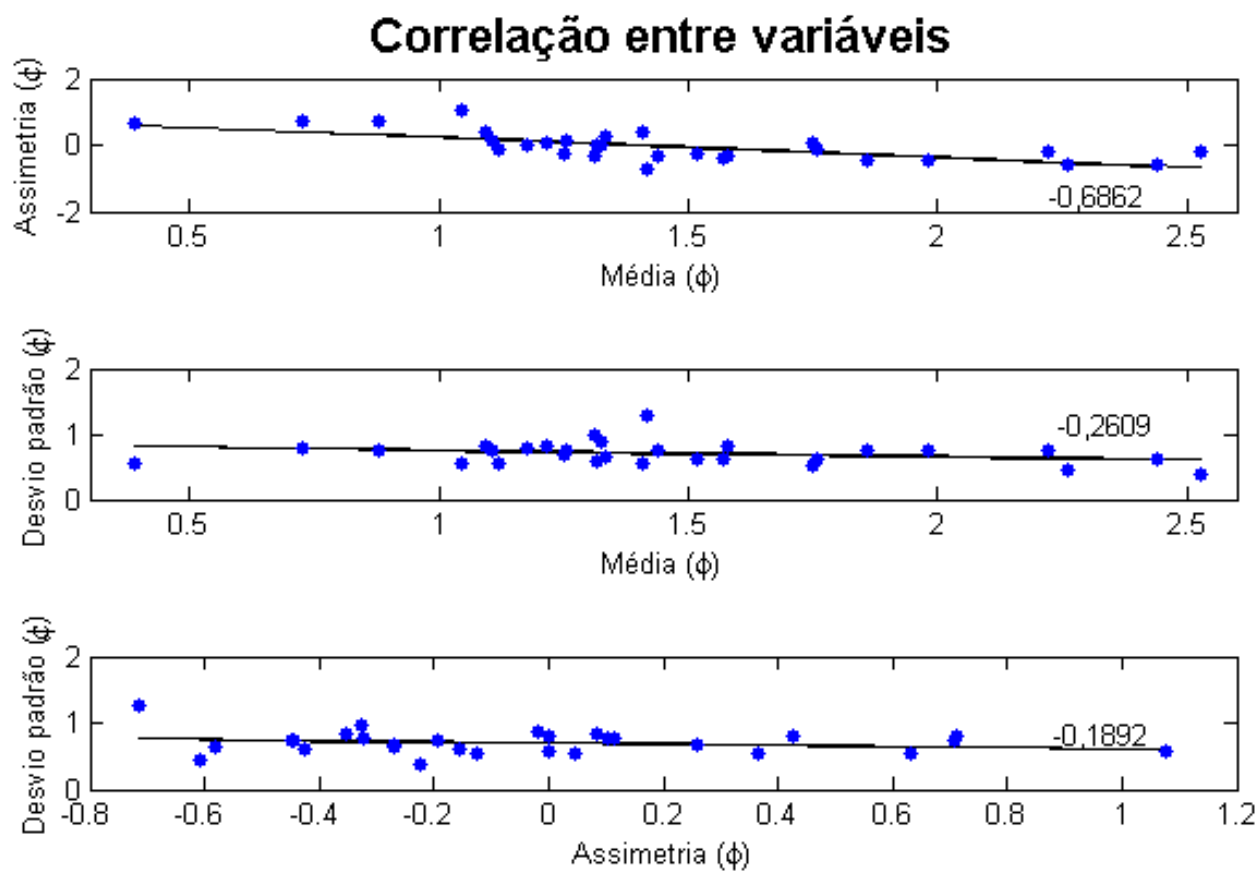

Figura 24: Correlação entre os parâmetros texturais usados na STA para o setor ITA. O número ao lado da linha representa o coeficiente de Correlação de Pearson calculado. 
A Figura 24 indica que a correlação pode ser considerada apenas para as variáveis assimetria e média. Os gráficos da Figura 24 indicam as tendências de variação para o setor:
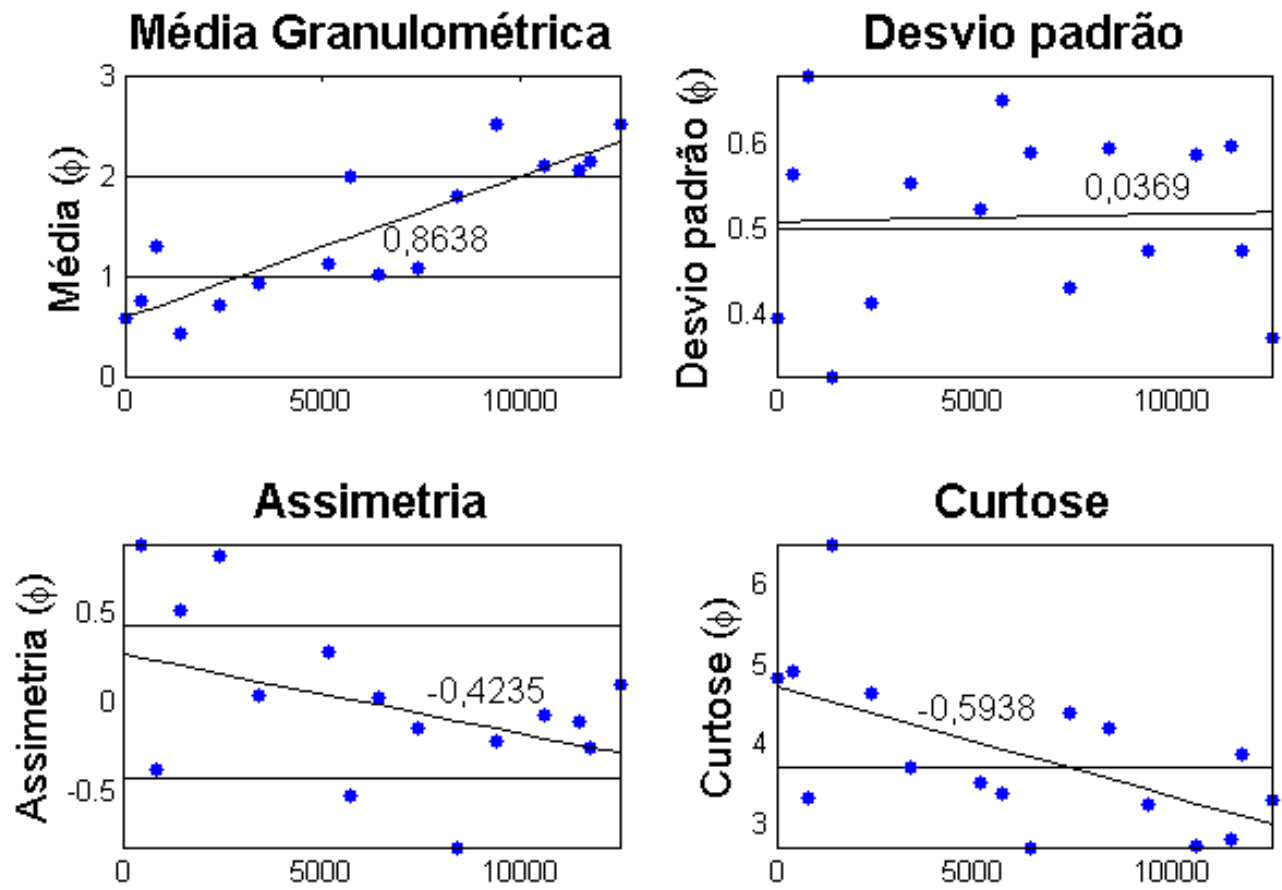

Distância para a estação ITA-A (m) Distância para a estação ITA-A (m)

Figura 25: Correlação espacial dos parâmetros texturais no setor ITA

Como pode ser observado na Figura 25, apenas a média granulométrica apresentou uma tendência espacial consideravelmente boa. Como a tendência nas outras foi muito baixa, principalmente no que diz respeito ao grau de seleção, é bem provável que a análise STA não apresente resultados muito confiáveis.

Devido ao padrão apresentado no que diz respeito à média granulométrica, as amostras do setor ITA foram consideradas em conjunto, sem subdivisões. A Tabela 7 indica o resultado da análise.

Tabela 7: Resultado da análise STA para o setor ITA

\begin{tabular}{|c|c|c|c|c|}
\hline & \multicolumn{4}{|c|}{$\begin{array}{l}\text { Teste de significância para amostras no } \\
\text { sentido norte }\end{array}$} \\
\hline & $\mathrm{FB}+\mathrm{N}$ & FB-N & $\mathrm{CB}+\mathrm{N}$ & $\mathrm{CB}-\mathrm{N}$ \\
\hline Número de amostras (n) & 16 & 16 & 16 & 16 \\
\hline $\begin{array}{l}\text { Número de pares possíveis } \\
(\mathrm{N})\end{array}$ & 120 & 120 & 120 & 120 \\
\hline $\mathbf{X}$ & 23 & 21 & 9 & 4 \\
\hline
\end{tabular}




\begin{tabular}{lrrrr}
\hline $\mathbf{P}$ & 0,125 & 0,125 & 0,125 & 0,125 \\
$\mathbf{Q}$ & 0,875 & 0,875 & 0,875 & 0,875 \\
Teste-Z & 2,2082098 & 1,656157 & $-1,65616$ & - \\
& & & & 3,03629 \\
$\begin{array}{l}\text { Teste de significância para } \\
\mathbf{0 , 0 5}\end{array}$ & aceita & aceita & rejeita & rejeita \\
$\begin{array}{lllll}\text { Teste de significância para } \\
\text { 0,01 }\end{array}$ & rejeita & rejeita & rejeita & rejeita \\
\end{tabular}

\begin{tabular}{|c|c|c|c|c|}
\hline & \multicolumn{4}{|c|}{$\begin{array}{l}\text { Teste de significância para amostras no } \\
\text { sentido sul }\end{array}$} \\
\hline & $\mathrm{FB}+\mathrm{N}$ & FB-N & $\mathrm{CB}+\mathrm{N}$ & $\mathrm{CB}-\mathrm{N}$ \\
\hline Número de amostras (n) & 16 & 16 & 16 & 16 \\
\hline $\begin{array}{l}\text { Número de pares possíveis } \\
(\mathbf{N})\end{array}$ & 120 & 120 & 120 & 120 \\
\hline $\mathbf{X}$ & 3 & 2 & 47 & 11 \\
\hline $\mathbf{P}$ & 0,125 & 0,125 & 0,125 & 0,125 \\
\hline $\mathbf{Q}$ & 0,875 & 0,875 & 0,875 & 0,875 \\
\hline Teste-Z & $-3,312315$ & $-3,58834$ & 8,832839 & $-1,1041$ \\
\hline $\begin{array}{l}\text { Teste de significância para } \\
0,05\end{array}$ & rejeita & rejeita & aceita & rejeita \\
\hline $\begin{array}{l}\text { Teste de significância para } \\
0,01\end{array}$ & rejeita & rejeita & aceita & rejeita \\
\hline
\end{tabular}

A Figura 26 representa os resultados da análise STA com a análise de campo. 


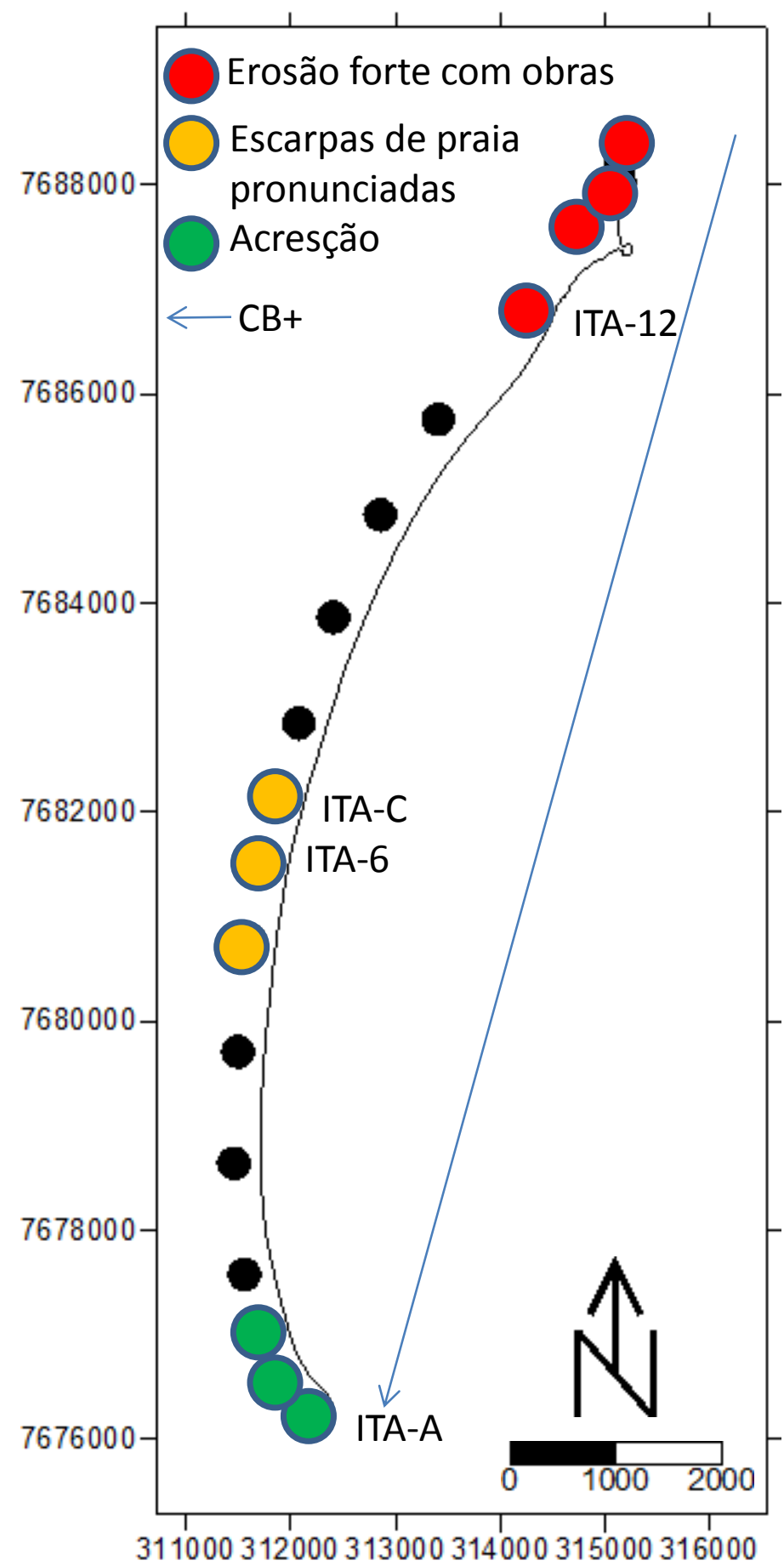

Figura 26: Representação gráfica dos resultados da análise de STA para o setor ITA, sendo CB+o sedimento mais grosso, melhor selecionado e com assimetria mais positiva.

$\mathrm{Na}$ parte sul do setor foram observadas mais de uma crista de praia no mesmo setor, uma pós-praia extensa, com acúmulo de resíduos diminuindo gradativamente para norte. Troncos de árvore, lixo e matéria orgânica podem ser resultados da proximidade com o rio, mas também podem ser indicativos de sentido de corrente (Souza et al., 2005). 
Nos pontos marcados em laranja foram observadas escarpas pronunciadas, com maior acúmulo de MP (visualmente e comprovado pelas análises laboratoriais), podendo refletir um ponto de incidência maior de ondas. Por fim, nos pontos em vermelho mais ao norte foram observadas altas concentrações de MP, pós-praia curto, troncos de árvore, além da própria obra de engenharia costeira (o píer com quebra-mar) indicando as tendências erosivas do local. Aparentemente, essa obra não mostra muita efetividade, já que o local continua sofrendo quando da entrada de frentes de ondas mais fortes.

Apesar de ter sido aceita a tendência FB+e FB- em sentido norte, fica evidente pelo número de amostras que é a tendência $\mathrm{CB}+$ que predomina, e no sentido sul, concordando com o setor PKMA.

\subsubsection{Análise de imagens e fotografias aéreas do setor ITA}

A análise da linha de costa foi feita em três pontos distintos, a saber: a foz do Rio Itapemirim (ao sul), a praia de Itaoca (local de coleta da amostra ITA-12) e ao norte, na praia de Itaipava, onde foi construído um píer em 2005. Seu resultado é indicado na Figura 27: 


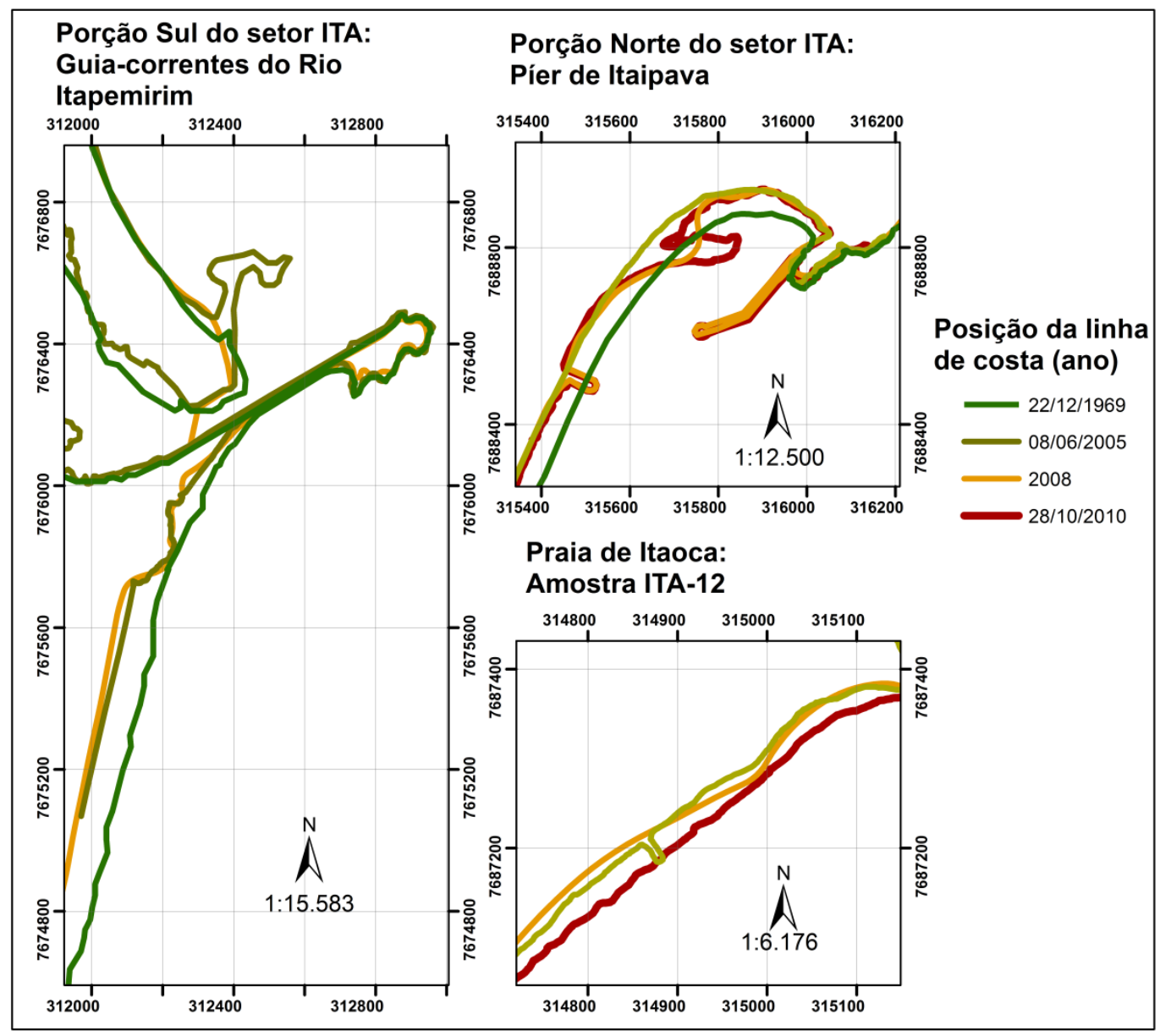

Figura 27:Análise da variação da linha de costa no setor ITA

Alguns pontos críticos puderam ser observados a partir da Figura 27. A presença do guia-corrente no Rio Itapemirim faz com que o balanço sedimentar seja quebrado, não havendo troca entre os setores ao norte e ao sul.

Foi observada também erosão significativa da área de manguezal na porção da barra interna (voltada para o rio) entre os anos estudados. Em 2005 foi identificada uma barra emersa transversal à linha de costa. Como se observa na Figura 28, foi nesse ano que o rio atingiu sua máxima histórica, tendo como consequência o maior aporte de sedimento, possibilitando a formação da barra longitudinal. 


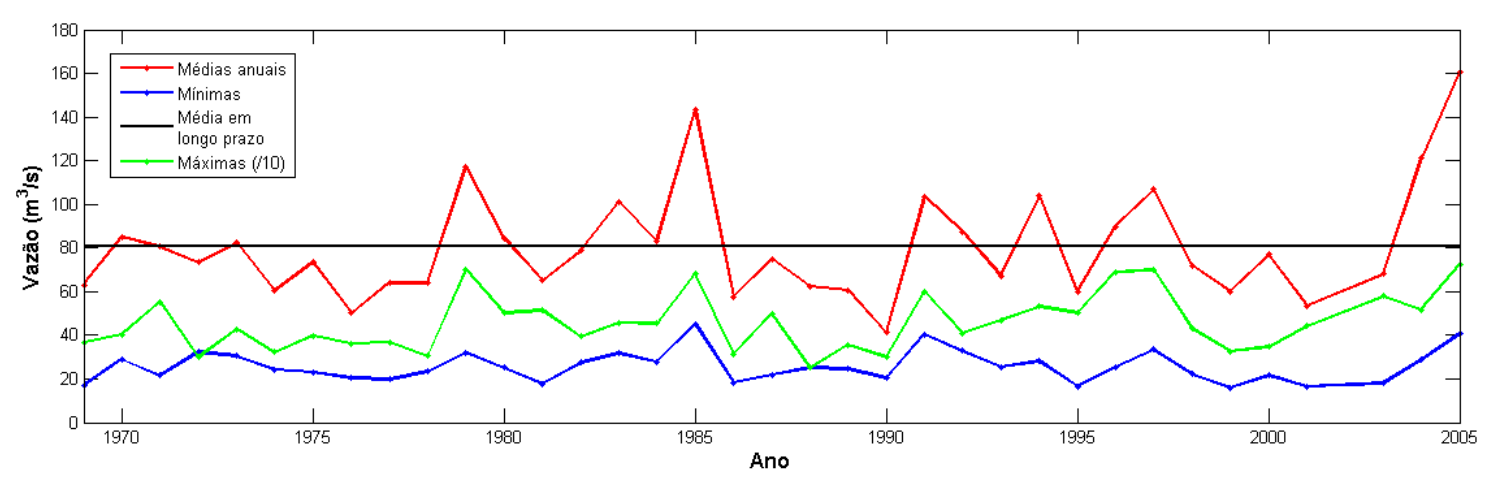

Figura 28: Registro das vazões médias, máximas e mínimas do Rio Itapemirim

Ao sul do guia-corrente foi observada significativa perda de faixa de pós-praia de $80 \mathrm{~m}$, aproximadamente. A faixa de praia que se manteve é resultado de controle estrutural, onde afloram hoje rochas cristalinas. Os fatos mostrados auxiliam na evidência de corrente predominantemente para sul, ou seja, esse trecho serviria como área fonte de sedimentos para a corrente longitudinal.

No píer de Itaipava (canto superior direito da Figura 27) fica novamente evidente a erosão da linha de costa desde 1969. Em 2003 a praia atinge seu menor comprimento, e começam então as obras de contenção da linha de costa, com a construção de dois píeres para que sirvam de marina. Os píeres, entretanto, agravam a situação, causando maior erosão e a construção de uma língua arenosa observável nos anos de 2008 e 2010. Tal feição reflete provavelmente uma difração das ondas por conta do promontório rochoso existente no local. Em 2008 a feição é completamente arenosa, passando a ser vegetada em 2010.

Na parte central, correspondente à estação de coleta ITA-12 houve aumento da faixa praial entre os anos de 2005 a 2010. No local há um riacho de vazão muito baixa e intermitente. $\mathrm{Na}$ imagem de 2005, entretanto, a foz do riacho se desloca para norte e provavelmente aumenta sua vazão (dados não disponíveis, porém esperados, já que no mesmo ano os rios Itabapoana e Itapemirim atingiram sua máxima histórica). Dados os dois motivos, é possível que nesse trecho do arco ITA haja uma inversão de circulação, com a corrente de deriva total sendo para norte.

É interessante observar também a presença de cúspides praiais no setor. Em todas as fotografias e imagens aéreas observadas, além do presenciado em campo, é marcante a presença das feições desde a construção do píer. Elfrink et al. (2006) afirma que obras de engenharia costeira feitas sem o devido planejamento podem ocasionar a construção dessas feições, causando riscos para os banhistas. 
Comparando os resultados com os de Albino et al. (2006), de fato a foz do Rio Itapemirim atua ora como prograndante, ora como retrogradante, a depender de sua vazão, já que a mesma é estabilizada por uma obra de contenção. É essa mesma obra, entretanto, a responsável pela falta de suprimento sedimentar para as praias vizinhas, principalmente as localizadas ao sul, como observado na Figura 27. Da mesma forma, a praia do pontal é estável, devido ao bom suprimento sedimentar representado pelas cristas de praia não ocupadas.

O trabalho de Albino et al. (opus cit.) enquadra a Praia de Itaoca como estável. Como é de 2006, antes da marinha ser construída, seus impactos não foram contabilizados no trabalho, e a praia hoje está em processo de erosão. A mudança ocorreu devido à construção da marina e da ocupação do pós-praia e da faixa de restinga, como mostra a Figura 23. A praia atua como principal fonte de sedimento carreado pela corrente longitudinal quando a mesma atua de norte para sul, em condições de tempo bom.

\subsection{SETOR UBU}

\subsubsection{Descrição dos parâmetros no setor UBU}

A Figura 29 indica os pontos de coleta e as praias no setor UBU. 


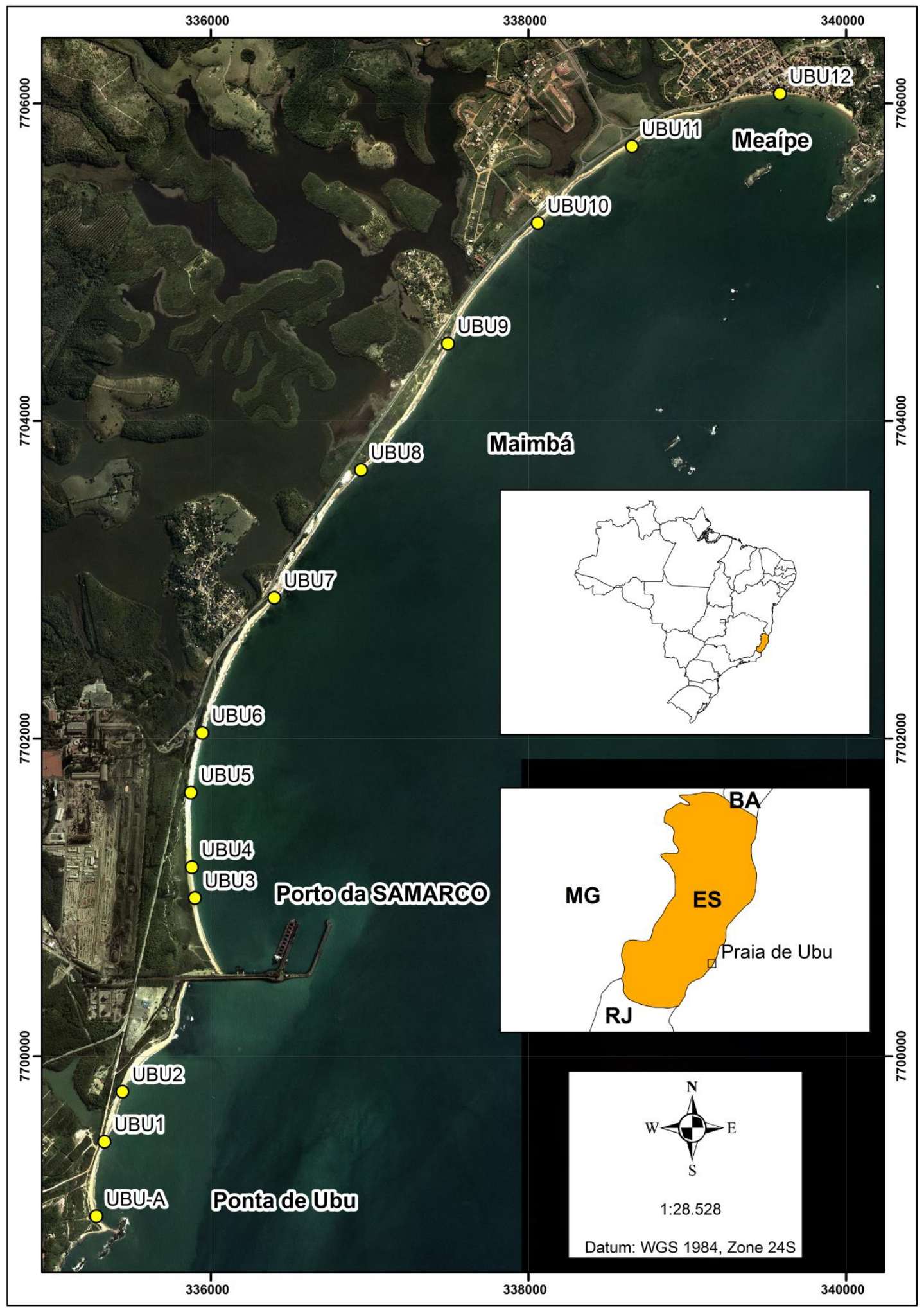

Figura 29: Localização dos pontos de coleta no setor UBU.

A Figura 30 indica os resultados obtidos através das coletas realizadas no setor UBU. 


\section{Resultados de campo do setor UBU}

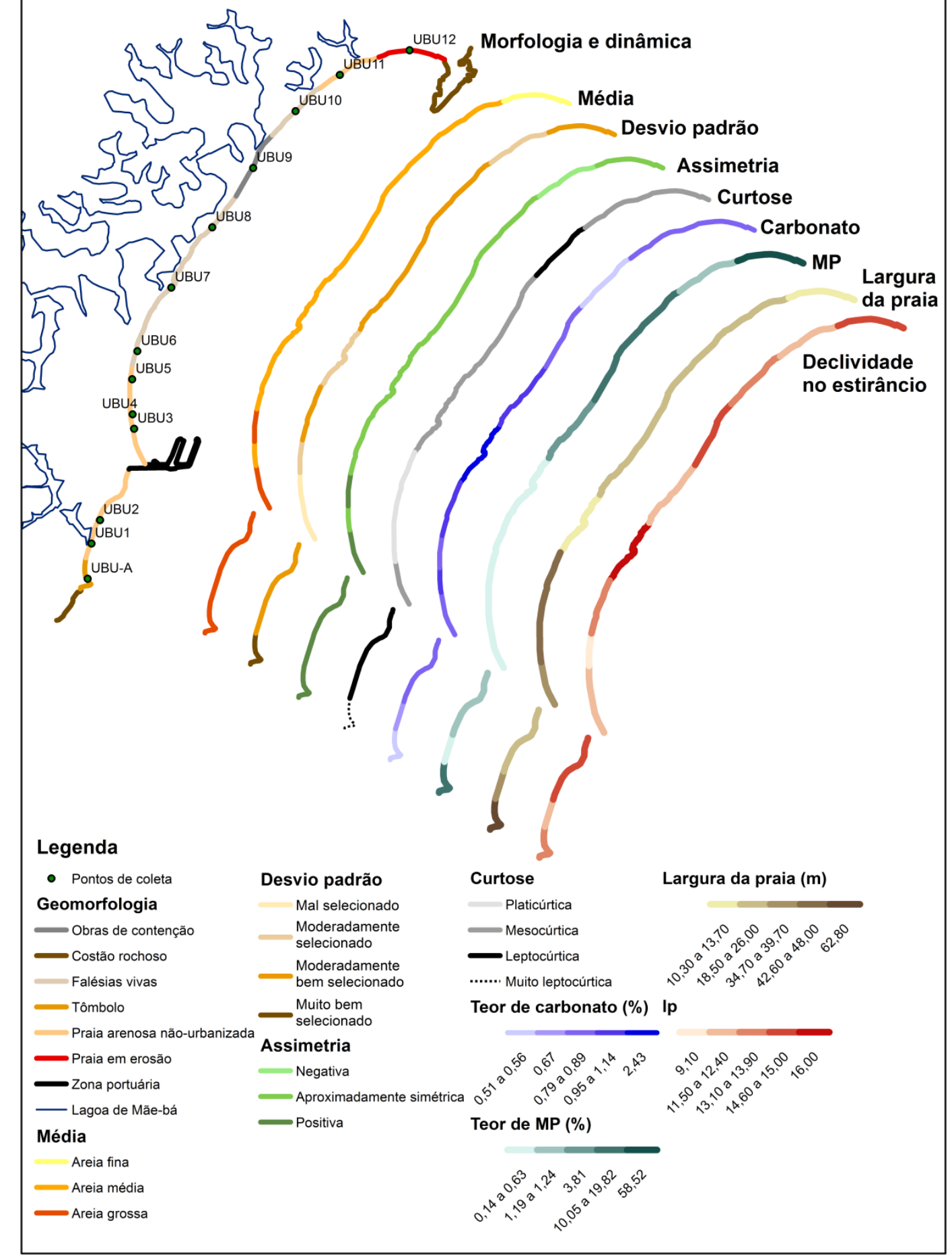

Figura 30: Caracterização sedimentar e geométrica das estações amostrais no setor UBU.

Pela Figura 30 é possível perceber uma tendência de afinamento dos grãos no sentido norte, com assimetria mais negativa. A curtose apresentou também um resultado interessante: os trechos em erosão apresentaram valores baixos, enquanto as praias com 
tendência refletiva apresentaram valores altos do parâmetro. Partindo-se do pressuposto que praias dissipativas são mais energéticas, e as refletivas, menos, pode-se dizer que curtose e energia são inversamente proporcionais, como atesta Souza (1997).

A largura da praia e declividade no estirâncio também seguiram uma correlação espacial: quanto mais se aproxima o norte do setor, menor a praia (por estarem em erosão, principalmente), e menor a declividade.

O teor de MP foi o fator que apresentou melhor correlação espacial, de maneira exponencial, com exceção do setor UBU-11. Esse setor não seguiu o padrão esperado para o local. Indo de sul para norte, é claro o aumento do teor de MP, de uma tendência mais dissipativa para as praias, entretanto a estação indica tendência refletiva, com baixíssimo teor de MP, assimetria positiva, praia em equilíbrio sedimentar, e declividade no estirâncio também maior, como mostra a Figura 30. Pode ser que ao redor desse ponto haja uma nova interação entre as correntes longitudinais, com provável concentração das regiões ao redor.

\subsubsection{Análise de STA no setor UBU}

Apenas a média e a assimetria, novamente, mostraram-se correlacionadas (Figura 31).
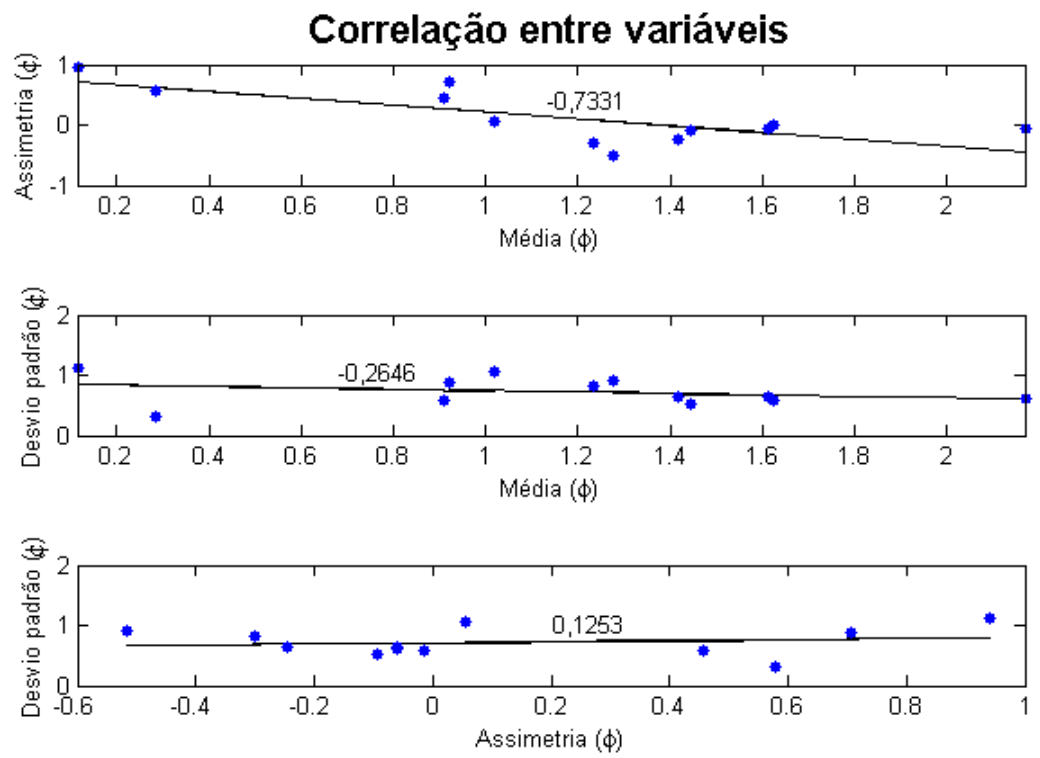

Figura 31: Correlação entre os parâmetros texturais usados na STA para o setor UBU

O ponto que mais destoa no gráfico assimetria x desvio padrão é o UBU-3, localizado exatamente ao sul da zona portuária, com sedimento mais grosso do setor, mas ao mesmo tempo assimetria muito positiva, indicando retirada do sedimento fino associada 
a energia média para alta. A Figura 32 retrata as escarpas de praia encontradas no local, que possui dois bermas, associados a diferentes eventos de tempestade.

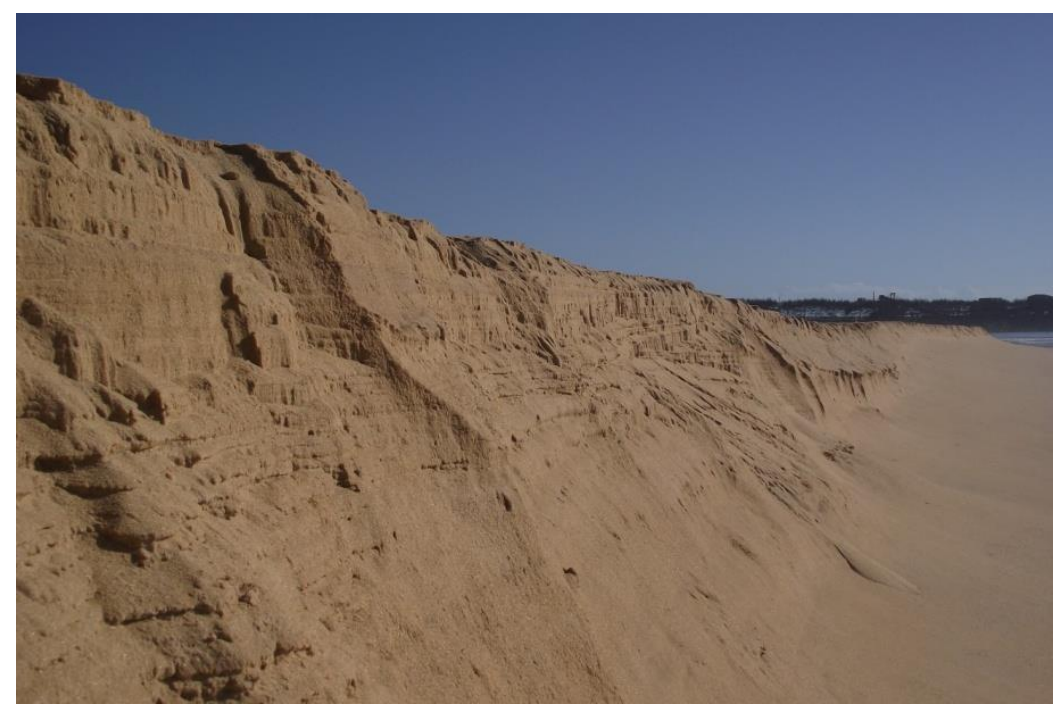

Figura 32: Escarpas na praia do setor UBU-3

A análise STA foi realizada usando todas as amostras e depois usando apenas as situadas ao norte do porto. Através da análise de desvio padrão, percebeu-se que as três primeiras amostras (ao sul do porto) não apresentam correlação espacial com as demais, por conta do próprio efeito de armadilha de sedimento que o píer causa.
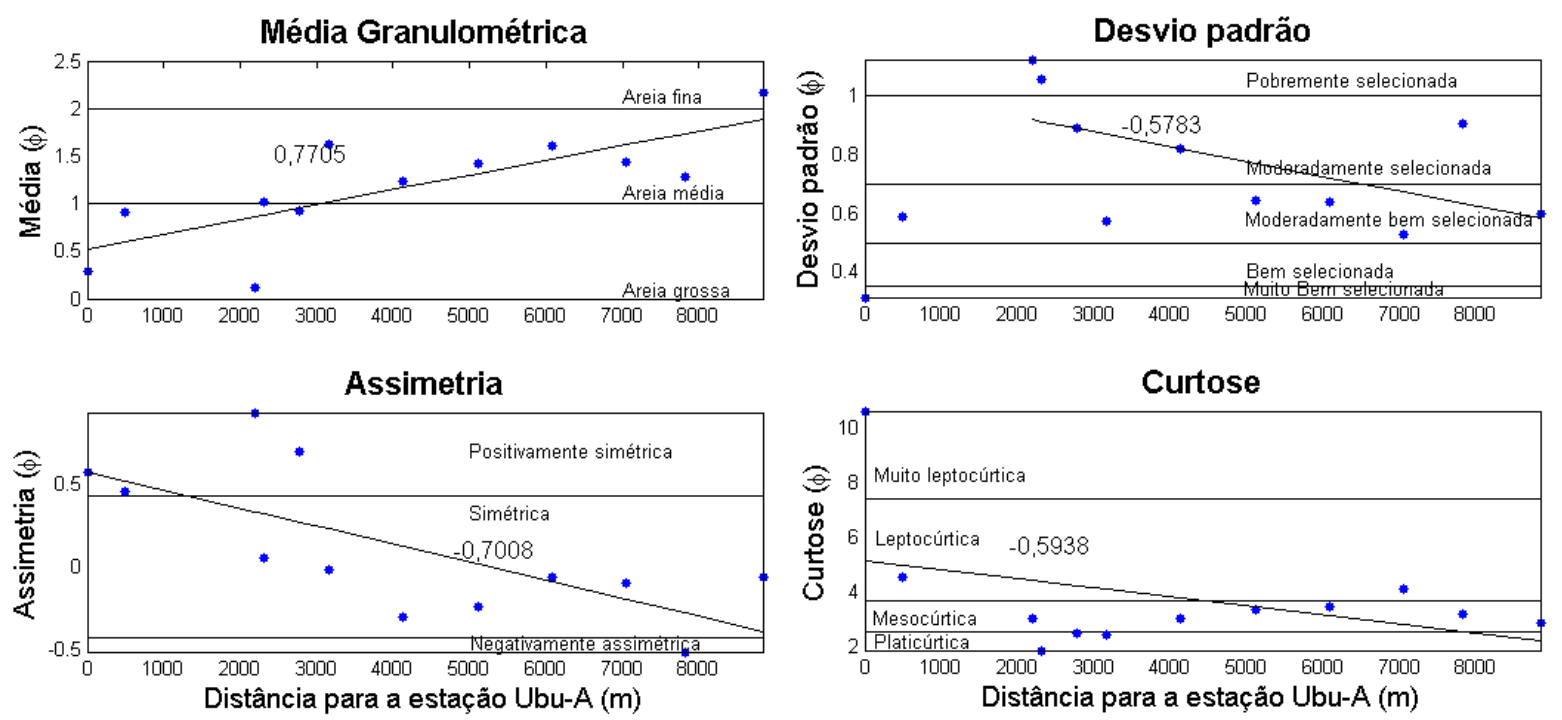

Figura 33: Correlação espacial dos parâmetros no setor UBU

A Figura 33 indica uma tendência FB- para norte. A Tabela 8 indica os resultados obtidos no setor UBU através da análise STA: 
Tabela 8: Resultado da análise STA no setor UBU utilizando todas as amostras

\begin{tabular}{|c|c|c|c|c|}
\hline & \multicolumn{4}{|c|}{$\begin{array}{l}\text { Teste de significância para amostras no } \\
\text { sentido norte }\end{array}$} \\
\hline & $\mathrm{FB}+\mathrm{N}$ & FB-N & $\mathrm{CB}+\mathrm{N}$ & $\mathrm{CB}-\mathrm{N}$ \\
\hline Número de amostras (n) & 12 & 12 & 12 & 12 \\
\hline $\begin{array}{l}\text { Número de pares possíveis } \\
(\mathrm{N})\end{array}$ & 66 & 66 & 66 & 66 \\
\hline $\mathbf{X}$ & 9 & 24 & 1 & 2 \\
\hline $\mathbf{P}$ & 0,125 & 0,125 & 0,125 & 0,125 \\
\hline $\mathbf{Q}$ & 0,875 & 0,875 & 0,875 & 0,875 \\
\hline Teste-Z & 0,279145 & 5,862051 & $-2,6984$ & $-2,32621$ \\
\hline $\begin{array}{l}\text { Teste de significância para } \\
0,05\end{array}$ & rejeita & aceita & rejeita & rejeita \\
\hline \multirow[t]{3}{*}{$\begin{array}{l}\text { Teste de significância para } \\
0,01\end{array}$} & rejeita & aceita & rejeita & rejeita \\
\hline & $\begin{array}{l}\text { Teste de si } \\
\text { sentido sul }\end{array}$ & gnificância & ara amostra & s no \\
\hline & $\mathrm{FB}+\mathrm{N}$ & FB-N & $\mathrm{CB}+\mathrm{N}$ & $\mathrm{CB}-\mathrm{N}$ \\
\hline Número de amostras (n) & 12 & 12 & 12 & 12 \\
\hline $\begin{array}{l}\text { Número de pares possíveis } \\
(\mathrm{N})\end{array}$ & 66 & 66 & 66 & 66 \\
\hline $\mathbf{X}$ & 7 & 2 & 17 & 4 \\
\hline $\mathbf{P}$ & 0,125 & 0,125 & 0,125 & 0,125 \\
\hline Q & 0,875 & 0,875 & 0,875 & 0,875 \\
\hline Teste-Z & $-0,46524$ & $-2,32621$ & 3,256695 & $-1,58182$ \\
\hline $\begin{array}{l}\text { Teste de significância para } \\
0,05\end{array}$ & rejeita & rejeita & aceita & rejeita \\
\hline $\begin{array}{l}\text { Teste de significância para } \\
0,01\end{array}$ & rejeita & rejeita & aceita & rejeita \\
\hline
\end{tabular}

Utilizando todas as amostras, foram aceitos tanto o sentido sul quanto o norte (esse apresentando significância maior); utilizando apenas as amostras ao norte do porto todas as tendências foram rejeitadas.

A Figura 34 representa graficamente o resultado da análise STA para o setor UBU. Depreende-se da análise das figuras resultantes do STA que as escarpas de praia (localizadas nas porções centrais dos setores ITA e PKMA) situam-se na porção sul do setor UBU. Isso se deve provavelmente à erosão que ocorre ao sul do porto. A morfologia da praia, com escarpas bastante pronunciadas, e a análise da linha de costa indicam, entretanto, que a perda de sedimento deva ser no sentido transversal, e não longitudinal. 


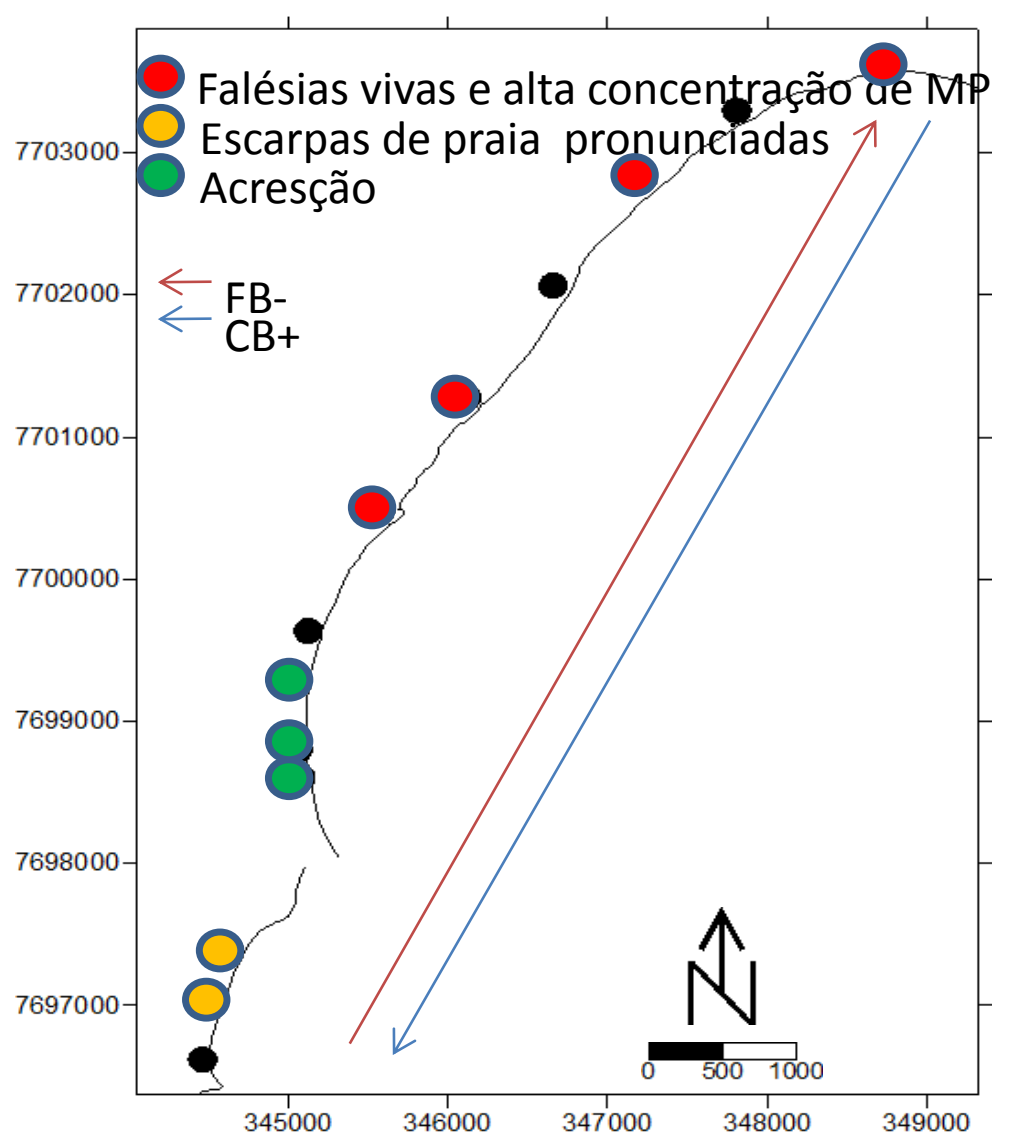

Figura 34: Representação gráfica dos resultados da análise STA para o setor UBU, sendo CB+ o sedimento mais grosso, melhor selecionado e com assimetria mais positiva; FB- o sedimento mais fino, melhor selecionado e com assimetria mais positiva.

$\mathrm{O}$ aceite de ambos os sentidos pode ser um indicativo de estabilidade do setor, com variação de sentido da onda tanto vinda de norte quanto de sul. O que corrobora tal afirmativa é o tômbolo que existe ao sul do porto, indicativo de correntes de S-SE (Figura 35), enquanto a morfologia ao norte do porto indica acúmulo de sedimento de ondas vindo do quadrante N-NE.

Há, entretanto, outra teoria também provável. Ainda que existência do tômbolo e da armadilha de sedimento do porto sejam, juntos, uma prova da variação no sentido da corrente longitudinal, o modelo STA pode mostrar-se tendencioso pelo mesmo motivo justificado no setor PKMA. O alto teor de MP (chegando a 50\% da amostra) faz com que o setor possua, naturalmente, maior quantidade de sedimento fino e assimetria mais positiva. Dessa maneira, a análise STA não é plenamente confiável para a região. 
Ratificam-se os resultados publicados por Albino et al. (2006): todos os pontos do setor UBU encontram-se em erosão, com uma pequena alteração para progradação no Porto de Ubu, e estabilidade na Ponta de Ubu (região do tômbolo).

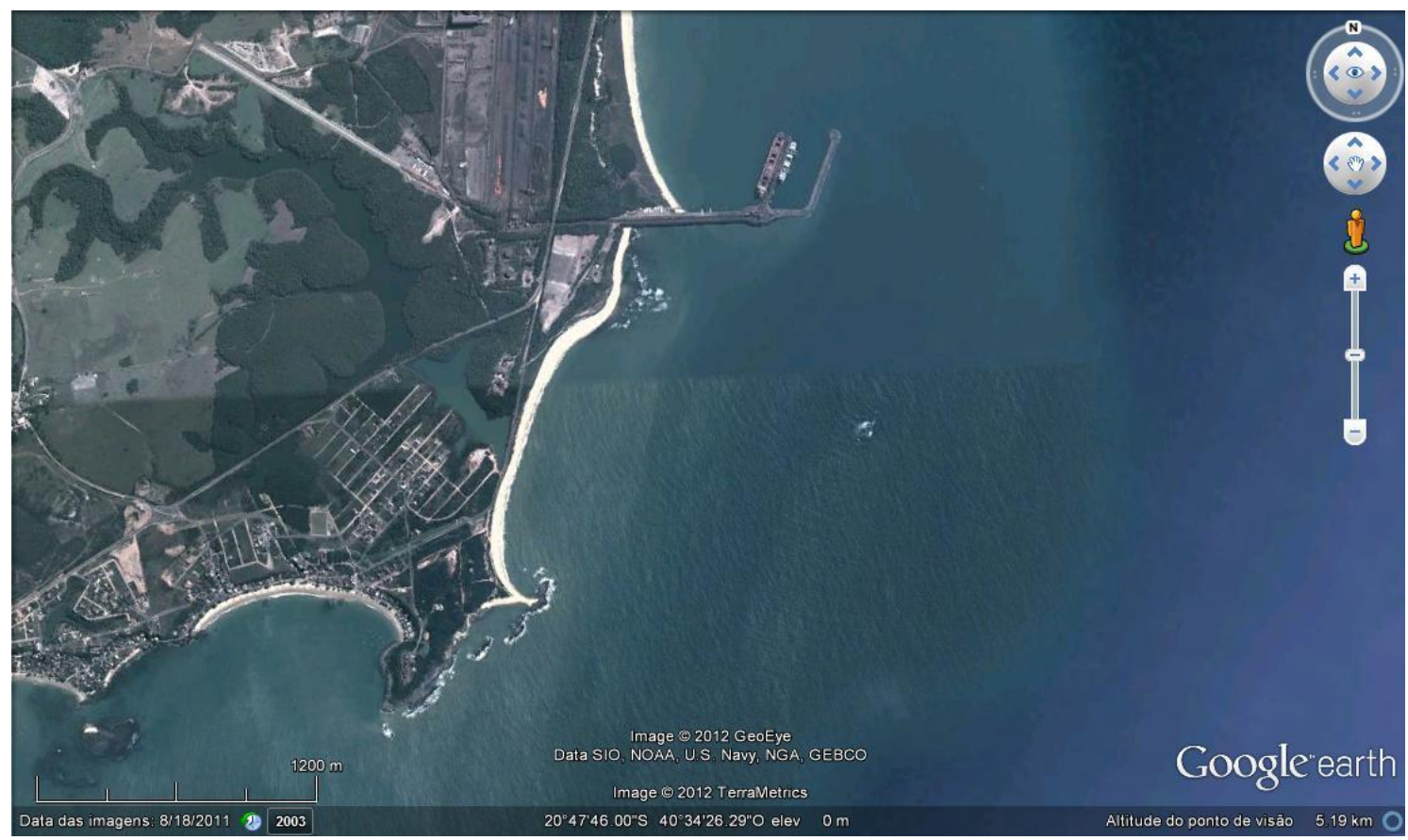

Figura 35: Tômbolo e Porto da SAMARCO no setor UBU. Fonte: Google Earth

\subsection{SETOR VVGU}

\subsubsection{Descrição dos parâmetros no setor VVGU}

A amostragem no setor foi bastante dificultada devido ao acesso. A Unidade de Conservação $(\mathrm{PCV})$ impede o acesso à praia como um todo, sendo possível apenas em alguns trechos. Mais ao norte, outra Unidade de Conservação, a Reserva Estadual de Jacarenema implicou na mesma problemática.

A Figura 36 indica os pontos de coleta do setor. Entre os pontos VVGU-11 e 12, e VVGU-21 e 22 situam-se as Unidades de Conservação previamente citadas, em que não foi possível realizar as coletas. 


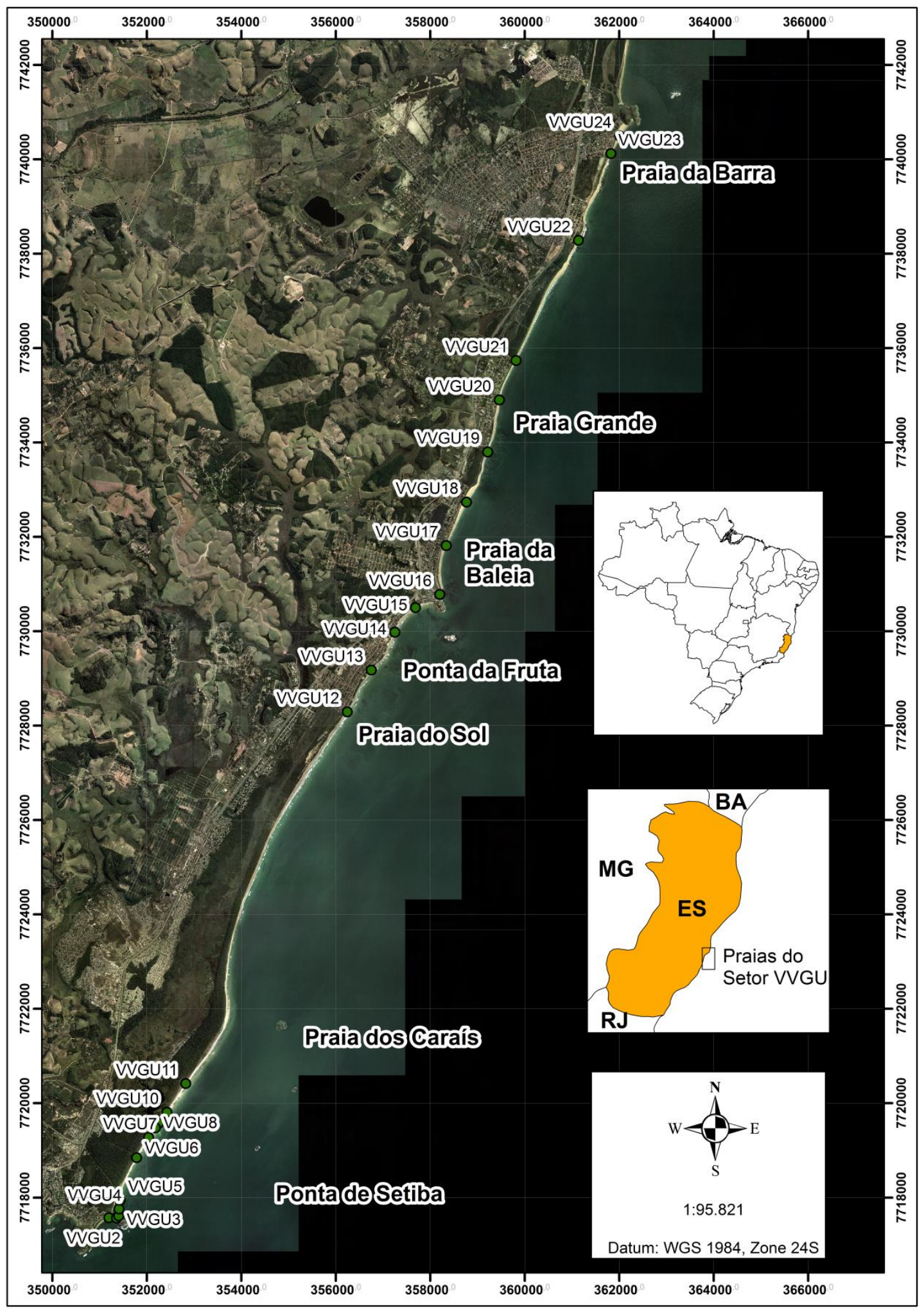

Figura 36: Localização dos pontos de coleta no setor VVGU

Os resultados descritivos do setor VVGU são mostrados na Figura 37: 


\section{Resultados de campo do setor VVGU}

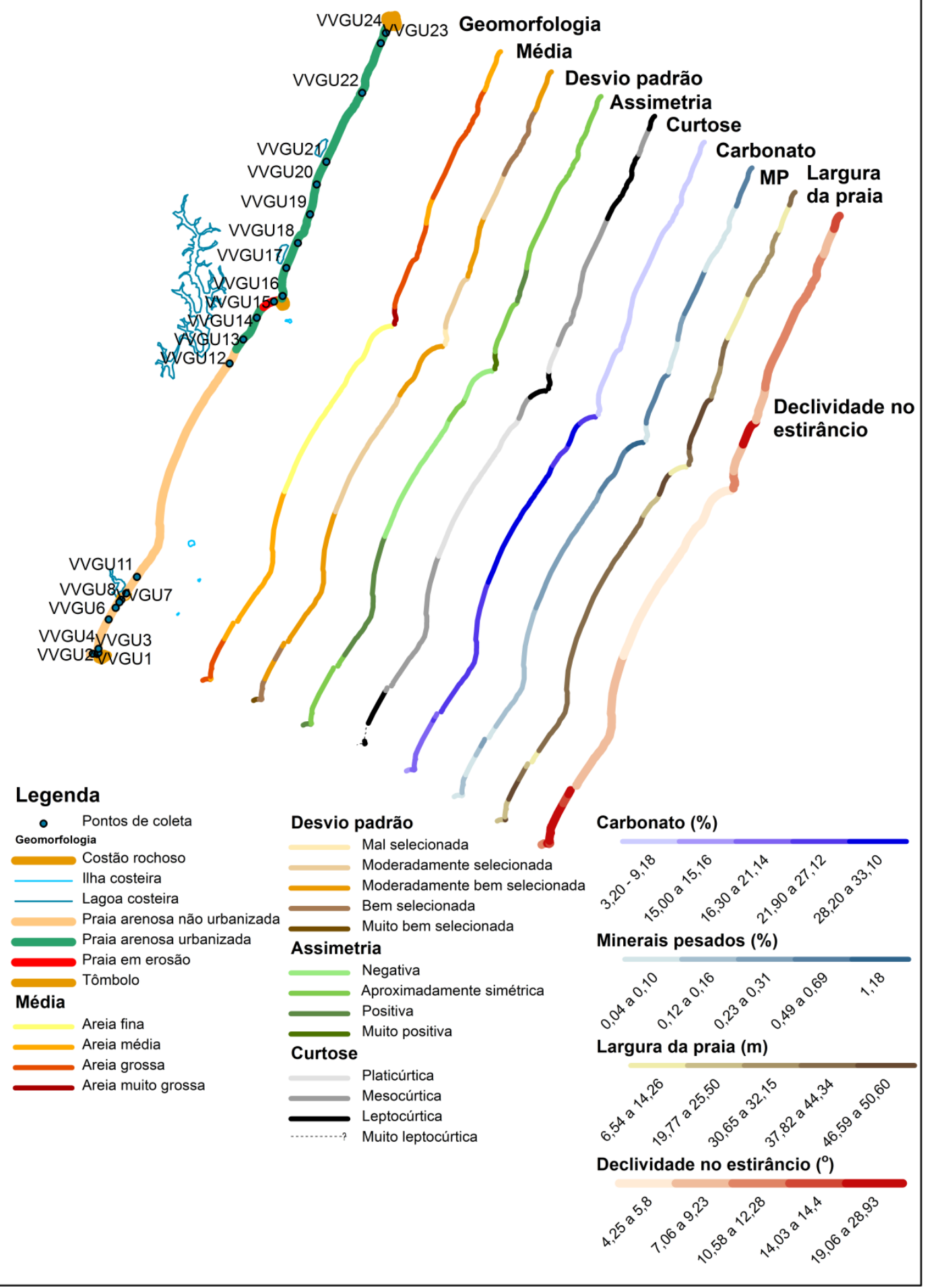

Figura 37: Caracterização sedimentar e geométrica das estações amostrais no setor VVGU

Observa-se claramente a presença de dois setores com propriedades bastante distintas, em que provavelmente não há troca de sedimento. O setor mais ao norte, entre as 
amostras VVGU-16 a 24 mostrou tendência de afinamento para norte, melhora no grau de seleção e assimetria mais negativa.

O setor mais ao sul, da amostra VVGU-1 a 15 mostra tendência muito clara para norte de afinamento, piora no grau de seleção, assimetria mais negativa, diminuição da curtose (tendência platicúrtica) e aumento no teor de carbonato e de MP (ainda que o teor mais alto não ultrapasse os $1,18 \%$, refletindo diferenças litológicas com o setor UBU, apesar da proximidade). A diminuição da declividade é marcante entre as amostras 1 e 8, mas nas outras não fica tão visível, provavelmente devido à distância. $\mathrm{O}$ parâmetro largura da praia não mostrou tendências marcantes.

Entre as amostras VVGU-12 e VVGU-24 a tendência de aumento da declividade é clara, o que reflete em praias com características intermediárias tendendo a refletivas, mas sem tendências evidentes de mudança no parâmetro largura de praia.

O setor VVGU-18, entretanto, foge dessa tendência abruptamente. Quando se analisa a fotografia aérea local, percebe-se o controle geológico exercido pelos arenitos de praia influenciando na sua morfologia, como mostrado na Figura 38. Albino (1996) atesta que durante a passagem de frentes frias, que carregam o sedimento para norte, os arenitos funcionam como armadilha do sedimento. Enquanto nas porções ao sul há mudança na morfologia de praia durante esses eventos, as estações ao norte permanecem praticamente sem modificações.

A Figura 38 ilustra o efeito descrito. Isso pode ser explicado pelas correntes de sul trazendo sedimento e não sendo capaz de passar pelo extenso terraço de arenito mais ao norte, o que deixa a praia mais estreita. A Figura 39 mostra a fotografia em campo desse setor. 


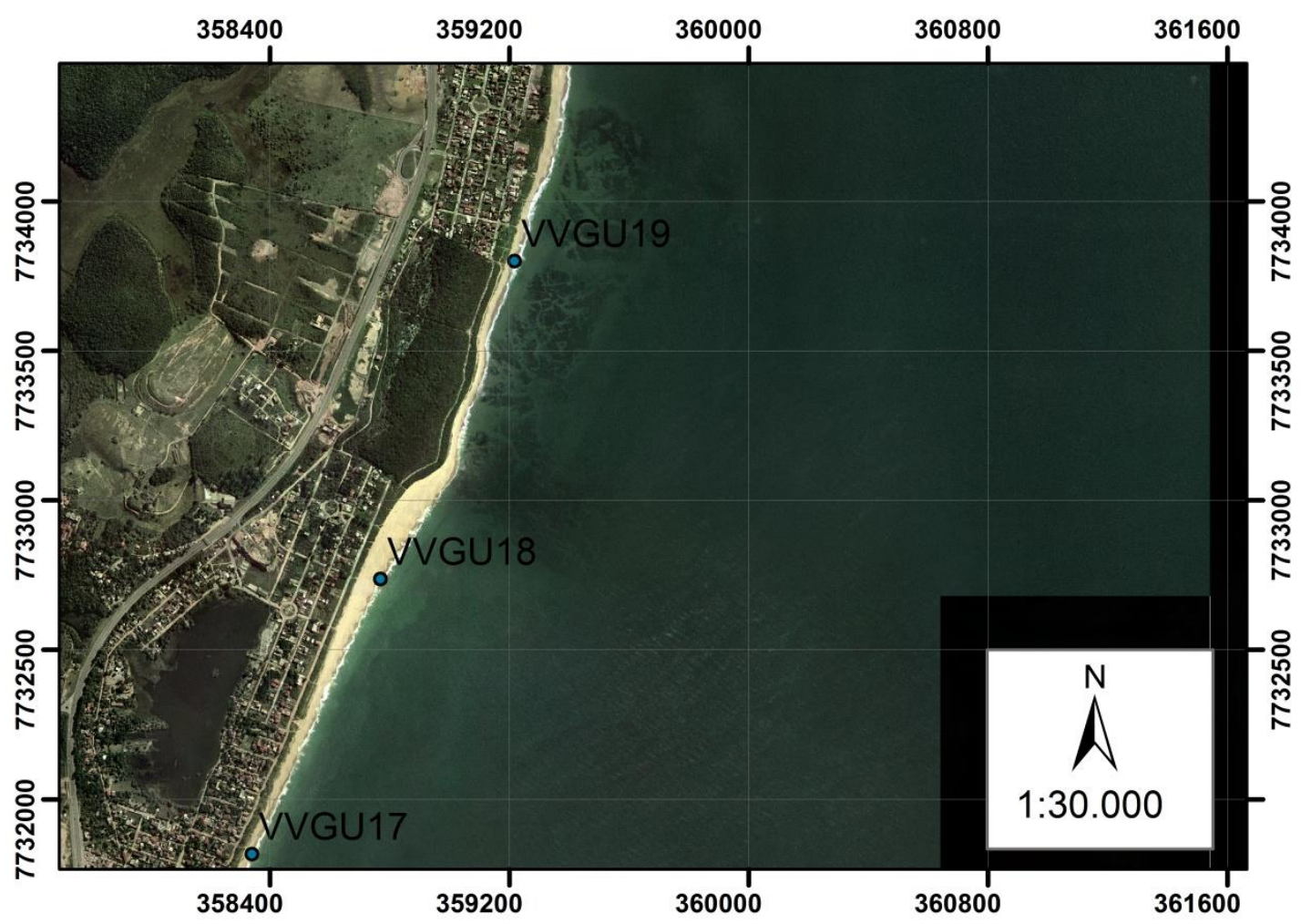

Figura 38: Arenitos de praia controlando a dinâmica oceanográfica no setor VVGU-18

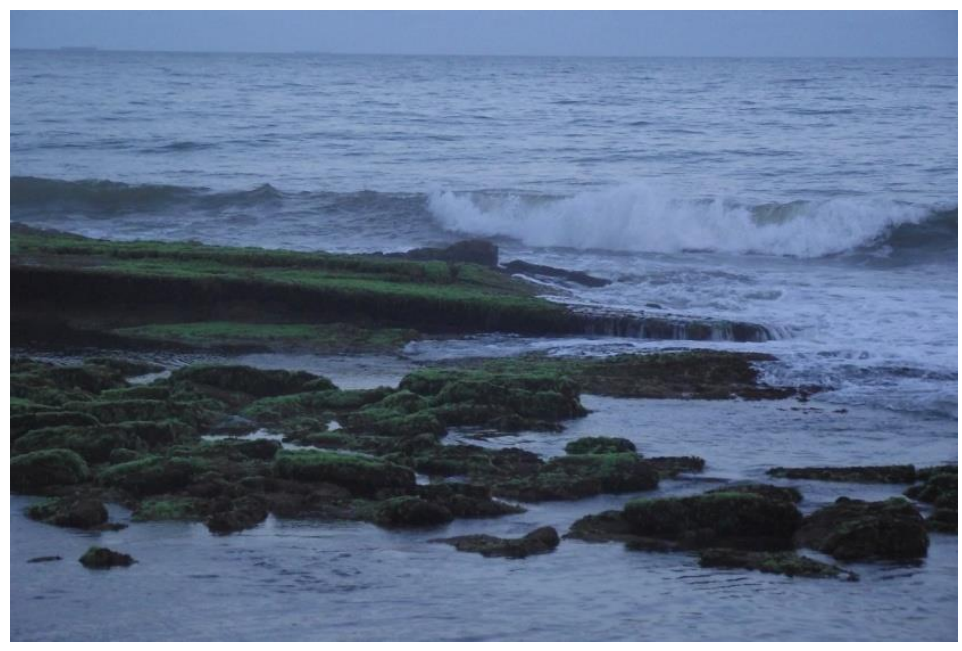

Figura 39: Fotografia em campo dos arenitos de praia (Praia do Sol)

\subsubsection{Análise de STA para o Setor VVGU}

Fazendo-se a correlação entre as variáveis, novamente apenas a assimetria com a média mostraram-se correlacionáveis (maior valor de $r^{2}$ ), como mostra a Figura 40. 

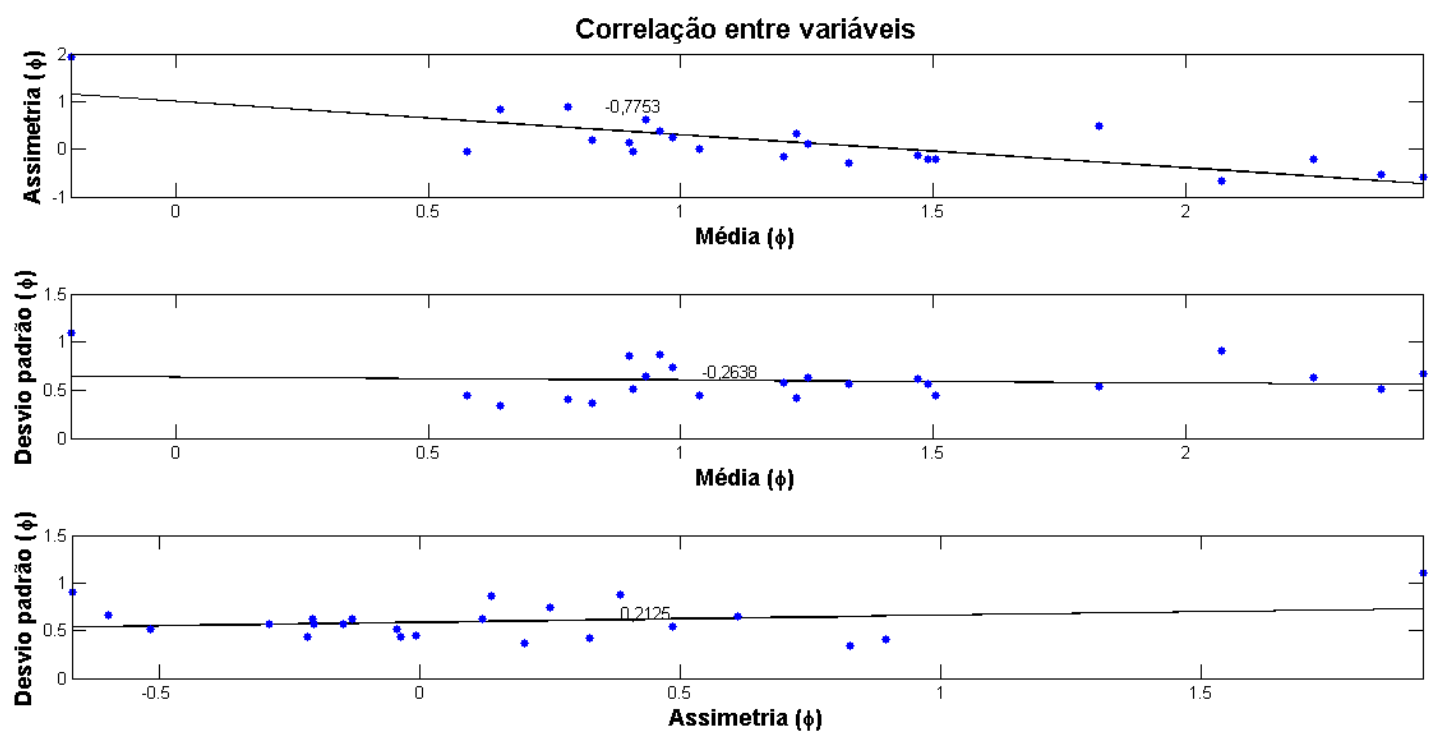

Figura 40: Correlação entre os parâmetros texturais usados na STA para o setor VVGU

Nos três gráficos é possível observar um ponto fora da curva (à esquerda nos dois gráficos superiores, e à direita no gráfico inferior). $\mathrm{O}$ ponto corresponde à estação VVGU-16, onde são observados os arenitos de praia submersos, correspondendo ao mesmo efeito explicado na seção 6.1.1.

A correlação espacial das variáveis mostrou valores bem confiáveis até mesmo visualmente, apesar da distância longa sem amostragem (Figura 41).
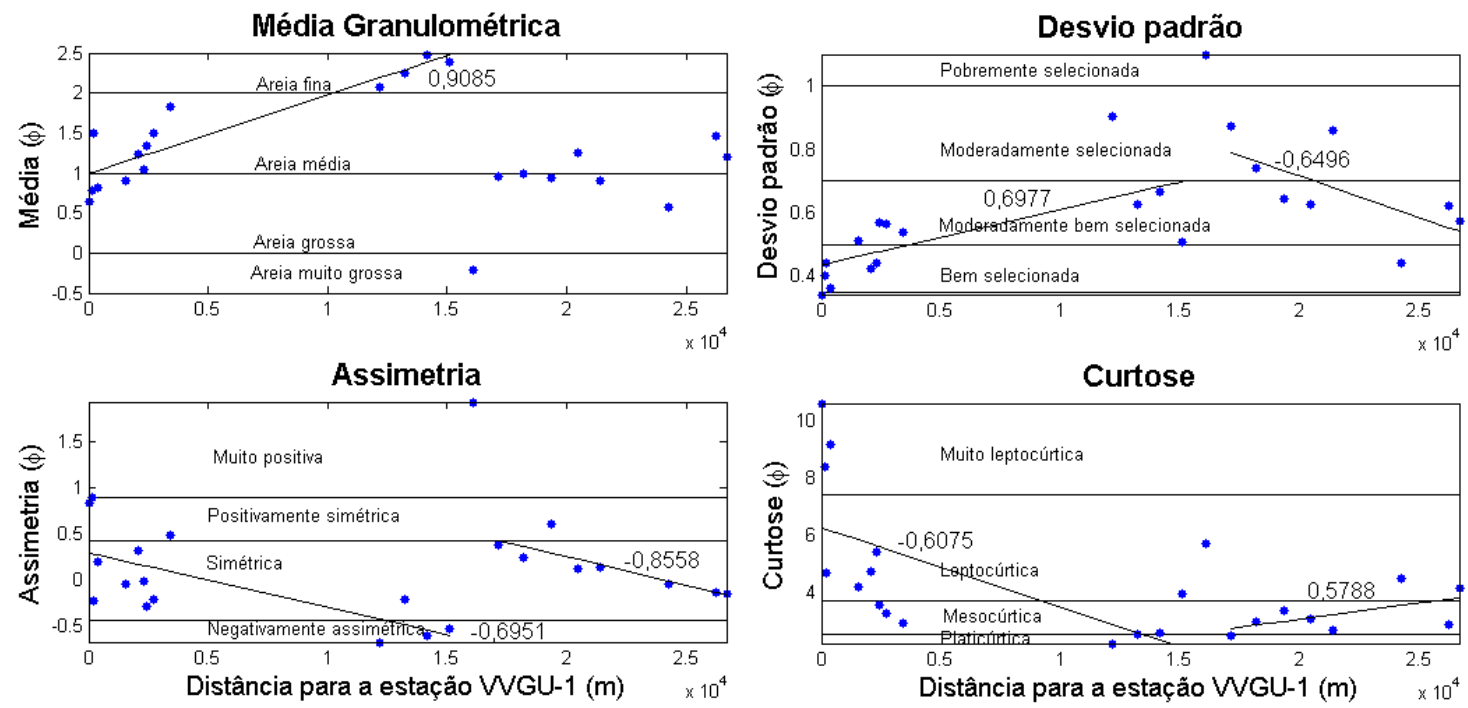

Figura 41: Correlação espacial dos parâmetros texturais no setor VVGU

A Figura 41 ratifica a presença de dois setores bem marcantes para todas as variáveis. Como dito, entre as amostras VVGU-1 e VVGU-15 pode ser observado um afinamento 
das amostras para norte, com piora na seleção, assimetria e curtose mais negativa. Entre as amostras VVGU-16 e VVGU-24 não há tendência significativa na média, mas há melhora de seleção para norte, com assimetria mais negativa e curtose mais positiva.

\subsubsection{Resultado da análise STA para o setor VVGU}

A análise de STA para o setor VVGU foi feita considerando-se todas as estações, posteriormente agrupando-as entre as supracitadas. $\mathrm{O}$ resultado encontra-se expresso na Tabela 9.

Tabela 9: Resultado da análise de STA para o setor VVGU

\begin{tabular}{ll}
\hline Estações utilizadas & Tendência \\
\hline Todas & $\mathrm{CB}+$ para sul \\
1 a 15 & $\mathrm{CB}+$ para sul \\
16 a 24 & $\mathrm{CB}$ - para norte \\
\hline
\end{tabular}

De acordo com os resultados obtidos, pode-se afirmar, como esperado, que não há resultados significativos quando se consideram todas as amostras do setor.

Quando se consideram os dois setores separadamente, a tendência para sul no setor sul, e para norte no setor norte fica evidente com alto grau de certeza, e é corroborada pela geomorfologia. A Figura 42 apresenta os resultados obtidos: 


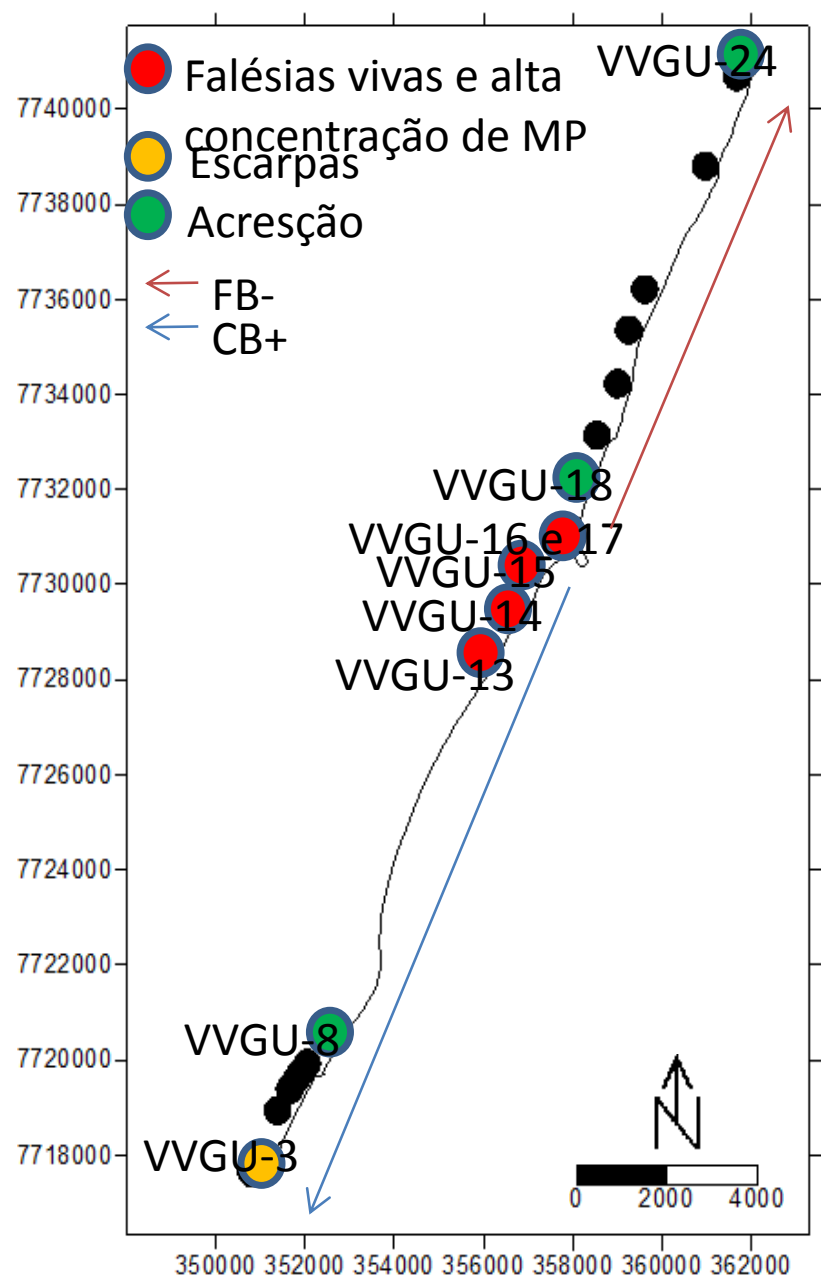

Figura 42: Representação gráfica dos resultados da análise de STA para o setor VVGU, sendo CB+ o sedimento mais grosso, melhor selecionado e com assimetria mais positiva; FB- o sedimento mais fino, melhor selecionado e com assimetria mais positiva.

No setor VVGU o controle geológico é exercido nas duas extremidades (tômbolo ao sul e promontório na foz do Rio Jucu) e na parte intermediária, na Ponta da Fruta. Nesse local ocorre inversão no padrão de transporte de sedimento, que passa a ser transportado para norte com o padrão FB-.

Por fim, a análise do presente trabalho discorda do resultado apresentado por Albino et al. (2006), classificando as praias de Ponta da Fruta e de do Sol como em retrogradação, atuando como fonte de sedimento para o sul e norte, respectivamente.

\subsection{SETOR VL}

\subsubsection{Análise de STA para o setor VL}


Em campo apenas na estação VL-3 foi encontrada evidência de erosão, com trecho da estrada que beira a praia destruída. O setor pertence ao município de Vila Velha, município mais populoso do estado, segundo o censo 2010 realizado pelo IBGE.

A foz do rio Jucu, que marca o sul do trecho é controlada por um promontório rochoso, e não foi analisada nas imagens e fotografias aéreas por não apresentar variações significativas.

A Figura 43 indica os pontos de coleta do setor. 


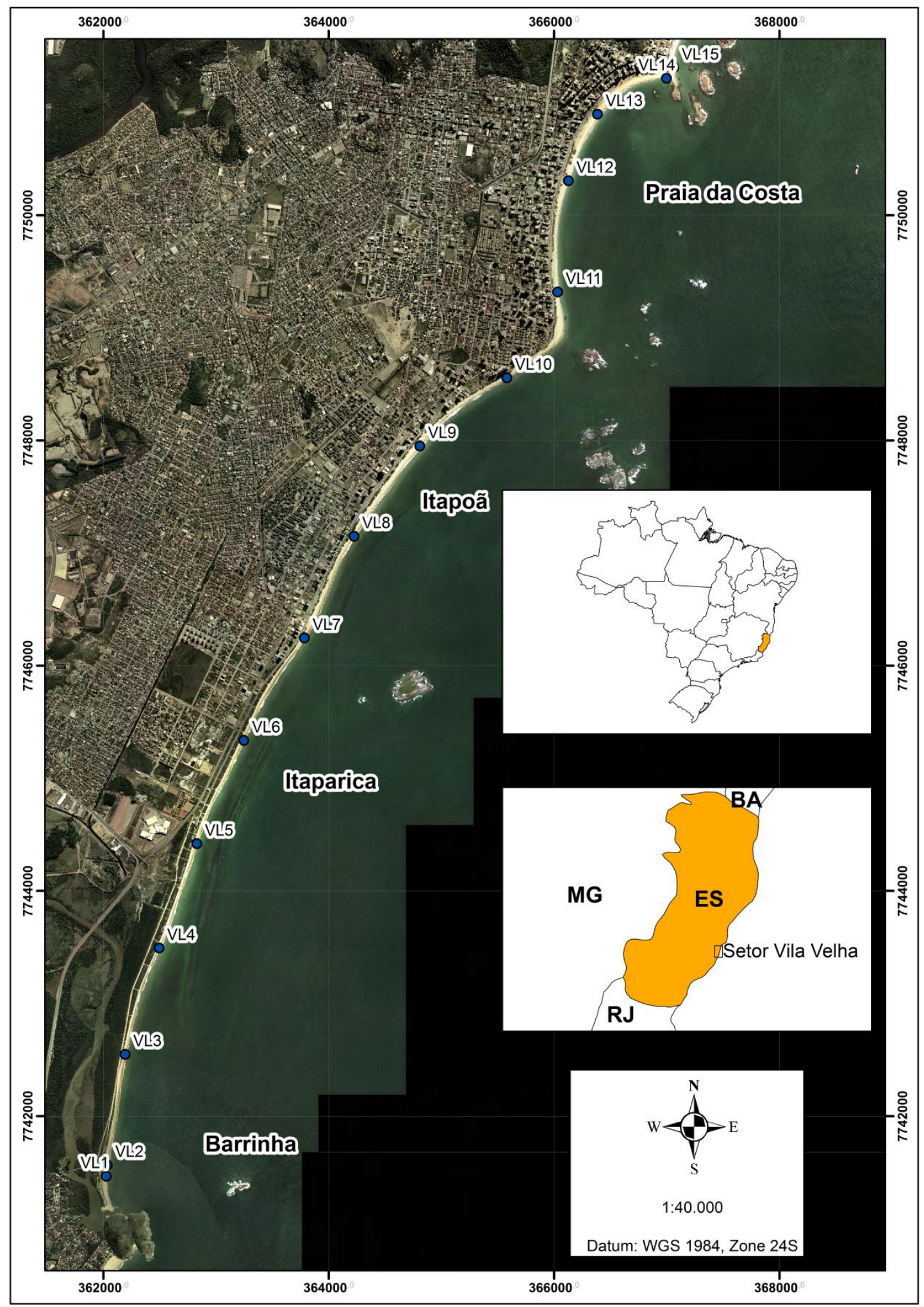

Figura 43: Localização dos pontos de coleta no setor VL

A mudança na orientação da linha de costa ao norte do setor VL-10 (Figura 43), acompanhado por um grande número de ilhas e promontórios rochosos que causam a refração de ondas no local. Nesse ponto fica evidente a maior concentração de MP, 
carbonato, curtose, maior largura da praia e menor declividade. A curtose alta pode estar relacionada à presença das ilhas costeiras barrando a entrada da frente de ondas, gerando zona de sombra.

A Figura 44 indica os resultados em campo do setor. Nota-se uma tendência de afinamento da média granulométrica para norte, melhora no desvio padrão, e assimetria mais negativa. 


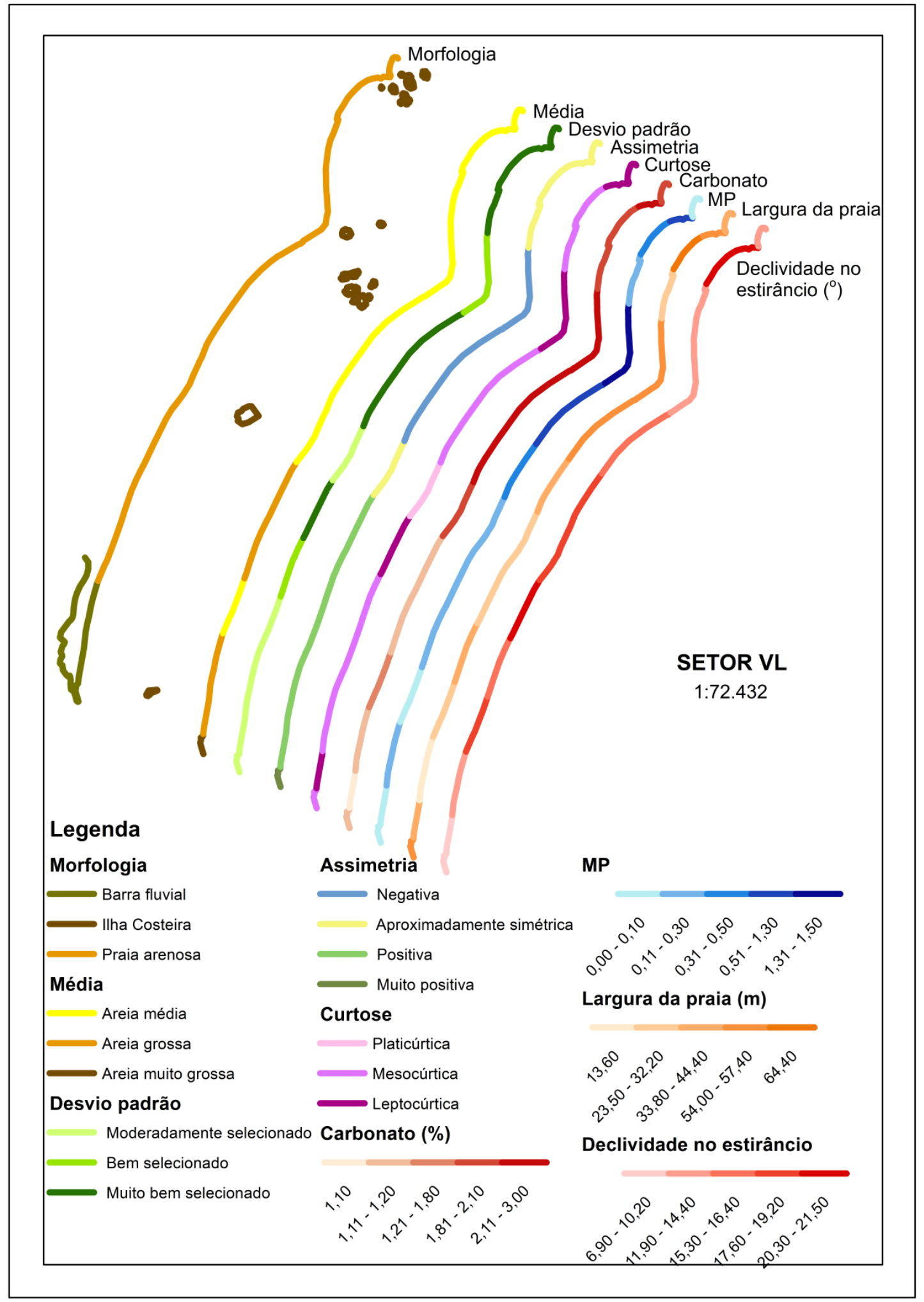

Figura 44: Caracterização sedimentar e geométrica das estações amostrais no setor VL 
As variáveis texturais no setor VL mostraram-se altamente correlacionáveis, atingindo os maiores fatores, como mostra a Figura 45.
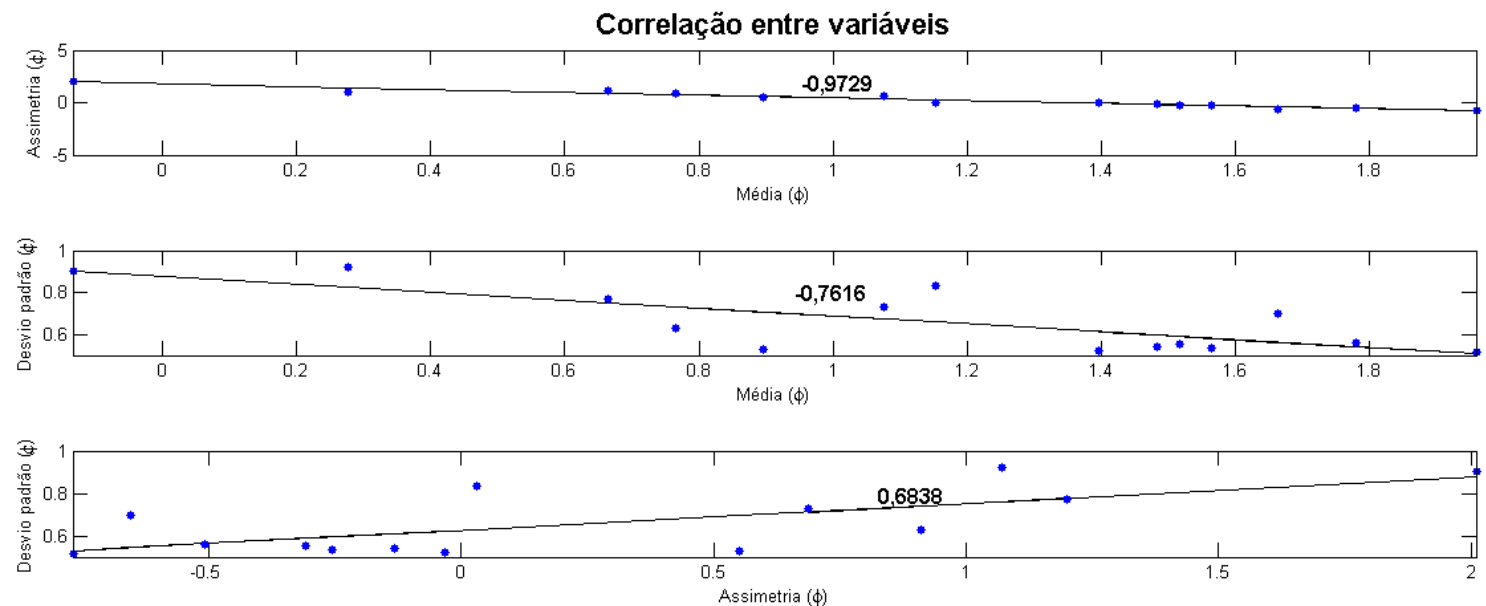

Figura 45: Correlação entre os parâmetros texturais usados na STA para o setor VL

Da mesma maneira, a correlação espacial das variáveis mostrou-se alta, havendo clara divisão entre as estações VL-1 e 9 e entre as estações VL-10 e 14.
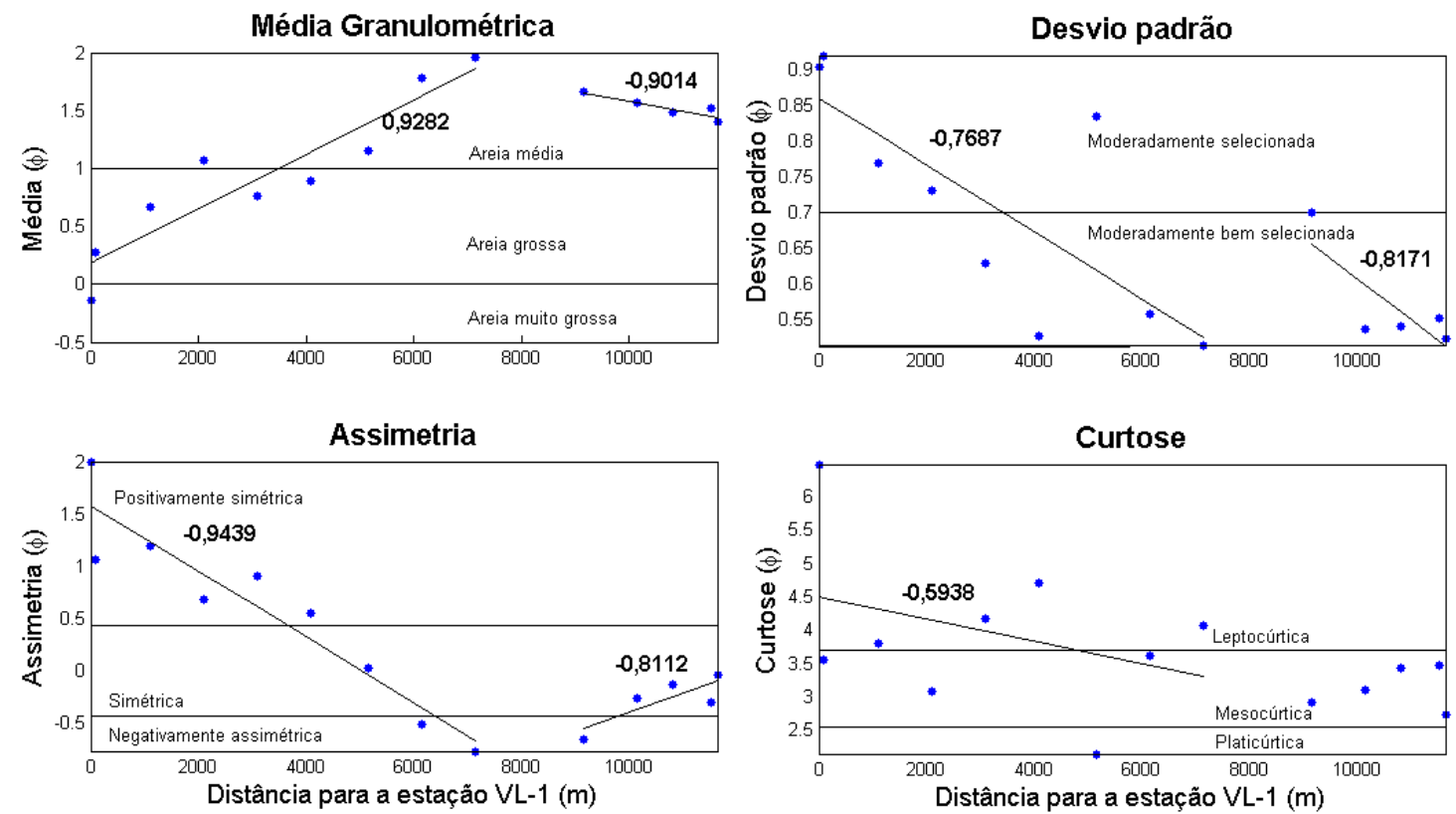

Figura 46: Correlação espacial dos parâmetros texturais no setor VL

Fica clara a tendência FB- para norte através da visualização da figura acima. Como não é possível realizar a análise STA para 4 amostras, essa foi realizada apenas entre as 9 primeiras, como mostra a Tabela 10: 
Tabela 10: Resultado da análise STA para o setor VL

\begin{tabular}{|c|c|c|c|c|}
\hline \multirow[t]{2}{*}{ Todas as amostras } & \multicolumn{4}{|c|}{$\begin{array}{l}\text { Teste de significância para amostras no } \\
\text { sentido norte }\end{array}$} \\
\hline & $\mathrm{FB}+\mathrm{N}$ & FB-N & $\mathrm{CB}+\mathrm{N}$ & $\mathrm{CB}-\mathrm{N}$ \\
\hline número de amostras (n) & 16 & 16 & 16 & 16 \\
\hline $\begin{array}{l}\text { número de pares possíveis } \\
(\mathrm{N})\end{array}$ & 120 & 120 & 120 & 120 \\
\hline $\mathbf{x}$ & 1 & 57 & 12 & 1 \\
\hline $\mathbf{p}$ & 0,125 & 0,125 & 0,125 & 0,125 \\
\hline $\mathbf{q}$ & 0,875 & 0,875 & 0,875 & 0,875 \\
\hline teste-Z & $-3,864367$ & 11,5931 & $-0,82808$ & $-3,86437$ \\
\hline $\begin{array}{l}\text { teste de significância para } \\
0,05\end{array}$ & rejeita & aceita & rejeita & rejeita \\
\hline $\begin{array}{l}\text { teste de significância para } \\
0,01\end{array}$ & rejeita & aceita & rejeita & rejeita \\
\hline \multicolumn{5}{|l|}{ Nível de significancia } \\
\hline \multirow[t]{2}{*}{ Todas as amostras } & $\begin{array}{l}\text { Teste de sigr } \\
\text { sul }\end{array}$ & ificância pa & ra amostras & no sentido \\
\hline & $\mathrm{FB}+\mathrm{N}$ & FB-N & $\mathrm{CB}+\mathrm{N}$ & CB-N \\
\hline número de amostras (n) & 16 & 16 & 16 & 16 \\
\hline $\begin{array}{l}\text { número de pares possíveis } \\
(\mathrm{N})\end{array}$ & 120 & 120 & 120 & 120 \\
\hline $\mathbf{x}$ & 2 & 6 & 12 & 0 \\
\hline $\mathbf{p}$ & 0,125 & 0,125 & 0,125 & 0,125 \\
\hline $\mathbf{q}$ & 0,875 & 0,875 & 0,875 & 0,875 \\
\hline teste-Z & $-3,588341$ & $-2,48424$ & $-0,82808$ & $-4,14039$ \\
\hline $\begin{array}{l}\text { teste de significância para } \\
0,05\end{array}$ & rejeita & rejeita & rejeita & rejeita \\
\hline $\begin{array}{l}\text { teste de significância para } \\
0,01\end{array}$ & rejeita & rejeita & rejeita & rejeita \\
\hline \multirow[t]{2}{*}{ Amostras 1 a 9} & \multicolumn{4}{|c|}{ Teste de significância para amostras no sentido norte } \\
\hline & $\mathrm{FB}+\mathrm{N}$ & FB-N & $\mathrm{CB}+\mathrm{N}$ & CB-N \\
\hline número de amostras (n) & 16 & 16 & 16 & 16 \\
\hline $\begin{array}{l}\text { número de pares possíveis } \\
(\mathrm{N})\end{array}$ & 120 & 120 & 120 & 120 \\
\hline $\mathbf{x}$ & 1 & 27 & 1 & 1 \\
\hline $\mathbf{p}$ & 0,125 & 0,125 & 0,125 & 0,125 \\
\hline q & 0,875 & 0,875 & 0,875 & 0,875 \\
\hline teste-Z & $-3,864367$ & 3,312315 & $-3,86437$ & $-3,86437$ \\
\hline $\begin{array}{l}\text { teste de significância para } \\
0,05\end{array}$ & rejeita & aceita & rejeita & rejeita \\
\hline $\begin{array}{l}\text { teste de significância para } \\
0,01\end{array}$ & rejeita & aceita & rejeita & rejeita \\
\hline
\end{tabular}




\begin{tabular}{|c|c|c|c|c|}
\hline & $\mathrm{FB}+\mathrm{N}$ & FB-N & $\mathrm{CB}+\mathrm{N}$ & CB-N \\
\hline número de amostras (n) & 9 & 9 & 9 & 9 \\
\hline $\begin{array}{l}\text { número de pares possíveis } \\
\text { (N) }\end{array}$ & 36 & 36 & 36 & 36 \\
\hline $\mathbf{x}$ & 0 & 0 & 6 & 0 \\
\hline $\mathbf{p}$ & 0,125 & 0,125 & 0,125 & 0,125 \\
\hline $\mathbf{q}$ & 0,875 & 0,875 & 0,875 & 0,875 \\
\hline teste-Z & $-2,267787$ & $-2,26779$ & $-2,48424$ & $-2,26779$ \\
\hline $\begin{array}{l}\text { teste de significância para } \\
0,05\end{array}$ & rejeita & rejeita & rejeita & rejeita \\
\hline $\begin{array}{l}\text { teste de significância para } \\
0,01\end{array}$ & rejeita & rejeita & rejeita & rejeita \\
\hline
\end{tabular}

A Tabela 10 (representada na Figura 47) indica claramente a tendência de transporte de sedimento no sentido norte para o setor VL, quando se consideram as amostras 1 a 9 ou mesmo quando todas são consideradas.

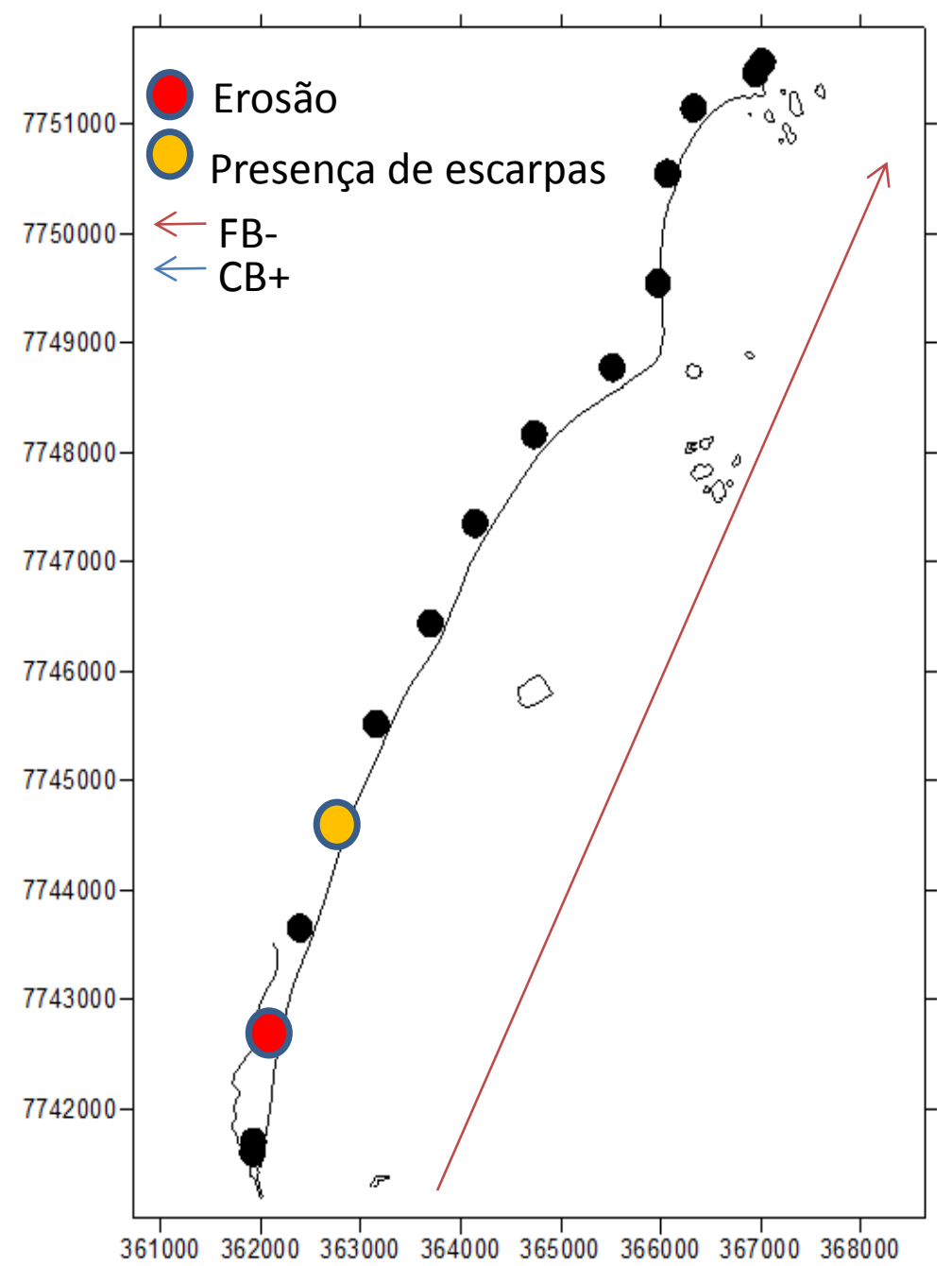

Figura 47: Representação gráfica dos resultados de STA para o setor VL, sendo FB- o sedimento mais fino, melhor selecionado e com assimetria mais positiva.

\subsubsection{Resultados da análise STA nos setores conjuntamente}


A Figura 48 apresenta os resultados das análises STA de todos os setores. Com exceção do setor PKMA, todos apresentaram a tendência FB- para norte e CB+ para sul, tendência que foi observada no campo.

Nos setores ao sul (PKMA, ITA e UBU), os parâmetros texturais do sedimento apresentaram correlação menor do que as dos setores ao norte (Figura 14, Figura 24, Figura 31, Figura 40 e Figura 45), o que atribui menor confiabilidade aos resultados.

Da mesma maneira, o nível de confiança dos resultados da análise STA mostraram-se menores nos arcos praiais ao sul comparativamente aos do norte. A presença de rios e alto teor de MP nos setores PKMA e ITA e a orientação da linha de costa mais variável nos três setores (somados ao UBU) são prováveis fatores que mascaram os resultados da análise STA. Quando se considera a entrada de sedimento dos rios, das falésias vivas e dos promontórios rochosos, ou seja, diferentes fácies sedimentares, os resultados são mascarados na análise STA, como o próprio autor afirma (McLaren et al., 2007), além de outras críticas, como de Masselink (1992).

A análise do software GSTAST não discordou da análise STA, apresentando apenas vetores com maiores níveis de confiança. 


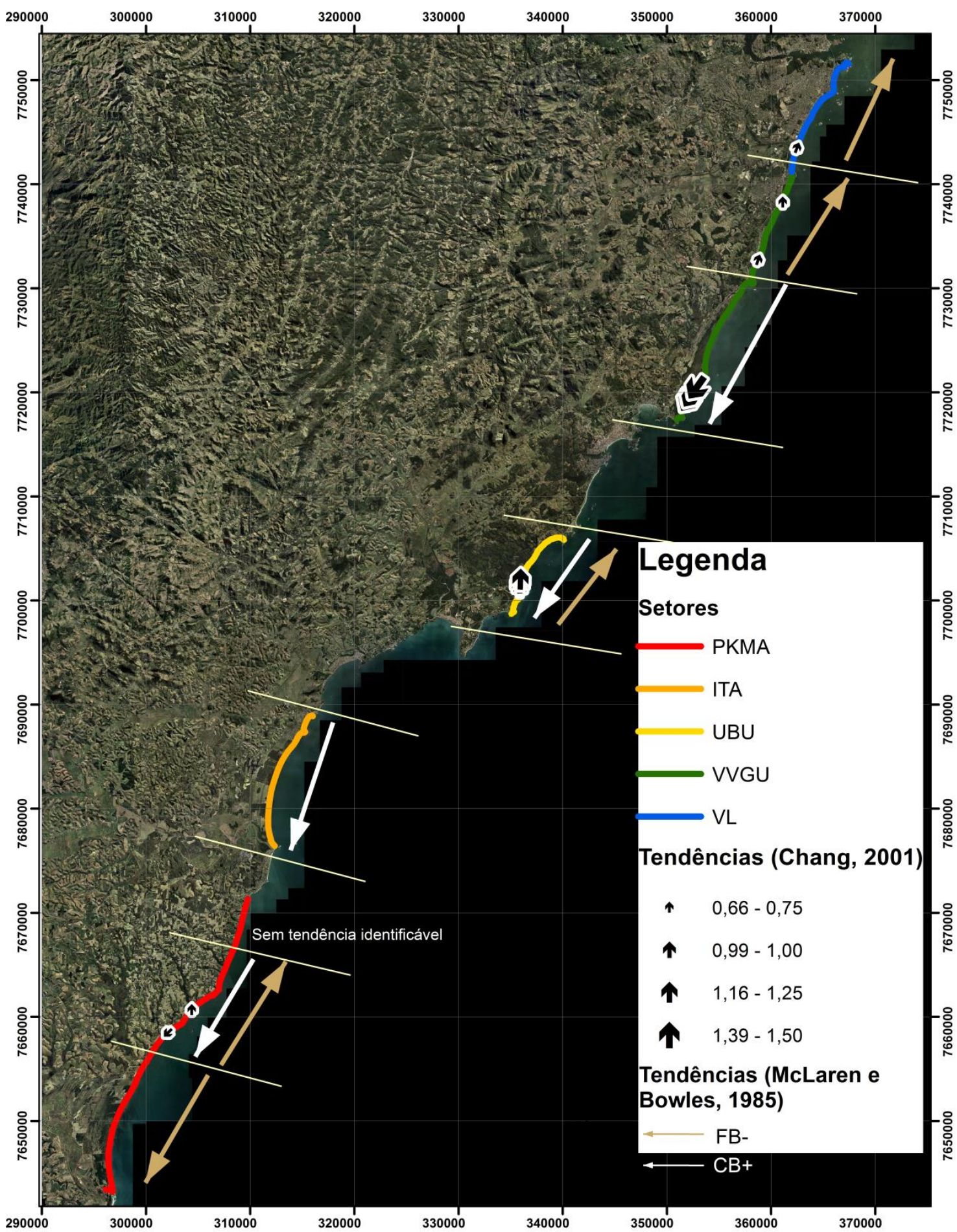

Figura 48: Análise STA em todos os setores conjuntamente 


\subsection{Análise de ondas do modelo WWIII}

Considerando todos os anos estudados, a Figura 49 indica o clima de ondas predominante para a região oceânica do sul do Espírito Santo. Os resultados de análise de climatologia geral são apresentados com resolução de $0,5 \mathrm{~m} ; 1,0$ s e $22,5^{\circ}$ de direção. Para os dados sazonais a resolução apresentada é de mesmo Hs e T, porém com $45^{\circ}$ na direção, a fim de simplificar a visualização, como sugerido por Pinho (2003) e Holthujsen (2007).
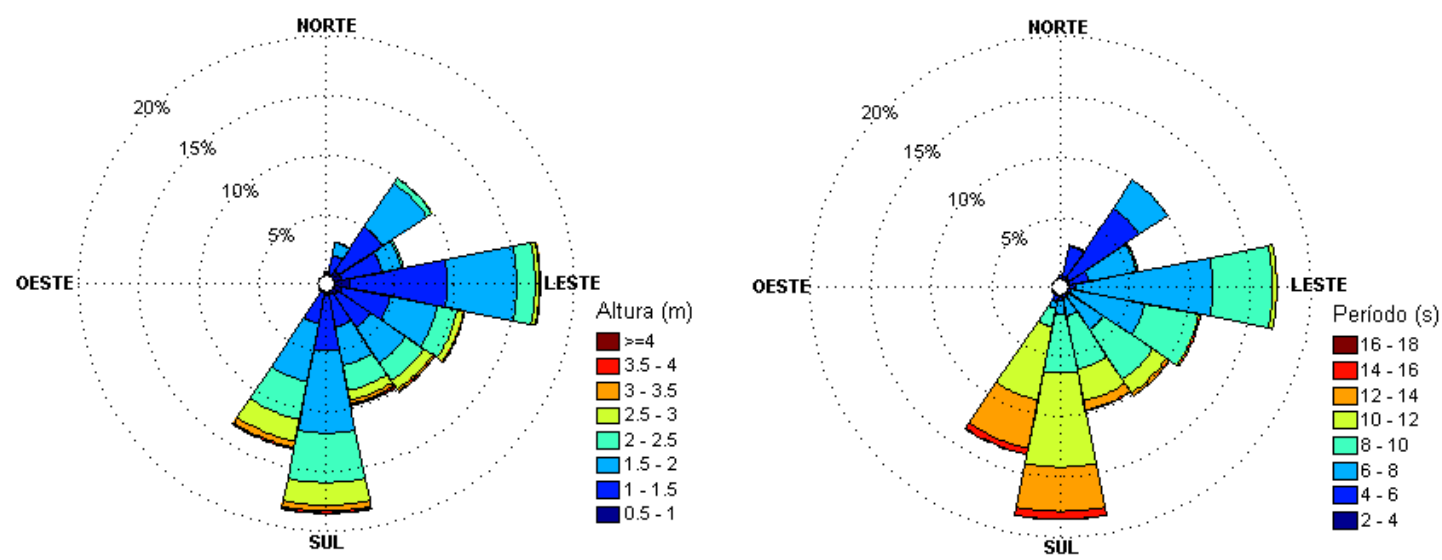

Figura 49: Clima de ondas na região sul Espíritossantense entre os anos de 1997 e 2010, modelados através do WWIII

As Figura 50,Figura 51,Figura 52 e Figura 53 indicam a média de cada estação do ano, dentro do período considerado:

\section{Verão}



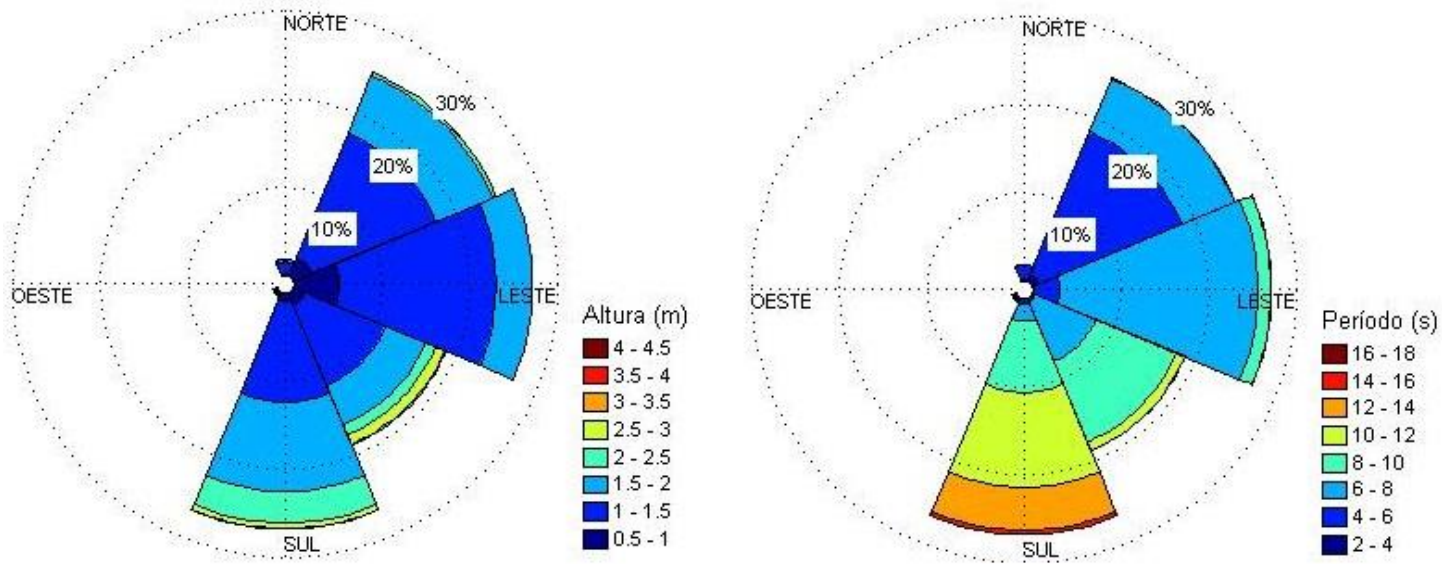

Figura 50: Rosa de ondas (altura e período) para o verão entre os anos 1997 e 2010

O padrão de ondas durante o verão obedece à circulação global de ventos no Atlântico Sul, como descrito na seção Área de estudos, segundo Monteiro (1949). O Anticiclone é responsável, na maior parte do tempo pela entrada de ondas de NE e E. Quando há entrada de frentes frias, comum durante o período de verão, são as ondas de S e SW que predominam. Como pode ser visto na Figura 50, o período das ondas provindas desses setores (maioria entre 10 e 14 s, mais energéticas) é maior do que o das ondas de E e NE (maioria entre 4 a 8 s).

\section{Outono}
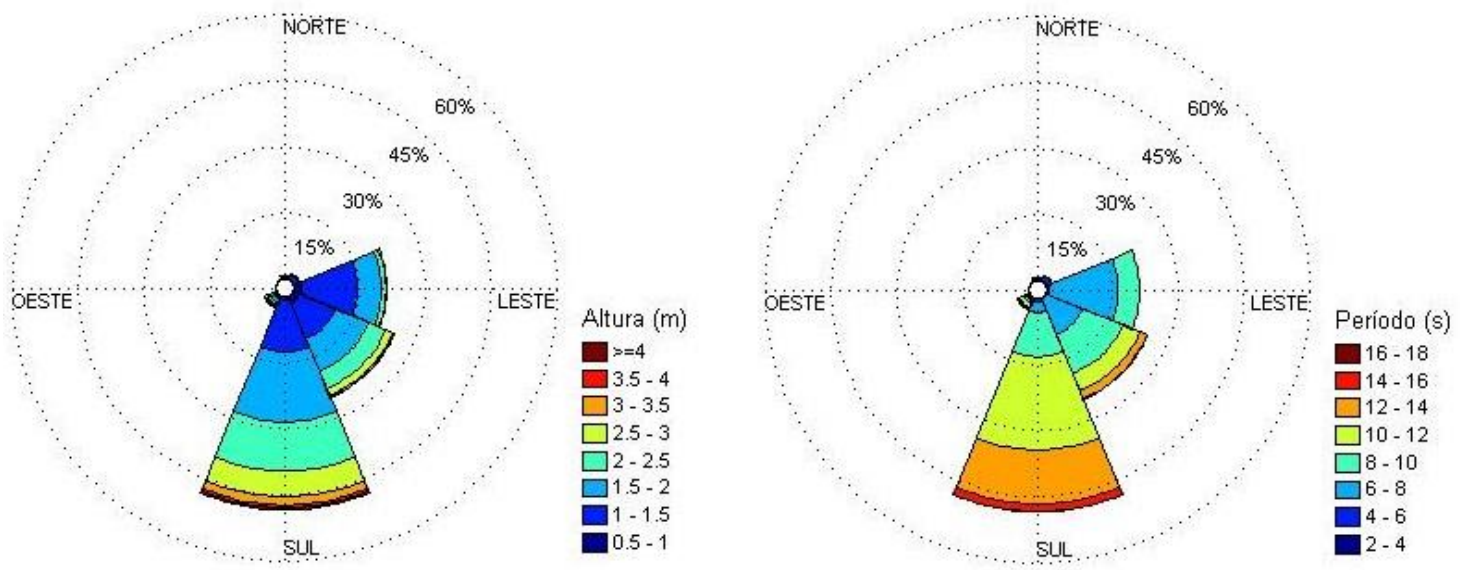

Figura 51: Rosa de ondas (altura e período) para o outono entre os anos 1997 e 2010

Durante o Outono as ondas de NE deixam de ser tão frequentes, e aumenta a frequência de ondas de S e SE. Ondas de S possuem T predominante entre 10 e 12 s e altura entre 1 a $2 \mathrm{~m}$.

\section{Inverno}



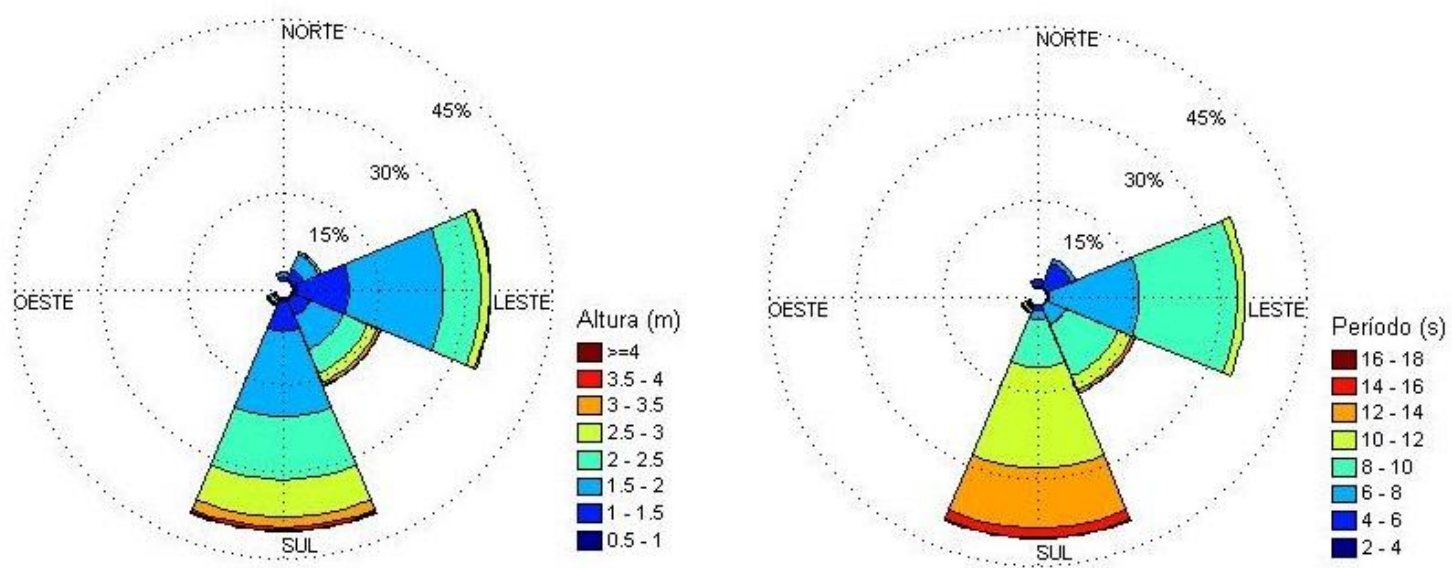

Figura 52: Rosa de ondas (altura e período) para o inverno entre os anos 1997 e 2010

Durante o Inverno as ondas de $\mathrm{E}$ e $\mathrm{S}$ predominam devido à intensificação do ASA. Predominam períodos de 8 a $10 \mathrm{~s}$ e altura s entre 1 e $2 \mathrm{~m}$ nas ondas de $\mathrm{E}$, enquanto nas ondas de $\mathrm{S}$ são mais comuns períodos entre 10 e $12 \mathrm{~s}$ e alturas entre 1,5 a 2,5 m.

\section{Primavera}
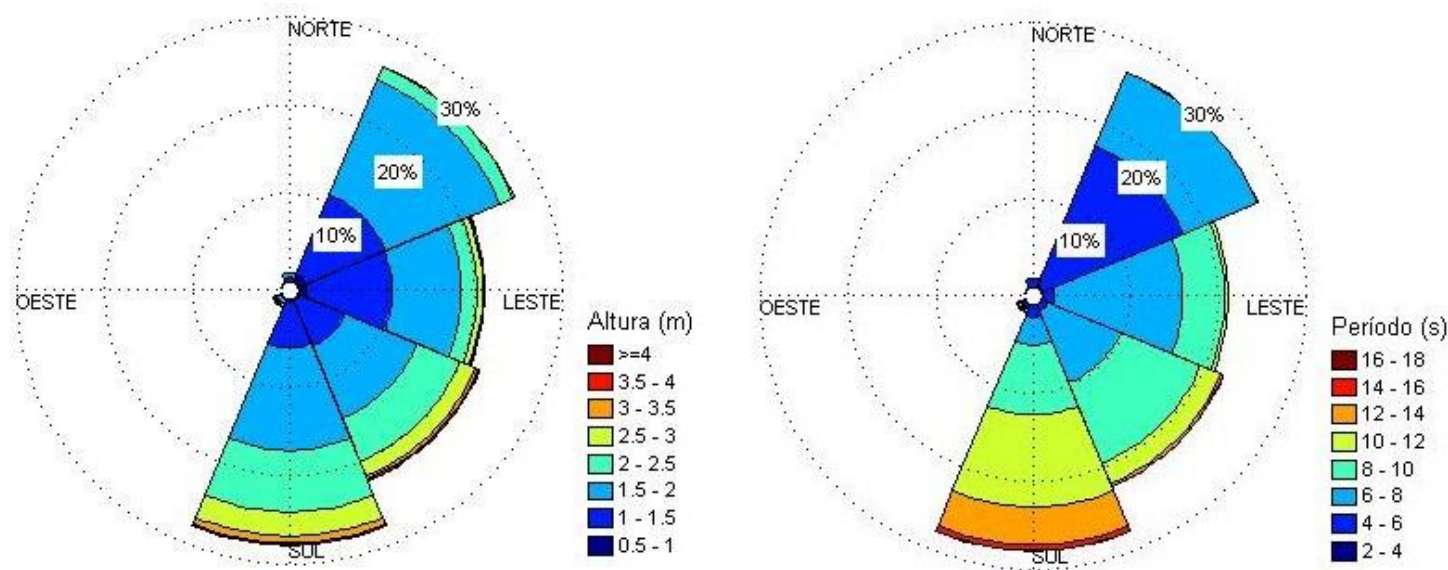

Figura 53: Rosa de ondas (altura e período) para a primavera entre os anos 1997 e 2010

Durante a primavera voltam a ser frequentes ondas de NE, com entrada de ondas de $\mathrm{S}$, como no verão. Ondas de NE possuem período predominante entre 4 e 6 s e altura entre 1,5 a 2,0; ondas de $\mathrm{S}, \mathrm{T}$ entre 10 e $12 \mathrm{~s}$ e Hs entre 1,5 e $2 \mathrm{~m}$.

\subsubsection{Resultados do modelo Delft-3D aplicados ao transporte longitudinal de sedimento}

O padrão de transporte gerado para a costa espíritossantense é mostrado na Figura 54: 


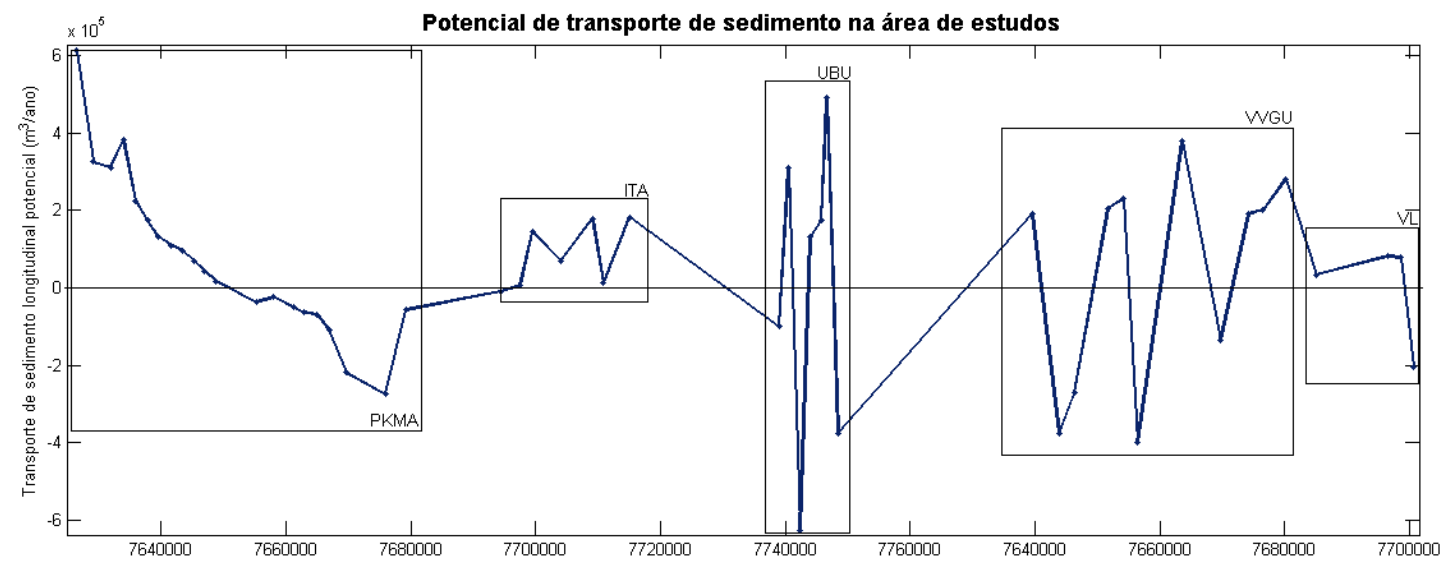

Figura 54: Transporte longitudinal médio $\left(\mathrm{m}^{3} / \mathrm{ano}\right)$ na área de estudos. Números positivos representam transporte para norte;números negativos, para sul.

Nota-se que no setor PKMA o transporte dá-se para norte até a estação PKMA-13, sendo que mais ao norte o transporte volta-se para sul. O mesmo ocorre no setor VVGU. No setor PKMA o local em que ocorre essa modificação é a zona identificada como erosiva, onde começam as falésias vivas observadas em campo. No setor VVGU, por sua vez, a transição ocorre do transporte da direção sul para norte, na região delimitada pela Ponta da Fruta, como pode ser visto nas Figura 55 e Figura 56: 


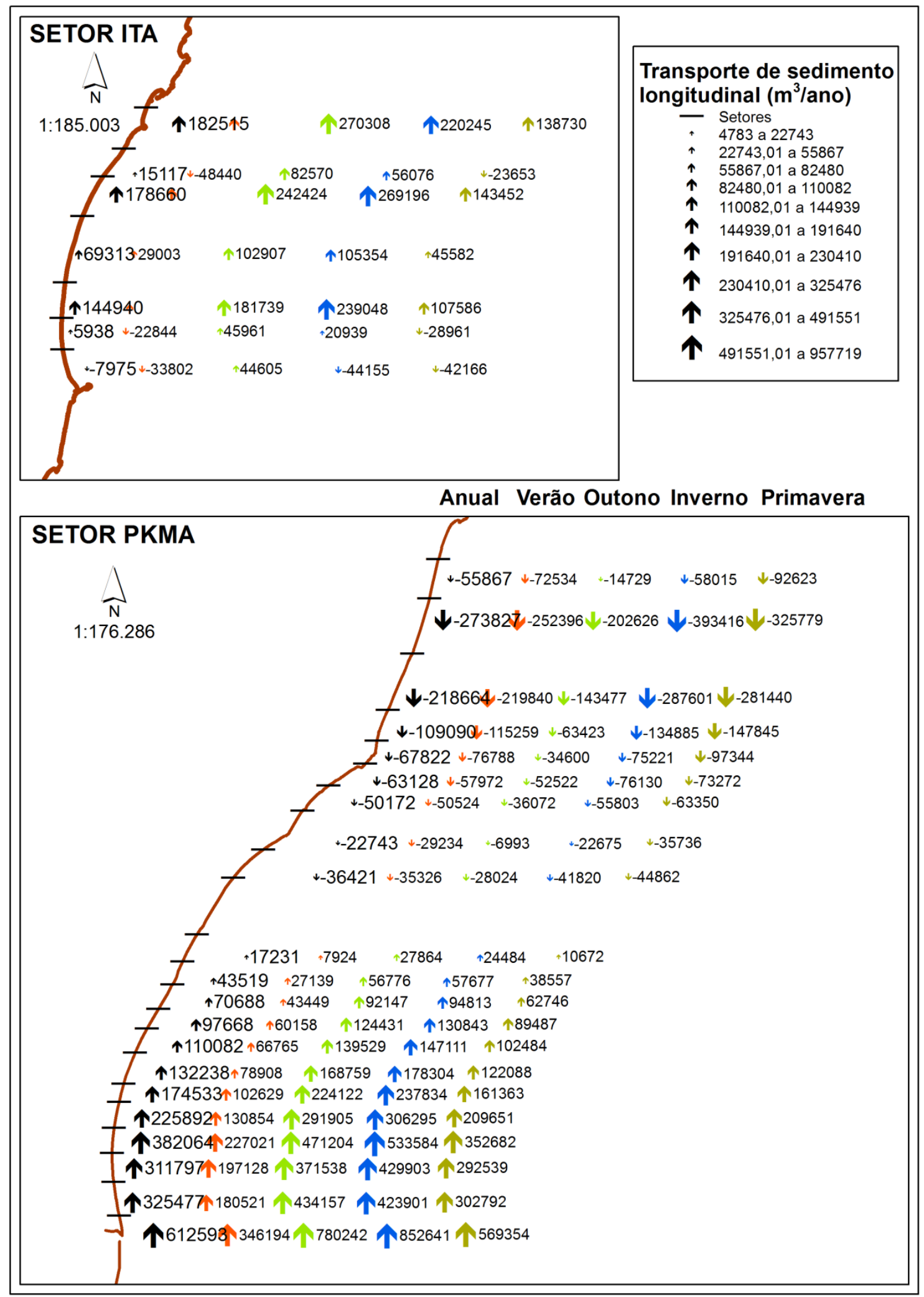

Figura 55: Representação dos vetores mais significativos de transporte longitudinal de acordo com as estações do ano, segundo resultados do modelo DELFT-3D 

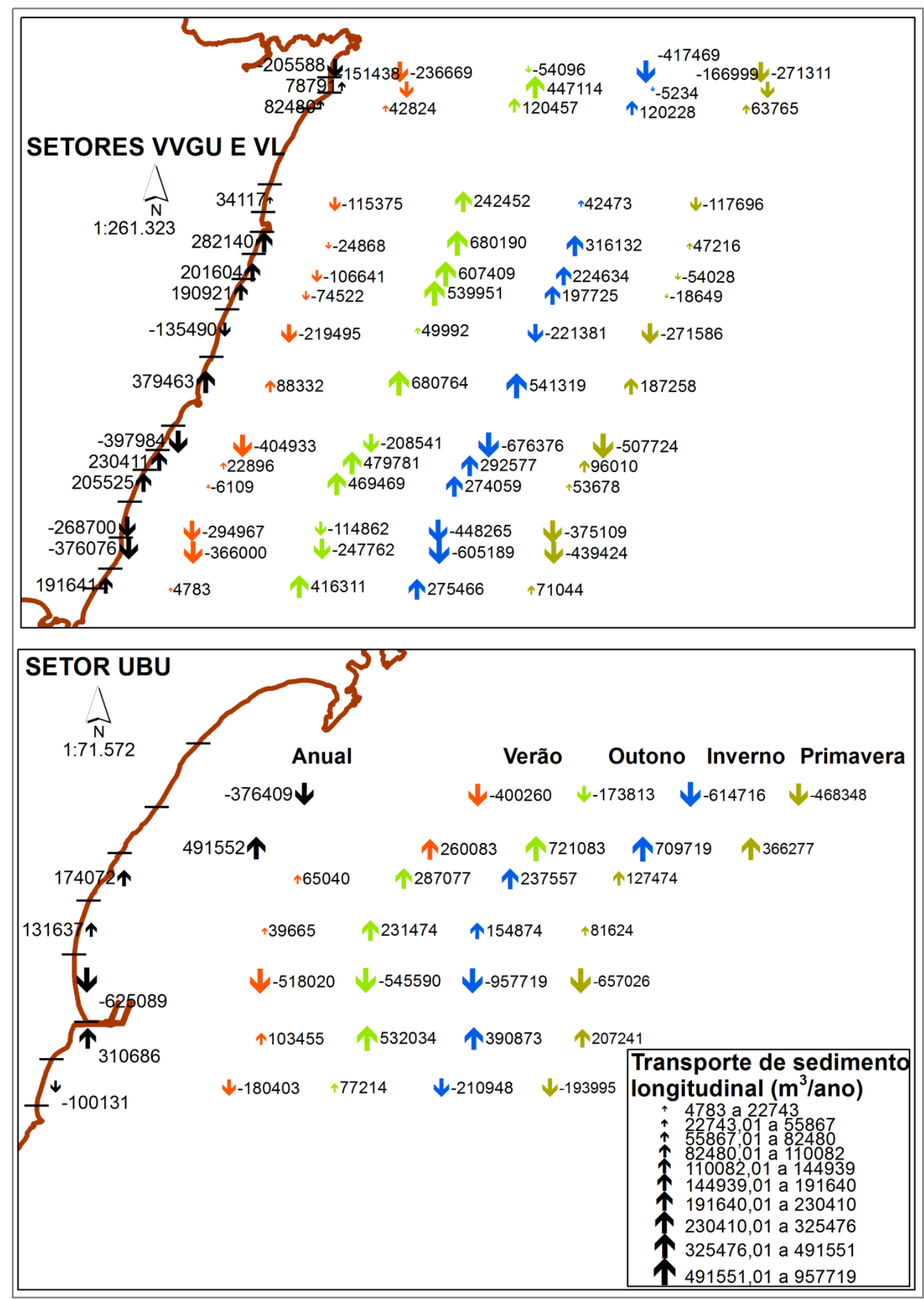

Figura 56: Representação dos vetores mais significativos de transporte longitudinal de acordo com as estações do ano, segundo resultados do modelo DELFT-3D 
Nota-se que no verão o potencial de transporte de sedimento aumenta para sul, enquanto no inverno e outono o potencial aumenta para norte. De maneira geral há inversões no sentido da corrente longitudinal.

Observa-se na porção central do setor ITA um transporte de sedimento expressivamente maior do que os pontos ao redor. Como constatado em campo, há nessa porção feições indicativas de erosão, como escarpas vivas, alto teor de MP e mudança textural do sedimento. No setor VL a tendência de transporte de sedimento é para norte.

\subsubsection{Análise da orientação da linha de costa}

Com os resultados expostos, supõe-se que parâmetros como a orientação da linha de costa e extensão da plataforma continental interna poderiam influenciar na relação entre as zonas de erosão, o modelo STA e o modelo hidrodinâmico.

A Figura 57 indica o azimute da área de estudos, bem como os locais em que foi detectada erosão intensa (com presença de obras de contenção, falésias vivas, alto teor de MP, raízes de árvores expostas, ausência de duna frontal ou destruição de construções em geral): 


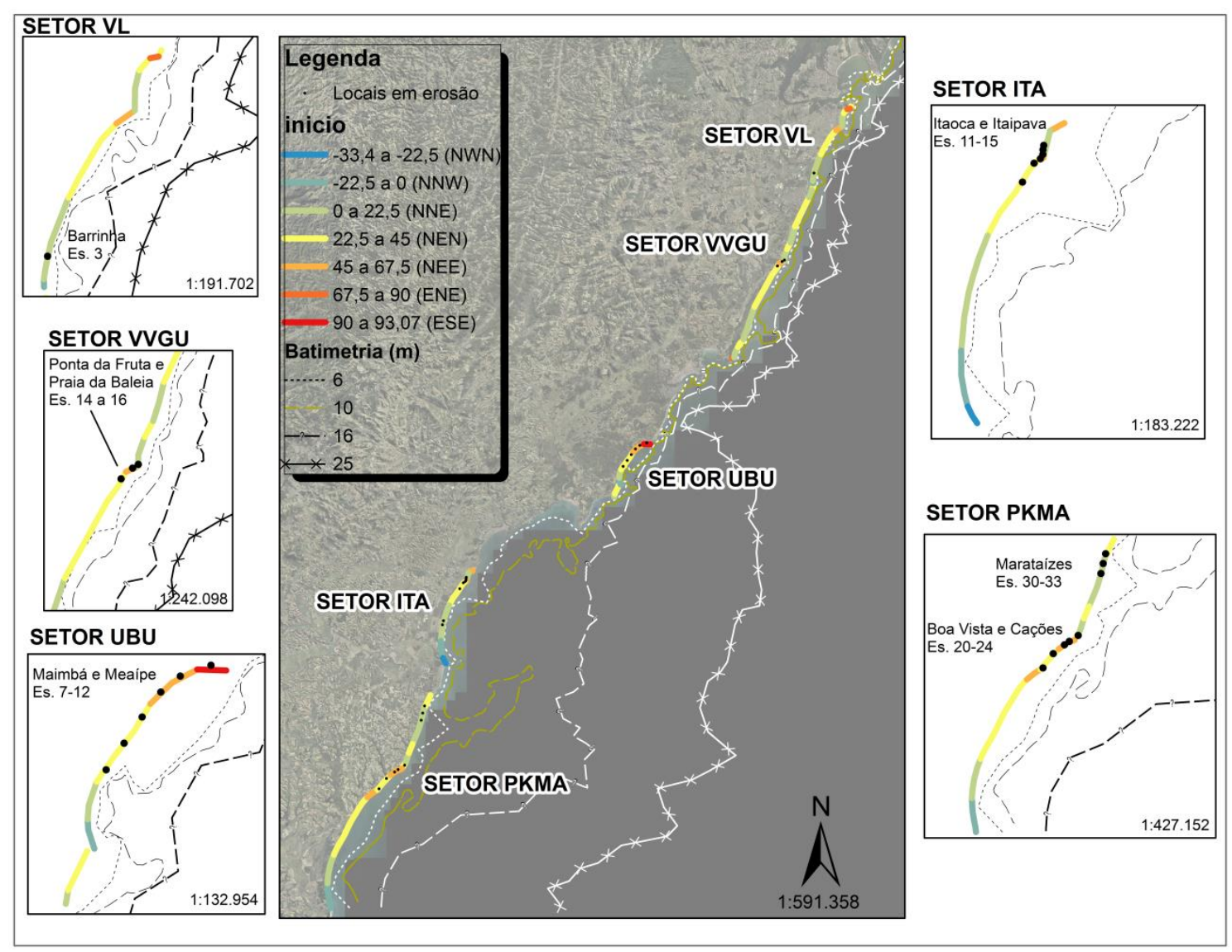

Figura 57: Orientação da linha de costa (azimute) da área de estudos

No setor VL observa-se orientação predominante de NNE e NEN, com apenas uma estação com erosão, em que parte da estrada foi destruída. No setor VVGU a orientação é em sua maioria a mesma do setor VL, apresentando 3 estações com erosão forte, com casas e estrada destruídas. Os setores são adjacentes, separados apenas por um promontório.

Os setores UBU e ITA apresentam a forma literal de arco praial, com a porção sul apresentando graus negativos (voltado para NNW) e a porção norte com ângulos superiores a $45^{\circ}$, chegando a $93,07^{\circ}$ no setor UBU. No setor UBU, 5 estações apresentaram erosão, todas ao norte; no setor ITA, 4 estações apresentaram erosão, todas ao norte, igualmente.

Através da análise do azimute é possível subdividir o setor PKMA em dois: (1) a planície costeira do setor, que constitui um arco praial com variações de azimute da mesma forma que os setores UBU e ITA e (2) da planície para norte, até a praia central de Marataízes, caracterizado por praias entrecortadas por falésias e poucas variações no azimute. A presença dos dois setores é corroborada pela análise STA e a modelagem 
hidrodinâmica explicitada, em que não foi observada correlação entre as amostras da planície costeira com as amostras da região das falésias.

\subsubsection{Análise do comprimento da praia}

A Figura 58 indica a distância de cada setor para a cota batimétrica de $10 \mathrm{~m}$. De maneira geral, nota-se a aproximação da cota de $10 \mathrm{~m}$ e $25 \mathrm{~m}$ de acordo com a aproximação das porções norte do litoral.

Nos arcos praiais PKMA e ITA a extensão das praias é maior, variando entre 1216 a $4155 \mathrm{~m}$. Nos demais setores a largura mínima é da ordem de $350 \mathrm{~m}$ atingindo o máximo de $1050 \mathrm{~m}$. Como é de se esperar, na desembocadura dos rios Itabapoana, Itapemirim e Jucu a largura da praia é maior, devido ao aporte de sedimento.

Não foi observada relação entre o comprimento da praia com as áreas em erosão de maneira qualitativa, já que nos setores UBU, ITA e PKMA localizam-se em áreas com praia mais extensa, e nos setores VVGU e VL na plataforma mais curta. 


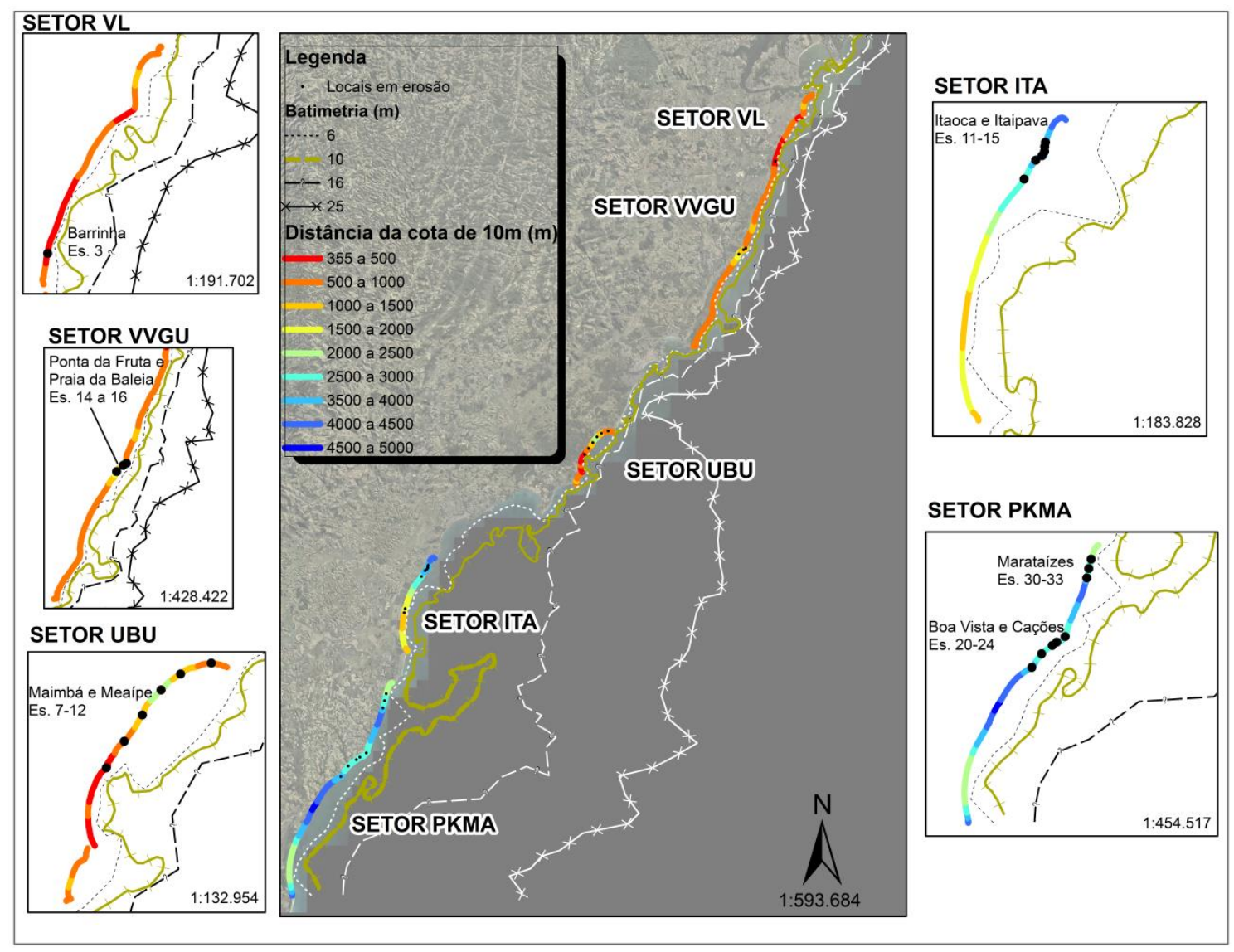

Figura 58: Comprimento da praia em todos os setores 


\section{DISCUSSÃO}

A importância deste trabalho reside principalmente na larga amostragem realizada na Área de estudos, e a primeira efetivada com pequeno espaçamento entre as mesmas. Predominam na região estudos envolvendo modelagem numérica.

Elfrink et al., (2006), e.g., estudaram a entrada da frente de ondas na praia central de Marataízes (Setor PKMA). De acordo com os autores, é do setor SE a procedência da maior parte das ondas, e também as maiores (Figura 59). Foi observado, entretanto, uma forte diferença intra-anual na tendência, com predominância de ondas de leste entre outubro e março; e ondas de sul no período de abril a setembro. Assim, no primeiro período o transporte de sedimento é predominantemente para sul, se opondo no segundo período.

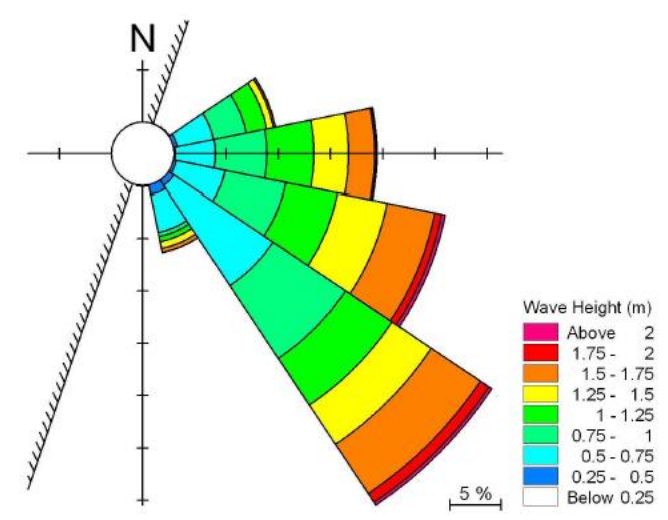

Figura 59: Rosa de ondas (1991 a 2004) para a praia central de Marataízes (Elfrink et al., 2006).

Chacaltana et al. (2012) encontraram uma anomalia de ondas no Porto da SAMARCO (Setor UBU) em 2008, com ondas predominantemente de E-SE variando a altura entre 0,5 e 1,0 m, chegando aos maiores valores de $\mathrm{H}_{\mathrm{s}}$ na primavera $(2,81 \mathrm{~m})$ e período médio de 6 a 7 s. Relacionaram a anomalia ao enfraquecimento da La Niña em 2008, diminuindo a influência da ASA, gerando ondas menos frequentes do quadrante N-NE. O modelo aplicado foi o mesmo do presente trabalho (SWAN/WWIII).

Consta no Plano de Manejo do Parque Paulo César Vinha (Setor VVGU) a descrição das ondas incidentes, feita a partir de dados coletados no porto de Vitória entre março de 1979 e setembro de 1980. O sentido predominante de procedência das ondas é os 
setores ENE e ESE, com alturas mais frequentes de 0,6 e 0,9 m e período em torno de 5 a 6,5 s (CEPEMAR, 2007b).

Piumbini (2009) avaliou o clima de ondas no estado do ES através do modelo global ECMWF (European Center for Medium-range Weather Forecast), validando dados direcionais com uma boia instalada em 2001 nas proximidades da Baía de Vitória entre 28/05 a 11/12. Os dados foram modelados entre os anos de 1957 e 2002, e apresentaram boa relação com os dados obtidos pelo modelo WWIII entre os anos 1997 e 2010. A frequência direcional de ondas nos setores $\mathrm{N}$, NE e E apresentaram-se muito semelhantes entre os dois trabalhos, com diferenças menores que $1 \%$. Nota-se uma diminuição na frequência de ondas de SE, compensada por aumento na frequência de ondas de $\mathrm{S}$.

A autora encontrou $\mathrm{T}$ predominante de 7 a $8 \mathrm{~s}(28,9 \%)$ e $\mathrm{H}_{\mathrm{s}}$ entre 1 e $2 \mathrm{~m}(80 \%)$; o que corresponde ao T predominante encontrado pelo WWIII de 7 a $8 \mathrm{~s}(32,01 \%)$ e $\mathrm{H}_{\mathrm{s}}$ entre 0,75 e $2,0 \mathrm{~m}(77,14 \%)$.

Santos (2003) mediu parâmetros de ondas na praia de Meaípe, encontrando predominância daquelas vindas de SE com variações de altura entre 0,5 a $0,8 \mathrm{~m}$ durante frentes frias. Os resultados obtidos por Piumbini (2009) com modelagem numérica usando o SWAN corroboram os da autora.

Observam-se semelhanças entre os resultados obtidos pelo modelo Delft-3D com os demais trabalhos apresentados. Comparando os resultados obtidos no presente trabalho com os de Piumbini (2009) e Pianca et al. (2010), novamente notam-se semelhanças: a altura de ondas reside entre 1 e 2 metros em $78 \%$ dos casos, enquanto o período varia entre 6 e 8 s (22,5\% dos casos) ou 10 e 12 s (26,4\%). A direção de entrada da frente de ondas é variável entre NE e S (97\% dos casos), pois representa consequências de enfraquecimento ou fortalecimento dos sistemas atmosféricos em escala global.

No âmbito do presente trabalho, a Tabela 11 sintetiza todas as informações apresentadas: 
Tabela 11: Tabela síntese dos resultados obtidos em campo e laboratório quanto à granulometria dos setores

\begin{tabular}{|c|c|c|c|c|c|}
\hline Setor & PKMA & ITA & $\mathbf{U B U}$ & VVGU & $\mathbf{V L}$ \\
\hline Tendência1/Sentido & $\mathrm{CB}+/ \mathrm{Sul}, \mathrm{FB}-/$ Norte & $\mathrm{CB}+/ \mathrm{Sul}$ & $\mathrm{CB}+/ \mathrm{Sul}$ & $\mathrm{CB}+/ \mathrm{Sul}, \mathrm{FB}-/$ Norte & FB-/Norte \\
\hline Tendência2/Sentido & FB-/Sul & - & FB-/Norte & - & - \\
\hline Tendência3/Sentido & - & - & - & - & - \\
\hline $\begin{array}{l}\text { Sentido de transporte } \\
\text { modelado (todos os } \\
\text { anos) }\end{array}$ & $\begin{array}{c}\text { Norte (1 a 18) e Sul (18 a } \\
33)\end{array}$ & Norte & Norte e sul & $\begin{array}{l}\text { Sul (1 a 15) e norte (16 a } \\
\text { 24) }\end{array}$ & Norte \\
\hline $\begin{array}{l}\text { Tendência no } \\
\text { afinamento dos grãos }\end{array}$ & $\begin{array}{c}\text { Norte entre estações } 9 \text { e } \\
23(0,76)\end{array}$ & Norte $(0,86)$ & Norte $(0,77)$ & Norte até $15(0,9)$ & Norte até $12(0,92)$ \\
\hline $\begin{array}{l}\text { Tendência na melhora } \\
\text { do grau de seleção }\end{array}$ & Entre 8 e $13(-0,93)$ & Não observável & Norte $(-0,57)$ & $\begin{array}{c}\text { Sul até } 15(0,69), \text { Norte } \\
\text { entre } 16 \text { e } 24(-0,64)\end{array}$ & Norte até $12(-0,78)$ \\
\hline Tendência na assimetria & $\begin{array}{c}\text { Negativa para norte entre } \\
5 \text { e } 23(-0,69)\end{array}$ & $\begin{array}{c}\text { Negativa para norte (- } \\
0,42)\end{array}$ & Negativa para norte $(-0,7)$ & $\begin{array}{c}\text { Negativa para norte }(-0,69 \\
\text { e }-0,85)\end{array}$ & Negativa até $12(-0,94)$ \\
\hline Tendência na curtose & Não observável & $\begin{array}{c}\text { Diminuição para norte (- } \\
0,59)\end{array}$ & $\begin{array}{c}\text { Diminuição para norte (- } \\
0,5)\end{array}$ & $\begin{array}{c}\text { Diminuição para norte } \\
(0,6)\end{array}$ & Negativa até $12(-0,52)$ \\
\hline $\begin{array}{l}\text { Tendência no teor de } \\
\text { Carbonato }\end{array}$ & $\begin{array}{l}\text { Aumento para norte } \\
(0,45)\end{array}$ & $\begin{array}{c}\text { Aumento para norte } \\
(0,53)\end{array}$ & Não observável & $\begin{array}{c}\text { Aumento para norte } \\
(0,65)\end{array}$ & Aumento para norte $(0,5)$ \\
\hline $\begin{array}{l}\text { Tendência no teor de } \\
\text { MP }\end{array}$ & Não observável & $\begin{array}{l}\text { Aumento para norte } \\
\qquad(0,42)\end{array}$ & $\begin{array}{l}\text { Aumento exponencial } \\
\text { para norte }(0,63)\end{array}$ & $\begin{array}{l}\text { Diminuição para norte } \\
\text { entre } 10 \text { e } 24(-0,8)\end{array}$ & $\begin{array}{l}\text { Aumento exponencial } \\
\text { para norte }(0,9)\end{array}$ \\
\hline $\begin{array}{l}\text { Teor máximo de MP } \\
(\%)\end{array}$ & 35,04 & 11,14 & 58,53 & 5,27 & 1,51 \\
\hline $\begin{array}{l}\text { Tendência na largura da } \\
\text { praia }\end{array}$ & Diminuição até $14(0,39)$ & Diminuição até $8(0,66)$ & $\begin{array}{c}\text { Diminuição para norte (- } \\
0,61)\end{array}$ & Não observável & $\begin{array}{c}\text { Aumento para norte } \\
(0,43)\end{array}$ \\
\hline $\begin{array}{l}\text { Tendência na } \\
\text { declividade da praia }\end{array}$ & $\begin{array}{c}\text { Aumento até } 10(0,70) \text {, } \\
\text { diminuição entre } 10 \text { e } 24 \\
(0,52)\end{array}$ & Aumento até $8(0,82)$ & Não observável & Não observável & Não observável \\
\hline $\begin{array}{l}\text { Setores com erosão } \\
\text { evidente }\end{array}$ & centro-norte, Norte & Norte & Norte & Centro & Sul \\
\hline Setor com escarpas & Central & Central & Sul & Sul & Sul \\
\hline Setor com acresção & Sul & Sul & Sul & Ausente & Ausente \\
\hline $\begin{array}{l}\text { Comprimento do setor } \\
(\mathrm{km})\end{array}$ & 33,5 & 13,7 & 9,7 & 26,40 & 12,4 \\
\hline
\end{tabular}




\begin{tabular}{|c|c|c|c|c|c|}
\hline $\begin{array}{l}\text { Porcentagem do setor } \\
\text { em erosão/comprimento } \\
(\mathrm{km})\end{array}$ & $29,8 / 9,98$ & $16,1 / 2,2$ & $54,6 / 5,3$ & $9,4 / 2,6$ & $8,5 / 1,06$ \\
\hline Rio (vazão média) & Itabapoana $(45,77$ m³/s) & Itapemirim $\left(80,91 \mathrm{~m}^{3} / \mathrm{s}\right)$ & Inexistente & Inexistente & Jucu $(26,4)$ \\
\hline Ano da vazão máxima & $\begin{array}{c}2005 \text { (aumento de } \\
291,52 \% \text { ) }\end{array}$ & 2005 (aumento de 586\%) & Não se aplica & Não se aplica & 2001 \\
\hline $\begin{array}{l}\text { Obras de engenharia } \\
\text { costeira }\end{array}$ & $\begin{array}{c}\text { Contenção de erosão ao } \\
\text { norte }\end{array}$ & $\begin{array}{l}\text { Guia-corrente ao sul, } \\
\text { marina ao norte }\end{array}$ & Porto de Ubu & $\begin{array}{c}\text { Contenção de erosão em } \\
\text { casas }\end{array}$ & Inexistente \\
\hline $\begin{array}{l}\text { Outros indicadores de } \\
\text { deriva na linha de costa }\end{array}$ & $\begin{array}{c}\text { Barra do Rio Itabapoana - } \\
\text { norte e sul }\end{array}$ & Tômbolo antigo & $\begin{array}{l}\text { Aprisionamento ao norte } \\
\text { do porto de Ubu }\end{array}$ & Arenitos de praia imersos & Tômbolo antigo \\
\hline $\begin{array}{l}\text { Maior distância para a } \\
\text { profundidade de } 10 \mathrm{~m} \\
\text { (m) }\end{array}$ & 4155,3 & 3649,2 & 2025,5 & 1527,5 & 1216,6 \\
\hline $\begin{array}{l}\text { Menor distância para a } \\
\text { profundidade de } 10 \mathrm{~m} \\
\text { (m) }\end{array}$ & 2063,7 & 1216,7 & 355,6 & 543,6 & 366,1 \\
\hline $\begin{array}{l}\text { Orientação geral do } \\
\text { setor }\left({ }^{\circ}\right)\end{array}$ & 25,19 & 16,08 & 34,2 & 24,92 & 26,42 \\
\hline Trabalhos publicados & Elfrink et al. (2006) & $\begin{array}{l}\text { Machado, Santos e } \\
\text { Albino (2003) }\end{array}$ & $\begin{array}{l}\text { Chacaltana et al. }(2012), \\
\text { Machado, Santos e } \\
\text { Albino (2003); Veiga et } \\
\text { al. (2006) }\end{array}$ & Albino (1996) & Inexistentes \\
\hline
\end{tabular}


A análise da Tabela permite comparações a partir da síntese por ela apresentada. $\mathrm{O}$ parâmetro carbonato não parece indicar nenhuma relação significativa com outros. Apesar de ter sido observado aumento para norte em 4 dos 5 arcos praiais, parece ser controlado fortemente por fatores locais de onde são formados, não sofrendo muita influência do transporte longitudinal.

Foram encontrados teores de MP muito grandes nos setores ao sul, atingindo quase $60 \%$ na estação central de UBU. Nos setores VVGU e VL o teor encontrado foi muito baixo.

Não foi encontrada correlação entre o parâmetro largura de praia e erosão/acresção, como sugerido por Souza (2007). Isso pode ser explicado pelo número de setores em erosão, em que se observam estruturas antrópicas marcando o final da praia e modificando sua forma natural. Aplica-se a mesma explicação para o parâmetro declividade.

Quanto aos parâmetros texturais, chama atenção os baixos valores de curtose encontrados em locais com escarpas de praia, já que o mesmo não ocorre para zonas de erosão, e o oposto não ocorre para zonas de acresção. Partindo do pressuposto que as escarpas de praia indicam erosão pontual, com maior incidência de ondas antes da coleta, não indicando erosão em longo prazo, postula-se que há correlação inversa entre curtose e energia de ondas, como atestado também por Souza (1997). É interessante notar, ainda, que os pontos em que foram evidenciadas escarpas encontram-se na parte central dos arcos praiais (PKMA, ITA,VL), ou ao sul (UBU e VVGU), exposto diretamente às ondas mais energéticas de $\mathrm{E}$ ou SE.

Em todos os arcos o sedimento tende a afinar e diminuir a assimetria em direção ao norte. Como mostrado na Figura 48, as tendências com maiores valores de confiança são FB- para norte e $\mathrm{CB}+$ para sul, em todos os setores. O setor UBU foi o único que indicou ser um arco praial com tendências nas duas direções, para todas as amostras. Enquanto nos setores ao sul, o transporte de sedimento para sul, nos setores ao norte a tendência é oposta.

Os modelos de Chang (2001 - GSTAST) e McLaren e Bowles (1985 - STA) concordaram quanto à direção de transporte em todos os setores. Como o teste estatístico do GSTAST é mais rigoroso e usa conceito de distância característica (relacionado à anisotropia), apresentou menos vetores. A inversão de correntes nos 
setores PKMA e VVGU pôde ser ratificada tanto pelo modelo numérico quando pelos conceituais.

A comparação dos resultados de saída do modelo DELFT-3D com a análise STA, deve ser feita analisando cada setor separadamente. Mas de maneira geral, o único setor que apresentou valores de correlação altos $\left(\mathrm{r}^{2}\right.$ acima de 0,68$)$ entre os parâmetros estatísticos foi o VL. Nos outros setores apenas a correlação Média x Assimetria superou 0,7. De acordo com McLaren (2007) valores baixos não impossibilitam a análise, mas essa deve ser realizada com cautela, por representarem a entrada natural de novas fácies no sistema ou interferência humana. Uma das razões que podem contribuir para a baixa correlação nos demais setores é a extensão da praia, maior ao sul do que ao norte.

Igualmente deve se levar em conta as limitações do modelo: a metodologia aplicada corresponde aos parâmetros de onda mais frequentes da região, e não a todos os existentes; a batimetria usada foi de carta náutica, não atualizada, e não refinada em pontos necessários para tal; a resolução aplicada do modelo não foi suficiente para estudar todos os efeitos de difração ao redor de obras costeiras.

Assim sendo, no setor PKMA a correlação foi baixa devido à presença de falésias vivas com entrada de MP na praia e à presença do Rio Itabapoana e/ou pelo modelo numérico não estar bem representado na região. A falta de detalhamento batimétrico em uma região bastante irregular é a provável causa de certa incoerência nos resultados: na região em que o modelo numérico apresentou convergência de correntes, o modelo STA indicou divergência. O modelo numérico na foz do Rio Itabapoana não corresponde ao observado nas imagens aéreas, indicando inversão. Quando se analisam os dados de vento para o Espírito Santo, vê-se que é nessa região que atingem suas maiores velocidades. Aliados à análise do comprimento da praia, pode-se dizer que aí outros fatores controlam as correntes longitudinais: a diferença de altura do nível d'água entre pontos distintos na costa, correntes de maré e o cisalhamento local do vento, como atestado por Bowen (1969), Komar e Inman (1970) e Noda (1971).

Ao analisar a série histórica das imagens e fotografias aéreas entre 2002 e 2008, nota-se que o modelo numérico parece representar bem a porção sul do arco, a Foz do Rio, já que representa correntes para o norte. 
No setor ITA esperava-se erro na análise STA pelo parâmetro principal - desvio padrão - não ter apresentado nenhuma tendência espacial. O modelo, por outro lado, parece ter representado bem a inversão de correntes observada na foz do riacho ao norte no setor. O mapa de extensão da praia indica que nesse ponto há um súbito alargamento da extensão de praia, o que pode vir a ser a causa da inversão. No verão e primavera apresentou vetores de transporte para sul (como na análise STA), invertendo para norte no outono e inverno.

O setor UBU apresentou resultado passível de interpretação errônea. O modelo STA indicou equilíbrio na praia, com inversão no sentido da corrente longitudinal, também observada no modelo numérico. O modelo DELFT-3D indicou, entretanto, dois resultados que puderam ser observados em campo e através das imagens de satélite: ao sul do Píer da SAMARCO há também acumulação sedimentar (devido às ondas de sul), e há outra acumulação ao norte do setor, correspondente ao ponto UBU-11, em que foram observadas quebras nos padrões de concentração de MP, assimetria, extensão e declividade, bem como a tendência dissipativa das praias em direção ao norte.

No setor VVGU o modelo DELFT-3D representou com fidelidade o esperado na análise STA, com inversão de corrente no promontório na porção central, indicando zona com fuga de sedimento. O ponto corresponde à Praia da Ponta da Fruta, como indica a Figura 60:

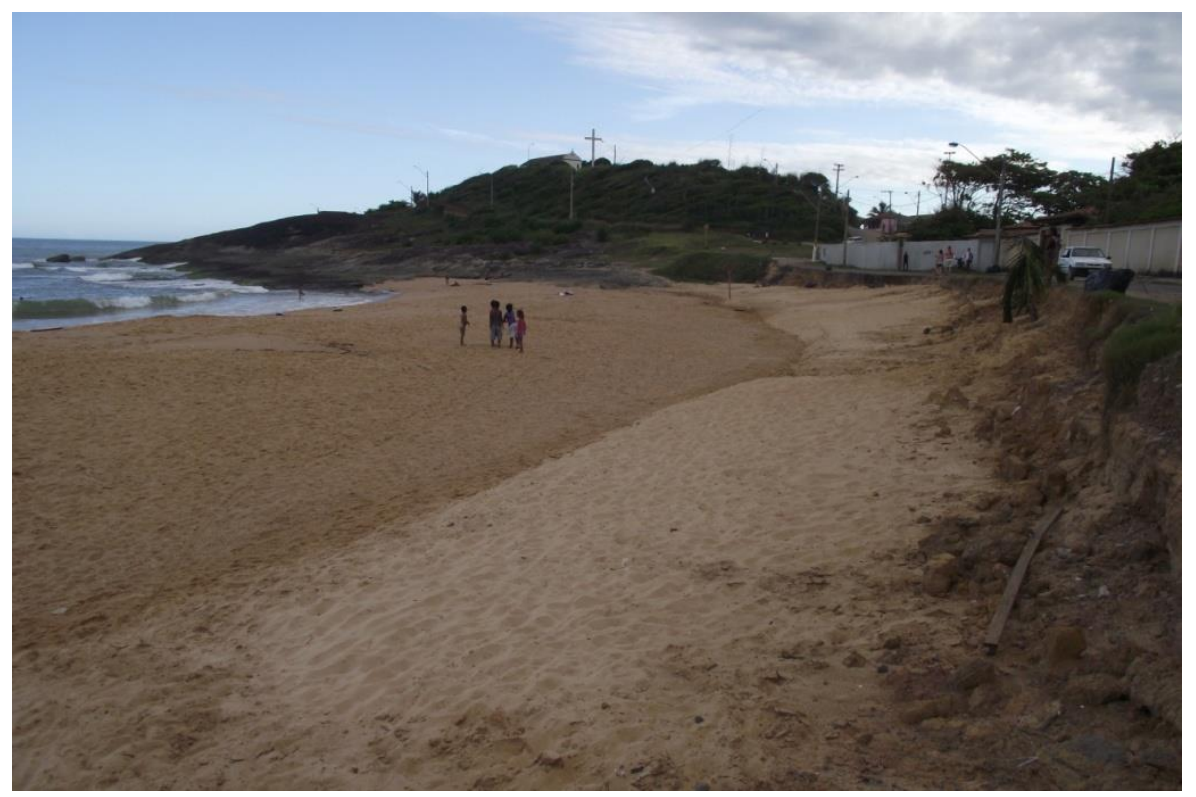

Figura 60: Praia em erosão na Ponta da Fruta 
No mesmo artigo, Albino (1996) calculou a energia de onda incidente nas três praias, encontrando os maiores valores para a praia da Baleia. Esse valor é diminuído localmente devido ao efeito de dissipação promovido pelos arenitos presentes na face da praia, concordando com o resultado apresentado pelo DELFT-3D, com diminuição da intensidade do vetor.

No setor VL o indicativo de transporte para o norte da análise STA pode ser comprovado através da modelagem numérica. Contribuem para o sucesso da análise no setor a extensão de praia curta, batimetria regular, formato de praia aberto (não arqueado, como nos demais), baixo teor de MP e carbonato e entrada sedimentar pequena pelo Rio Jucu.

Como esperado, os maiores vetores de transporte de sedimento foram encontrados nos setores ao norte, principalmente o UBU, em que a praia possui menor extensão, devido à menor extensão da praia. Praias mais planas dissipam mais a energia das ondas do que praias refletivas.

Foram utilizados como indicadores de erosão costeira as falésias vivas, alta concentração de MP, obras de contenção de erosão e árvores com raízes expostas, indicados na Figura 61. Em A, trecho de falésias vivas com grande quantidade de MP; em B, raízes de árvores expostas; em C e D, obras de contenção de erosão. No setor UBU todos esses indicadores foram encontrados.

Nos setores ao sul os locais com erosão ou com obras contra erosão situam-se ao norte, no setor VVGU ao centro e no setor VL, ao sul. O setor com maior parte em erosão é o UBU, devido à estrada que beira as falésias vivas, situada entre a lagoa de Maimbá e a praia. A ausência de rios atua como fator impulsionador de erosão, não fornecendo suprimento sedimentar para esse setor e VVGU. 

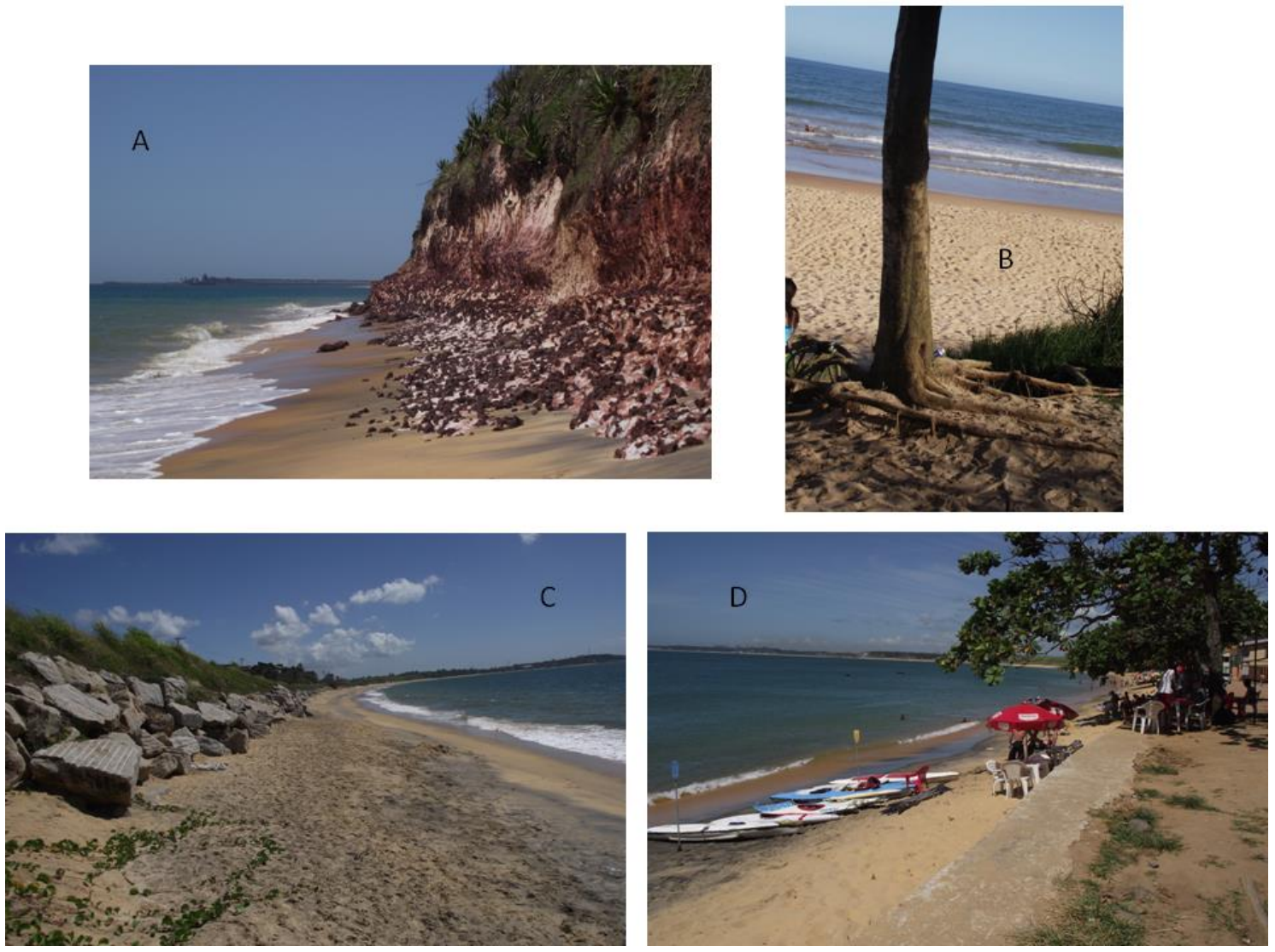

Figura 61: Fotografias em campo do setor UBU.

A análise de MP como indicador de corrente longitudinal não foi possível. Nos setores UBU e PKMA o teor é muito alto em uma única estação e uniforme nas demais. O setor ITA apresentou baixa correlação espacial. No setor VL o transporte de sedimento e o teor de MP indicam aumento para norte e transporte para norte, o que não faria sentido em se considerando a área fonte como o norte (onde sua concentração é maior). Pode-se considerar como resultado marcante de MP apenas o realizado na porção sul do setor VVGU, que diminui na direção do transporte indicado pela análise STA. O estudo da proveniência, com identificação dos minerais provavelmente forneceria resultados mais concisos. O parâmetro, entretanto, foi um ótimo indicador de zonas erosivas.

A presença de obras de engenharia costeira na Área de estudos é marcante. Obras malsucedidas de contenção de erosão no setor PKMA, o guia-corrente e marina no setor ITA, o píer no setor UBU e a contenção de erosão nas casas do setor VVGU indicam que houve ocupação irregular, acarretando em falta de suprimento sedimentar para praias vizinhas. A análise de fotografias aéreas e imagens de satélite mostraram-se bastante úteis no processo da compreensão da dinâmica sedimentar e padrões de correntes. 
Em análise realizada com fotografias aéreas de 1970, 1995, 2003 e 2004, CEPEMAR (2007a) afirma que a linha de costa junto ao Porto avançou entre 230 e $240 \mathrm{~m}$ em um trecho imediatamente ao norte, com modificações insignificantes ao sul. Segundo o autor, as maiores modificações foram entre 1970 e 1995, e a partir de então, "praticamente não ocorreram modificações na linha de costa". Dessa maneira, a linha de costa teria se estabilizado na região, e caracterizam o setor como praia rotacional.

Enquanto CEPEMAR (2007a) afirma que a construção do terminal não causou erosão da linha de costa nem ao norte nem ao sul da estrutura (localizada na porção sul do setor UBU), Machado et al. (2003) afirmam que o recuo da linha de costa na praia de Meaípe e Maimbá foi induzido ou, no mínimo, acelerado pela sua implantação ou por conta das dragagens periódicas realizadas na região, que alteram o regime de ondas. CEPEMAR (2007a) afirma também que a alteração da linha de costa está restrita a uma faixa de 1200 a $1300 \mathrm{~m}$ ao norte do porto, apenas. A Tabela 8 apresenta o histórico das dragagens ocorridas:

Tabela 12: Anos, volumes e locais de despejo do material dragado no Terminal de Ubu.

\begin{tabular}{ccc}
\hline Ano de dragagem & Volume dragado $\left(\mathbf{m}^{\mathbf{3}}\right)$ & Local de lançamento \\
\hline $\mathbf{1 9 8 5}$ & 600.000 & Imediatamente ao sul do molhe \\
$\mathbf{1 9 9 2}$ & 600.000 & Ao leste do terminal $(\mathrm{h}=18 \mathrm{~m})$ \\
$\mathbf{2 0 0 1}$ & 375.000 & idem \\
$\mathbf{2 0 0 6 / 2 0 0 7}$ & 43.000 & idem \\
\hline
\end{tabular}

As feições geomorfológicas auxiliaram grandemente no entendimento dos processos de erosão e progradação das praias: escarpas e falésias vivas indicaram pontos em erosão, enquanto planícies de deflação e indicaram pontos de acresção. Barras fluviais e tômbolos serviram como grandes indicadores de sentido predominante das ondas. No setor ITA, por exemplo, a morfologia da barra fluvial indicou sentido norte com inversões perto do guia-corrente, e foi corroborado pelo modelo conceitual e numérico STA e Delft.

O mapa da orientação da linha de costa parece indicar que esse seja o fator principal atuante na erosão da linha de costa sul-espiritossantense: a entrada do trem de ondas com ângulos de $45^{\circ}$ propicia a formação de correntes longitudinais com maior capacidade de transporte de sedimento. Os setores PKMA e ITA possuem azimute negativo (voltados para oeste), o que os expõe para ondas de NE, menos energéticas. 
Quando se observam os locais em erosão, vê-se que, em sua grande maioria (12 estações) estão orientados no sentido NEN. A capacidade máxima da corrente longitudinal dá-se quando as ondas incidem em $45^{\circ}$ com a linha de costa. Assim, ondas de ESE e SE seriam as ondas de capacidade máxima para os setores orientados em NEN. Segundo os trabalhos aqui apresentados, são provenientes desses setores as ondas de maior período e maior altura. Dessa maneira, há relação clara entre a erosão, a orientação da linha de costa e a incidência de ondas.

Da mesma maneira, foi vista relação no sentido oposto. Dos setores em que foi observada progradação da linha de costa, todos estão voltados para NWN ou NNW, e situam-se na porção sul de cada setor.

\section{CONCLUSÃO}

A partir do exposto, conclui-se que:

- A direção predominante das ondas no setor sul da costa Espíritossantense é de Sul, com ondas entre 1,5 e 2,5 m de altura e 10 a $12 \mathrm{~s}$ de período e ondas de Leste, com altura entre 1 e $2 \mathrm{~m}$ de altura e 6 a $8 \mathrm{~s}$ de período. No verão as ondas de Nordeste se tornam mais frequentes, atingindo 1,5 a $2 \mathrm{~m}$ de altura e 4 a $6 \mathrm{~s}$ de período; no outono as ondas de sul são muito mais frequentes que as demais (mais de $45 \%$ dos casos); no inverno a influência das ondas de Leste aumentam e equilibram-se com as de Sul; e na primavera as ondas de Nordeste atingem frequência maior que as do verão, porém com alturas e períodos ligeiramente maiores. Dessa maneira a variação sazonal é mais marcante entre outono/primavera do que verão/inverno.

- Os resultados do modelo numérico mostrou-se condizente com a morfologia em todos os setores, com excessão do PKMA, dificultado pela falta de detalhamento batimétrico. Nos demais, foi capaz de representar inversões sazonais de corrente atestadas em campo.

- Os pontos de erosão foram identificados através da presença de falésias vivas e escarpas praiais, alto teor de MP (indicando também local com maior incidência de ondas), sedimento fino com assimetria negativa e estruturas de contenção. A progradação por sua vez pôde ser observada a partir de pós-praias extensos com 
planícies de deflação. Foi observada relação entre locais com erosão e seu azimute. A maioria dos pontos em estado de retrogradação da linha de costa possui orientação NEN, o que estaria alinhado $45^{\circ} \mathrm{com}$ a entrada de frente de ondas, justamente como ocorre o transporte máximo de sedimento. Por outro lado, zonas em progradação estão orientadas NWN e NNW, voltadas para ondas de NE e E, menos energéticas que as ondas de S.

- Ainda que as recomendações de Maclaren (2007) tenham sido seguidas (profundidade de coleta, análise granulométrica e estatística de pré-tratamento dos dados), a presença de obras de engenharia costeira (aterro hidráulico em PKMA, guia-corrente e píer em ITA e píer em UBU), a largura da plataforma interna (que diminui gradativamente em direção ao norte) e a irregularidade da batimetria (atestado pela distância até a isóbata de $10 \mathrm{~m}$ e pela presença de arenitos de praia forçando sua morfodinâmica como TBM), alto teor de MP e carbonato contribuíram para baixos valores de correlação, o que mascarou os resultados.

- As estruturas antrópicas encontradas por vezes auxiliaram o processo de erosão praial. Citam-se como exemplo o guia-corrente de Itapemirim, não permitindo by-pass de sedimento para a praia de Marataízes; o píer de Itaipava que causou erosão no mesmo local e o píer em UBU, causando erosão na praia de Meaípe, como atestado neste e em outros trabalhos.

- Ratificam-se resultados da literatura através do presente trabalho: o teor de MP aumenta a assimetria negativa; há relação entre formação de escarpas de praia e curtose; dragagens, alto teor de carbonato e MP mascaram resultados de análise STA. A análise obteve resultados condizentes com o modelo apenas no setor VL e VVGU, que possuem pouca entrada de material sedimentar pelos rios, nenhuma obra de engenharia costeira (como dragagem e aterro hidráulico), baixo conteúdo de carbonato e MP.

- O modelo GSTA apresentou resultados mais condizentes com o modelo DELFT-3D, por apresentar apenas vetores com maior nível de confiança. Dessa maneira, é de se esperar que vetores encontrados na análise STA não apareçam nesse outro tipo de análise, como ocorreu em toda área de estudos. Todos os vetores encontrados, entretanto, coincidiram com o modelo numérico. Sendo 
assim, recomenda-se o uso do GSTA para análises unidimensionais, não menosprezando a técnica STA, que serviu de base para essa.

- Quando se observam os locais em erosão, vê-se que, em sua grande maioria (12 estações) estão orientados no sentido NEN. A capacidade máxima da corrente longitudinal dá-se quando as ondas incidem em $45^{\circ}$ com a linha de costa. Assim, ondas de ESE e SE seriam as ondas de capacidade máxima para os setores orientados em NEN. Segundo os trabalhos aqui apresentados, são provenientes desses setores as ondas de maior período e maior altura. Dessa maneira, há relação clara entre a erosão, a orientação da linha de costa e a incidência de ondas.Da mesma maneira, foi vista relação no sentido oposto. Dos setores em que foi observada progradação da linha de costa, todos estão voltados para NWN ou NNW, e situam-se na porção sul de cada setor. 


\section{REFERÊNCIAS}

ALBINO, J. 1996. Morphodynamics and coastal processes on Baleia, Fruta and Sol beaches, State of Espírito Santo, Brazil. Anais da Academia Brasileira de Ciências, v. 68, n.2, p. $425-432$.

ALBINO, J.; GIRARDI, G.; NASCIMENTO, K.A. Espírito Santo, 2006. In: MUEHE,

D. Erosão e progradação do litoral brasileiro. Brasília: Ministério do Meio Ambiente. p.227-264. 2006.

AMARAL, C.A.B.,1979. Recursos minerais da margem continental brasileira e das áreas oceânicas adjacentes. Projeto REMAC, vol. 10, PETROBRAS, Rio de Janeiro: $112 \mathrm{p}$.

ARAI, M.,2005. A grande elevação eustática do Mioceno: a verdadeira origem do Grupo Barreiras. In: XVIII Congresso da Associação Brasileira dos Estudos do Quaternário, 2005. Guarapari. Anais... Guarapari: ABEQUA, 2005.

ASSELMAN, N.E.M.,1999 Grain-size trends used to assess the effective discharge for floodplain sedimentation, River Waal, the Netherlands. Journal of Sedimentary Research 69 (1), 51-61.

Boggs Jr., S., 2001. Principles of Sedimentology and Stratigraphy. New Jersey: Prentice Hall.

Carriquiry, J.D., Sanchez, A., Camacho-Ibar,V.F., 2001. Sedimentation in the northern Gulf of California after cessation of the Colorado River discharge. Sedimentary Geology 144, 37-62.

CEPEMAR. 2007. Estudo Hidrodinâmico da Área de Influência do Porto de Ubu Relatório Consolidado. Relatório Técnico CPM RT 18/07.

CEPEMAR. 2007. CONSOLIDAÇÃO DOS ENCARTES 1, 2, 3, 4, 5, E 6 DO PLANO DE MANEJO DO PARQUE ESTADUAL PAULO CESAR VINHA. Relatório Técnico CPM RT 307/07. 
CEPEMAR. 2011. RCA/ PCA DO TERMINAL MARÍTIMO DE UBU ANCHIETA/ES. Relatório Técnico CPM RT 109/11, pp.608.

COELHO, B. A. 2005. Morfodinâmica e variação da linha de costa a praia de Meaípe, Guarapari - ES. In: Instituto do Milênio do Mar - Uso e Apropriação de Recursos Costeiros - RECOS.

Contti Neto, N.; Albino, J. 2011 Quaternary evolution of rio Itabapoana coastal plain and its relation with vulnerability. Búzios, Rio de Janeiro: XIII Congresso da Associação Brasileira de Estudos do Quaternário ABEQUA

CHACALTANA, J. T. A. ; INNOCENTINI, V. ; NOGUEIRA, I. C. M. . Hindcast and seasonal characterization of wind waves for the year 2008 at the marine Terminal Ponta de Ubu Brazil. In: 8th INTERNATIONAL CONFERENCE ON COASTAL AND PORT ENGINEERING IN DEVELOPING COUNTRIES, 2012, Chennai. Proceedings of the Eighth International Conference on Coastal and Port Engineering in Developing Countries. Chennai: Department of Ocean Engineering, Indian Institute of Technology Madras, 2012. v. 1. p. 32-41.

DADALTO, T. P. ; ALBINO, J. . Análise morfotextural e aplicação de modelos de transporte de sedimentos na zona submersa adjacente a uma praia artificial em processo erosivo. Quaternary and Environmental Geosciences, v. 1, p. 16-24, 2009.

DECRETO Estadual No. 193/2008, DE 01 DE DEZEMBRO DE 2008.Cria o Monumento Natural Municipal Falésias de Marataízes e dá outras providências. Prefeitura de Marataízes

Duck, R.W., Rowan, J.S., Jenkins, P.A., Youngs, I., 2001. A multi-method study of bedload provenance and transport pathways in an estuarine channel. Physics and Chemistry of the Earth. Part B: Hydrology, Oceans and Atmosphere 26 (9), 747-752.

Duman, M., Avci, M., Duman, S., Demirkurt, E., Duzbastilar, M.K., 2004. Surficial sediment distribution and net sediment transport pattern in Izmir Bay, western Turkey. Cont. Shelf Res. 24 (9), 965-981. 
Duman, M., Duman, S., Lyons, T.W., Avci,M., Izdar, E., Demirkurt, E., 2006. Geochemistry and sedimentology of shelf and upper slope sediments of the southcentral Black Sea. Mar. Geol. 227 (1-2), 51-65.

Ehrhold, A., 1999. Dynamique de comblement d'un bassin sédimentaire soumis à un régime mégatidal: exemple de la Baie du Mont-Saint-Michel. Thesis, University of Caen, France, 294 pp.

Elfrink, B.; Acetta, D.; Mangor, K. Innovative shoreline protection scheme for the city of Marataízes, Espirito Santo, Brazil. Paper presented at the International Conference on Coastal Engineering (ICCE). Clearwater, Florida, E.U.A. 2006

FRANÇA, A.M.C. 1979. Geomorfologia da margem continental leste brasileira e da bacia oceânica adjacente. In: Geomorfologia da margem continental leste brasileira e das áreas oceânicas adjacentes. Série Projeto Remac n.7. p.89-127.

Frihy, O.E., Dewidar, Kh.M., 1993. Influence of shoreline erosion and accretion on texture and heavy mineral compositions of beach sands of the Burullus coast, northcentral Nile Delta, Egypt. Mar. Geol. 114, 91-104.

Frihy, O.E. \& Dewidar, K.M., 2004. Patterns of erosion / sedimentation, heavy mineral concentration and grain size to interpret boundaries of littoral sub cells of the Nile Delta, Egypt. Mar. Geol., vol. 199, no. 1-2, pp. 27-43.

Frihy, O.E., Komar, P.D., 1991. Patterns of beach-sand sortingand Shoreline erosion on the Nile Delta. J. Sediment.Petrol. 61, 544-550.

Frihy, O.E., Komar, P.D., 1993. Long-term shoreline changes and the concentration of heavy minerals in beach sands of the Nile delta, Egypt. Mar. Geol. 115, 253-261.

Frihy, O.E., Lotfy, M.F., Komar, P.D., 1995. Spatial variations in heavy minerals and patterns of sediment sorting along the Nile Delta, Egypt. Sediment. Geol. 97, 33-41.

Friend, P.L., Velegrakis, A.F., Weatherston, P.D., Collins, M.B., 2006. Sediment transport pathways in a dredged ria system, southwest England. Estuar. Coast. Shelf Sci. 67 (3), 491-502. 
Fujinami, N., Koga, T., Morishima H., (2000) External Exposure Rates from Terrestial Radiation at Guarapari and Meaipe in Brazil, in Proceedinng of "The 10h International Congress of the International Radiation Protection Association”, Hiroshima, Japan, 1419 May 2000

Gao, S. e COLLINS, M., 1991, A critique of the "McLaren method" for defining sediment transport paths - discussion: Journal of Sedimentary Petrology, v. 61, p. 143146.

GAO, S., AND COLlinS, M., 1992, Net sediment transport patterns inferred from grain-size trends, based upon definition of 'transport vectors': Sedimentary Geology, v. 80 , p. $47-60$.

Gao, S., Collins, M., 1994. Analysis of grain size trends, for defining sediment transport pathways in marine environments. Journal of Coastal Research 10, 70-78.

Gao, S., Collins, M., 1994a. Net sediment transport patterns inferred from grain-size trends, based upon definition of "transport vectors"-reply. Sediment. Geol. 90, 157159.

Garnaud, S., 2003. La sédimentation fine sur une plate-forme interne actuelle macrotidale: la Baie de Seine sud-orientale (France). Thesis, University of Caen, France, 307 pp.

Ghiassi-Nejad, M.; Mortazavi, S. M. J.; Cameron, J. R.; Niroomand-Rad, A.; Karam, P. A. (2002). Very high background radiation areas of Ramsar, Iran: preliminary biological studies. Health Physics 82 (1): 87-93.

GIANNINI, P., ANGULO, R., SOUZA, M., KOGUT, J., DELAI, M. A erosão na costa leste da Ilha do Mel, Baía de Paranaguá, estado do Paraná: modelo baseado na distribuição espacial de formas deposicionais e propriedades sedimentológicas. Revista Brasileira de Geociências, América do Norte, 34, jan. 2004. Disponível em: < http://sbgeo.org.br/pub_sbg/rbg/vol34_down/3402/1413.pdf >. Acesso em: 28 Set. 2012.

Giannini, P.C.F., Guedes, C.C.F., Nascimento Jr., D.R., Tanaka, A.P.B., Angulo, R.J., Assine, M.L., Souza, M.C., 2009. Sedimentology and Morphologic Evolution of the 
Ilha Comprida Barrier System, Southern São Paulo Coast. In: DILLENBURG, S.R., HESP, P. (Eds.), Geology of the Brazilian Coastal Barriers: Lecture Notes in Earth Sciences. Springer-Verlag.

GOMES, R.C. 2004. Perfil Praial de Equilíbrio da Praia de Meaípe - Espírito Santo. Monografia de Graduação. Programa de Graduação em Oceanografia, UFES, Vitória.

González-Yajimovich, Oscar et al. Sediment transport trends in Bahía Concepción, Baja California Sur, Mexico, based on textural parameters and heavy mineral concentrations. Bol. Soc. Geol. Mex, Aug 2010, vol.62, no.2, p.281-304. ISSN 14053322

Guedes, C.C.F. ; Giannini, P.C.F. ; Nascimento Jr., D.R. ; SAWAKUCHI, A.O. ; Tanaka, A.P.B. ; Rossi, M.G. . Controls of heavy minerals and grain size in a holocene regressive barrier (Ilha Comprida, southeastern Brazil). Journal of South American Earth Sciences, v. 31, p. 110-123, 2011.

Guillen, J., Jimenez, A., 1995. Processes behind the longshore variation of the sediment grain size in the Ebro Delta coast. J. Coast. Res. 11 (1), 205-218.J. Coast. Res. 11 (1), 205-218

Hair Jr., A.; Anderson, R.E.; Tatham, R.L.; Black, W.C. 1995. Multivariate data analysis. New Jersey: Prentice Hall, 788 pp.

Hartmann, D. (2007). From reality to model: Operationalism and the value chain of particle-size analysis of natural sediments. Sedimentary Geology , 202, 383-401.

Hughes, S.A., 2005. Use of Sediment Trend Analysis (STA) for coastal projects. US Army Corps of Engineers ERDC/CHL, CHETN-VI-40, pp. 1-17

IBGE (Instituto Brasileiro de Geografia e Estatística).2002. Mapa de climas do Brasil. Disponível em <www.ibge.gov.br/ibgteen/atlasescolar/mapas_pdf/brasil_clima.pdf>. Acesso em 25/02/13

Instituto Estadual de Meio Ambiente e Recursos Hídricos (2009). Aerolevantamento do Estado do Espírito Santo na escala de 1:10.000 nos anos de 2008-2009. 
Instituto Jones dos Santos Neves. Análise da variação da linha de costa do Espírito Santo: Resultados preliminares. Vitória, ES, 2012.

Komar, P.O., 1973. Computer models of delta growth due to sediment input from rivers and longshore transport. Geological Society American Bulletin, V. 84

Komar, P.O., 1989. Physical processes of waves and currents and the formation of marine placers. Rev. Aquat. Sci. 1,393-423.

Komar, P.O., Clemens, K.E., Li, Z., Shih, S.M., 1989. The efect of selective sorting on factor analyses of heavy-mineral assemblages. J. Sediment. Petrol. 59, 590-596

Kunte, P.D.; Wagle, B.G. 1993. Remote sensing approach to determine net shore drift direction - a case study along the Central East Coast of India. Journal of Coastal Research, 9(3), pp. 663-672

Lanckneus, J., De Moor, G., Van Lancker, V., De Schaepmeester, G., 1993. The use of the McLaren model for the determination of residual transport directions on the Gootebank, southern North Sea. Progress in Belgian Oceanographic Research, vol. 1. Institute of Marine Research and Air Sea Interaction (IRMA), pp. 75-94.

Le Bot, S., Trentesaux, A., Ehrhold, A., 2001. Contrôle exercé par lês bancs sableux sur la morpho-dynamique des dunes. Apports pour la modélisation du transport sédimentaire résiduel par la méthode de Gao et Collins. proceedings 8ième Congrès Français de Sédimentologie. ASF, Paris, France, pp. 211-212

Le Roux, J.P., 1994a. Net sediment transport patterns inferred from grain size trends, based upon definition of "transport vectors" — comment. Sedimentary Geology 90, $153-156$.

Le Roux, J.P., 1994b. An alternative approach to the identification of sand sediment transport paths based on a grain-size trends. Sediment. Geol. 94, 97-107.

Le Roux, J.P., Rojas, E.M., 2007. Sediment transport patterns determined from grainsize parameters: overview and state of the art. Sedimentary Geology. doi:10.1016/j.sedgeo.2007.03.014. 
Li, M.Z., Komar, P.D., 1992. Longshore grain sorting and beach placer formation adjacent to the Columbia River. J. Sediment. Petrol. 62, 429-441.

Liu, J.T., Liu, K., Huang, J.C., 2002. The effect of a submarine canyon on the river sediment dispersal and inner shelf sediment movement in southern Taiwan. Mar. Geol. $181,357-386$.

Liu, J.T., Lin, H.L., Hung, J.J., 2004. Some additional insights into the spatial distribution patterns of individual grain sizes in a river-sea system that includes a submarine canyon. In: Flemming, B.W., Hartmann, D., Delafontaine, M.T. (Eds.), From Particle Size to Sediment Dynamics. International HWK-Senckenberg Workshop, 1518 April 2004, Delmenhorst, Germany. Extended Abstracts, pp. 106-111.

Lucio, P.S., Gama, C., Andrade, C., 2002. One-dimensional alternatives to determined sediment trend transport. Case study: Troia-Sines Arcuate coast-Portugal. Proceedings Littoral 2002. The Changing Coast EUROCOAST, EUCC, Porto, Portugal, pp. 391396.

Lucio, P.S.,Dupont, H.S.,Bodevan, E.C., 2004. Sediment transport paths in the Westerschelde: one-dimensional alternative to determine sediment trend. Journal of Coastal Research 20, 771-775.

MACCARTHY, G. R., Coastal sands of the eastern United States: Am. Jour. Sci., 22 (1931), 35-50.

MACHADO, G. M. V. ; SANTOS, M. M. S. ; ALBINO, J. . Ocupação sobre zonas vulneráveis à erosão do litoral sul do Estado do Espírito Santo: caso das praias de Meaípe-Maimbá, gurarapari e Itaoca, Itapemirim. In: IX Congresso brasileiro de Estudos do Quaternário, 2003, Recife - PE. Anais do IX Congresso brasileiro de Estudos do Quaternário, 2003.

Malanca, A., de Pieri, R. and Gazzola, A.: 1998, Radiogenic Heavy Minerals in Brazilian Beach Sand, J. Radioanal. Nucl. Chem. 230, 257-260.

Mallet, C., Howa, H.L., Garlan, T., Sottolichio, A., Le Hir, P., 2000. Residual transport model in correlation with the sedimentary dynamics over an elongate tidal sandbar in 
the Gironde Estuary (Southwestern France). Journal of Sedimentary Research 70, 10051016.

MARTIN, L., SUGUIO, K. F., \& ARCHANJO, J. (1996). Coastal Quaternary Formations of the southern part of the State of Espirito Santo (Brazil). Academia Brasileira de Ciências , 389-404.

Martins, L.R., 1965, Significance of skewness and Kurtosis in Environmental interpretation. Journal of Sedimentary Petrology, vol. 35: 786-776. Tulsa, EUA.

Martins, L.R., 2003, Recent Sediments and Grain-Size Analysis. Gravel, CECO, Instituto de Geociências, UFRGS, 1: 90-105.

Masselink, G., 1992. Longshore variation of grain size distributions along the coast of the Rhone Delta, Southern France: a test of the "Mc Laren Model". J. Coast. Res. 8 (2), 286-291.

Masselink, G., 1993. Longshore variation of grain size distributions along the coast of the Rhone Delta, Southern France: a test of the "Mc Laren Model" — reply. J. Coast. Res. 9 (4), 1142-1145.

McCave, I. N., 1978, Grain-size trends and transport along beaches: an example from eastern England: Marine Geology, v. 28, no. 1/2, p. M43-M51.

McLaren, P., 1981. An interpretation of trends in grain-size measurements J. Sediment. Petrol., 51: 611-624.

McLaren, P., 1983. Coastal sediments of the Strait of Juan de Fuca: implications for oil spills. Current Research, Pt A. Geological Survey of Canada Paper 83-1A, pp. 241-244.

McLaren, P., 1984. The Whytecliff oil spill, British Columbia: sediment trends and oil movement on a beach. Current Research, Pt B. Geological Survey of Canada Paper 84$1 \mathrm{~A}$, pp. 81-85.

McLaren, P., 1993. Discussion of: Masselink, G., 1992. Longshore variation of grain size distribution along the coast of the Rhône Delta, southern France: a test of the Mc Laren Model. J. Coast. Res. 8 (2), 286-291. 
McLaren, P. e Bowles, D., 1985. The effects of sediment transport on grain-size distributions. J. Sediment. Petrol., 55: 457-470.

McLaren, P. e Bowtes, D., 1991. A critique of the 'Mc-Laren Method' for defining sediment transport paths: reply. J. Sediment. Petrol., 61: 147.

McLaren, P., Collins, M.B., Gao, S., Powys, R.I.L., 1993a. Sediment dynamics of the Severn Estuary and inner Bristol Channel. Journal of the Geological Society 150, 589603.

McLaren, P., Cretney,W.J., Powys, R.I., 1993b. Sediment pathways in a BritishColumbia fjord and their relationship with particle-associated contaminants. Journal of Coastal Research 9, 1026-1043.

McLaren, P., Little, D.I., 1987. The effects of sediment transport on contaminant disposal: an example from Milford Haven. Marine Pollution Bulletin 18, 586-594.

McLaren, P., Hill, S.H. and Bowles, D. (2007). Deriving transport pathways in a sediment trend analysis (STA). Sed. Geol., doi: 10.1016/j.sedgeo.2007.03.014.

de Meijer, R. J. (1998) Heavy minerals: from 'Edelstein' to Einstein. Journal of Geochemical Exploration, 62(1-3), pp. 81-103.

Ministério do Meio Ambiente, Ministério de Planejamento, orçamento e gestão. 2004. Projeto Orla: Subsídios para um projeto de gestão. Brasília, 104 p.

Moreira, P.S.C. (2009). Variação da linha de costa e sensibilidade aos processos costeiros de erosão e progradação entre Vitória (ES) e Cabo Frio (RJ) no intervalo entre 1954 e 2000. Tese apresentada ao Programa de Pós-Graduação em Geologia e Geofísica Marinha da Universidade Federal Fluminense. Niterói, 2009.

Nascimento Jr., D.R., Tanaka, A.P.B., Giannini, P.C.F., Guedes, C.C.F., 2005. Morfologia e granulometria ao longo do sistema praia-duna frontal da Ilha Comprida, SP. In: X Congresso da Associação Brasileira de Estudos do Quaternário, 2005, Guarapari - ES, vol. 1. ABEQUA, Rio de Janeiro - RJ, Anais do X Congresso da ABEQUA 2005 p. $48 \mathrm{e} 48$

Nascimento Jr., D.R., Giannini, P.C.F., Tanaka, A.P.B., Guedes, C.C.F., 2008. Evidências diretas de mais de 130 anos de mudanças morfológicas e sedimentológicas 
no entorno da extremidade NE da barreira de Ilha Comprida, SP. São Paulo. GeologiaUSP - Série Científica 8 (1), 25 e39.

Nogueira, I.C.M. CARACTERIZACAO SAZONAL DE ONDAS NA REGIAO ADJACENTE AO PORTO DE UBU, ANCHIETA - ES, PARA O ANO DE 2008. Monografia de graduação em Oceanografia. Universidade Federal do Espírito Santo, 2010.

Nordstrom, K.F., 1981. Differences in grain size distribution with shoreline position in a spit environment. Northeastern Geology 3, 252-258.

Nordstrom, K.F., 1989. Downdrift coarsening of beach foreshore sediments at tidal inlets: an example from the coast of New Jersey. Earth Surface Processes and Landforms 14, 691-701.

Pascoe, G.A., McLaren, P., Soldate, M., 2002. Impact of offsite sediment transport and toxicity on remediation of a contaminated estuarine bay. Marine Pollution Bulletin 44, 1184-1193.

Pavani, F.C. Determinação da direção e da taxa de transporte longitudinal no arco praial compreendido entre a praia da Ponta da Fruta, Vila Velha e Setiba, Guarapari ES. Monografia de graduação do curso de Oceanografia. Vitória: Universidade Federal do Espírito Santo.

Pettijohn, F. (1975). Sedimentary Rocks (3a ed.). New York: Harper \& Row.

Pettijohn, F. G. e Ridge, J. D., 1932. A textural variation series of beach sands from Cedar Point, Ohio: Jour. Sed. Pet., v. 2, no. 2, p. 76-88.

Pettijohn, F. G., Potter, P. D., e Siever, R., 1972, Sand and sandstone: Springer-Verlag, New York, 618 p.

Piumbini, P.P. Clima de ondas de gravidade e estado de agitação marítima em ambientes marinhos no Espírito Santo. Dissertação de Mestrado em Engenharia Ambiental Mestrado em Engenharia Ambiental Universidade Federal do Espírito Santo. 2009 
Poizot, E., Méar, Y., Thomas, M., Garnaud, S., 2006. The application of geostatistics in defining the characteristic distance for grain size trend analysis. Comput. Geosci. 32 (3), 360-370.

Poizot, E.; Méar, Y.; Biscara, L. (2008) Sediment Trend Analysis through the variation of granulometric parameters: A review of theories and applications. Earth-Science Reviews 86:1-4, 15

Rittenhouse, G., 1943. Transportation and deposition of heavy minerals. Bull. Geol. Soc. Am. $54,1725^{\wedge} 1750$.

Ríos, F., Cisternas, M., Le Roux, J., Correa, I., 2002. Seasonal sediment transport pathways in Lirquen Harbor, Chile, as inferred from grain-size trends. Invest. Mar. Valparaiso 30 (1), 3-23.

SAMARCO, 2012. Acesso em: 15/05/2012. Disponível em: <http://www.samarco.com.br/uploads/k8e5j.pdf>

SANTOS, M. M. S. 2003. Variação morfológica e textural das areias nas praias de Meaípe e Maimbá em Guarapari - ES durante a passagem de frente fria. Monografia Cursos de Especialização. UFES, Vitória

Self, R.P., 1977. Longshore variation in beach sands, Nautla area, Veracruz, Mexico. Journal of Sedimen-tary Petrology, 47, 1437-1443.

Schalk, M., 1938. A textural study of the outer beach of Cape Cod, Massachusetts. J. Sediment. Petrol., 8: 41-54.

SILVA, C.G. 2000. Placeres marinhos. Revista Brasileira de Geofísica, 18(3):327-336, 2000

SILVA, Q. K., PATCHINEELAM, M. S., NETO, B. A. J., PONZI A. R. V. Ambiente de sedimentação costeira e processos morfodinâmicos atuantes na linha de costa. In: NETO, B. A. J., PONZI, A. B. V., SICHEL, E. S. (Org). Introdução à Geologia Marinha. Rio de Janeiro: Interciência. p. 175- 218; 2004. 
SOUZA, C.R. de G., 1997. As Células de Deriva Litorânea e a Erosão nas Praias do Estado de São Paulo. São Paulo: Universidade de São Paulo, Tese de Doutoramento, 2 vol. (text: 184p. e figures: 175p.).

SOUZA, Celia Regina de Gouveia. Determination of net shore-drift cells based on textural and morphological gradations along foreshore of sandy beaches. Journal of Coastal Research, v. SI 50, p. 620-325, 2007.

SOUZA, Celia Regina de Gouveia; SUGUIO, Kenitiro; OLIVEIRA, A. M. S. ; OLIVEIRA, P. E. . Quaternário do Brasil. Riberão Preto (SP): Holos Editora, 2005. $378 \mathrm{p}$.

Spiegel, M. R., 1961, Theory and Problems of Statistics: Sehaum's Outline Series: New York, M . raw-Hill Book Co., 359 p.

TAGGART, B.E. \& SCHWARTZ, M.L., 1988. Net shore-drift direction determination: a systematic approach. Journal of Shoreline Management, 3(4), 285-309.

Tanaka, A.P.B.; Giannini, P.C.F.; Fornari, M.; Nascimento, D.R., Jr.; Sawakuchi, A.O.; Rodrigues, S.I.; MENEZES, P.M.L.; DEBLASIS, P.; PORSANI, J.L. 2009. A planície costeira holocênica de Campos Verdes (Laguna, SC): evolução sedimentar inferida a partir de georradar (GPR), granulometria e minerais pesados. São Paulo, Revista Brasileira de Geociências, 39(4): 750-766.

Tchoukanski, $\quad$ 1. Disponível em: $\quad<\quad$ http://www.ianko.com/free/EC10/EC10_download.htm>. Acesso em: 23/09/2012

Trask, P.D., 1952. Sources of beach sand at Santa Barbara, California, as indicated by mineral grain studies. Beach Erosion Board Tech. Memo No. 28, U.S. Army Corps of Engineers, $24 \mathrm{pp}$.

Uriarte, A., Franco, J., Borja, A., Valencia, V., Castro, R., 1998. Sediment and heavy mineral distribution and transport in a coastal area affected by a submarine outfall in the Basque Country (northern Spain). Water Science and Technology 37, 55-61. 
Van Andel, Tj.H., 1964. Recent marine sediments of Gulf of California. In: Van Andel, Tj.H., Shore, G.G. (Eds.), Marine Geology of the Gulf of California, Memoir 3. Am. Assoc. Petrol. Geol., pp. 216-310.

VALENTIN, J. L. Ecologia numérica: uma introdução à análise multivariada de dados ecológicos. Rio de Janeiro: Interciência, 2000.

Van Wesenbeck, V., Lanckneus, J., 2000. Residual sediment transport paths on a tidal sand bank: a comparison between the modified McLaren model and bedform analysis. J. Sediment. Res. 70 (3), 470-477.

Veiga, F.A., Angulo, R.J., Marone, E., Brandini, F.P., Soares, C.R., 2005. Net sediment transport paths based on three grain-size trends analysis programs in the south sector of the Parannagua estuarine complex outlet delta - South Brazil. Bol. Parana. Geociênc. $57,75-87$.

Veiga, R.; Sanches, N.; Anjos, R.M.; Macario, K.; Bastos, J.; Iguatemy, M.; Aguiar, J.G.; Santos, A.M.A.; Mosquera, B.; Carvalho, C.;Baptista Filho, M.; Umisedo, N.K. 2006. Measurement of natural radioactivity in Brazilian beach sands. Radiation Measurements, 41 189-196

Wu, J.X., Shen, H.T., 1999. Estuarine bottom sediment transport based on the 'McLaren model': a case study of Huangmaohai Estuary, South China. Estuarine, Coastal and Shelf Science 49, 265-279

Zhang, H., Zhu, D., 1989. The stability of Yangpu Harbour, a tidal inlet on the west coast of Hainan Island, China (in Chinese). Haian Gongcheng 8, 31-38. 